\title{
Variable-Interval and Variable-Ratio Schedules of Punishment by Timeout from Positive Reinforcement
}

\author{
Ezra G. Hall
}

Follow this and additional works at: https://researchrepository.wvu.edu/etd

\section{Recommended Citation}

Hall, Ezra G., "Variable-Interval and Variable-Ratio Schedules of Punishment by Timeout from Positive Reinforcement" (2015). Graduate Theses, Dissertations, and Problem Reports. 5738.

https://researchrepository.wvu.edu/etd/5738

This Dissertation is protected by copyright and/or related rights. It has been brought to you by the The Research Repository @ WVU with permission from the rights-holder(s). You are free to use this Dissertation in any way that is permitted by the copyright and related rights legislation that applies to your use. For other uses you must obtain permission from the rights-holder(s) directly, unless additional rights are indicated by a Creative Commons license in the record and/ or on the work itself. This Dissertation has been accepted for inclusion in WVU Graduate Theses, Dissertations, and Problem Reports collection by an authorized administrator of The Research Repository @ WVU.

For more information, please contact researchrepository@mail.wvu.edu. 


\title{
Variable-Interval and Variable-Ratio Schedules of Punishment by Timeout from Positive Reinforcement
}

\section{Ezra G. Hall}

Dissertation Submitted to the Eberly College of Arts and Sciences at West Virginia University in partial fulfillment of the requirements for the degree of

\author{
Doctor of Philosophy \\ in \\ Psychology
}

\author{
Kennon A. Lattal, Ph.D., Chair \\ Michael Perone, Ph.D. \\ Claire C. St. Peter, Ph.D. \\ Miranda N. Reed, Ph.D. \\ Daniel E. Hursh, Ph.D.
}

Department of Psychology

\section{Morgantown, West Virginia 2015}

Keywords: timeout; punishment; variable interval; variable ratio; yoking procedure; pigeons Copyright 2015 Ezra Hall 


\section{ABSTRACT \\ Variable-Interval and Variable-Ratio Schedules of Punishment by Timeout from Positive Reinforcement}

Ezra G. Hall

Timeout punishment is among the most commonly reported disciplinary procedures (Barkin, Scheindlin, Ip, Richardson, \& Finch, 2007). Despite the frequent use of timeout, little basic research has systematically examined different schedule effects of timeout from positive reinforcement. Using pigeons as subjects, the current series of experiments arranged variable schedules of timeout from positive reinforcement within a multiple-schedule arrangement where 20-s timeouts were response-dependent, response-independent, and delayed. Experiment 1 used a within-subject yoking procedure to compare schedules of variable-ratio (VR) and yokedinterval (YI) timeouts. Experiment 2 arranged separate parametric analyses of variable-interval (VI) and VR schedules of timeout. Within-session, yoked-control components delivered response-independent timeouts according to the same temporal distribution as in the preceding response-dependent timeout components in an attempt to isolate a direct response-decreasing effect of timeout presentations from indirect reductions in reinforcement rate. In Experiment 3, delays to timeout were studied using the same yoked-control procedure as in Experiment 2. Experiment 4 was designed to address confounds in the control conditions that were arranged for reduced timeout rate during delays in Experiment 3. The primary findings were: 1) responsedependent VR 2 and VR 3 timeout resulted in the most response reduction and the highest timeout rates across Experiments 1, 2, 3, and 4, 2) schedules of VI timeout reduced responding relative to baselines for the most frequent mean schedule values in Experiments 1 and 2, 3) response rate increases occurred during the introductions of delays to timeout in Experiment 3 and were partially attributed to the introduction of the delays in Experiment 4, and 4) response rates in the response-dependent timeout components were not always lower than their corresponding response-independent timeout components. 


\section{Acknowledgments}

Thank you to Andy Lattal for providing supervision to me as an undergraduate and graduate student. I truly appreciated his valuable experience, guidance, and patience during my time at West Virginia University. Andy is an amazing person, teacher, and mentor.

Thank you to the members who served on my committee, Andy Lattal, Mike Perone, Claire St. Peter, Dan Hursh, and Miranda Reed for their helpful comments and discussion at all stages of this project. Thank you to Toshikazu Kuroda and Megan Maxwell for supporting my initial interest in behavior analysis. Thank you to all the graduate students and lab mates with whom I've had the pleasure of working. And finally, thank you to my amazing family. 


\section{Table of Contents}

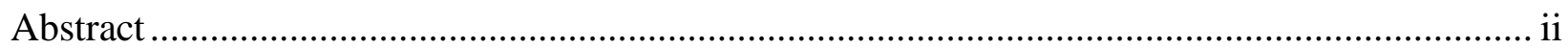

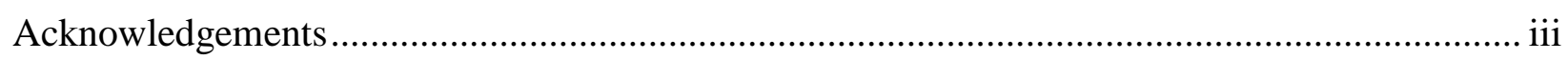

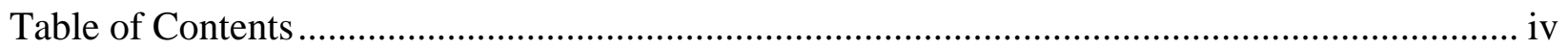

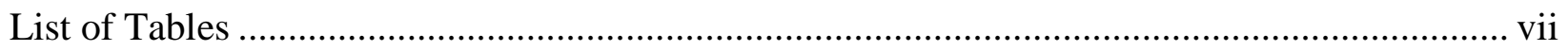

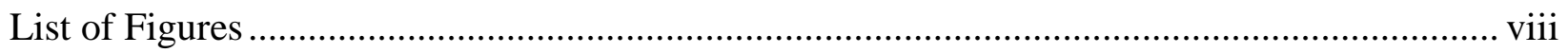

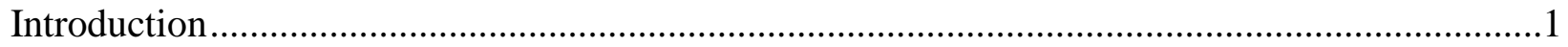

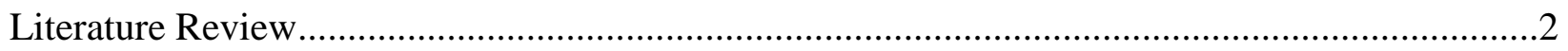

Methodological Considerations in the Analysis of Timeout-Punishment Effects ....................2

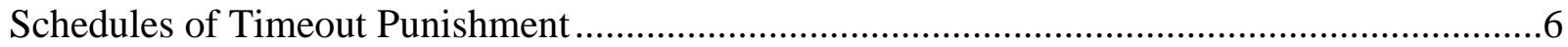

Variable-Ratio and Variable-Interval Schedules of Positive Punishment ..............................10

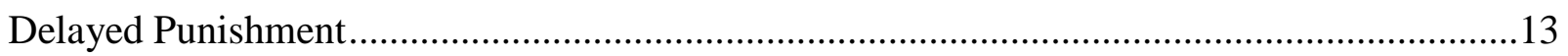

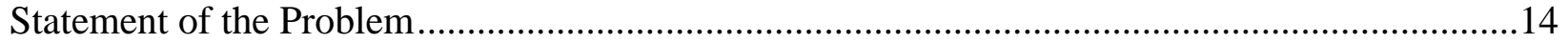

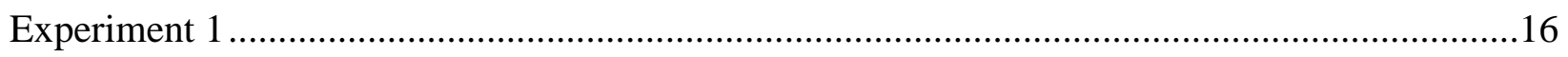

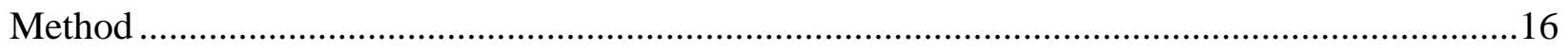

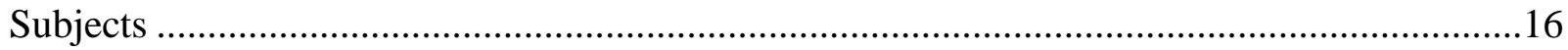

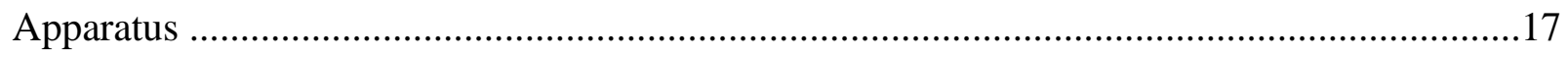

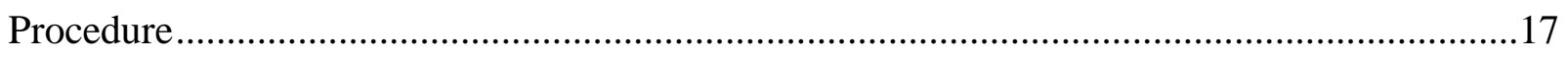

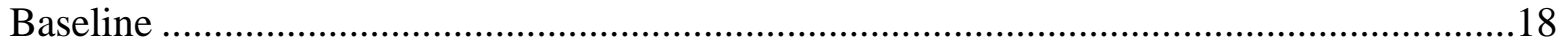

Variable-ratio and yoked-interval timeout .............................................................. 18

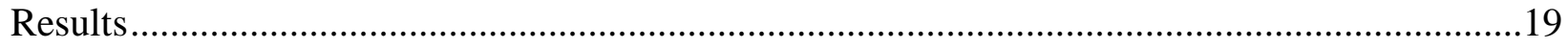

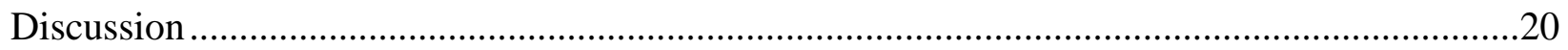

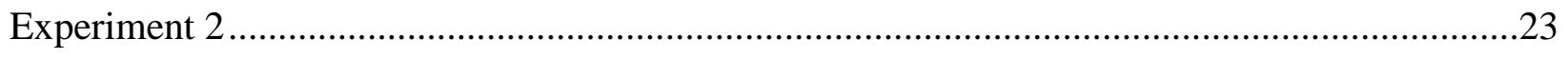

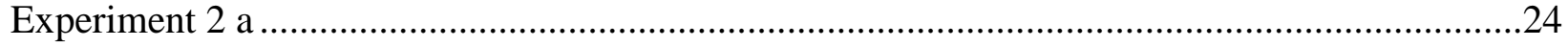

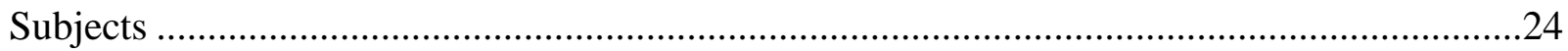

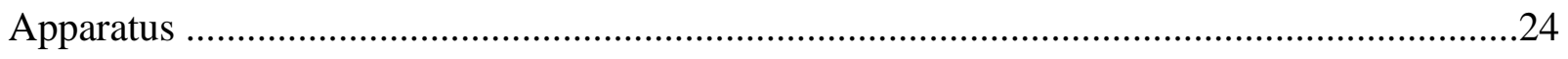

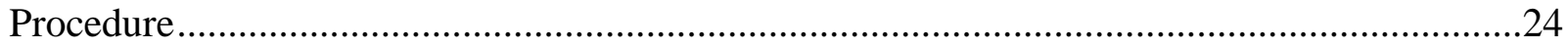

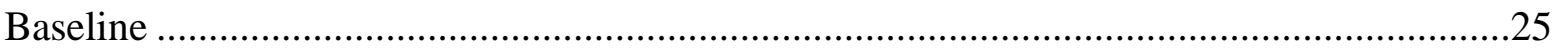

Sequences of variable-interval schedules of timeout ...............................................25

Variable-ratio schedules of timeouts and variable-interval replications ...........................25 


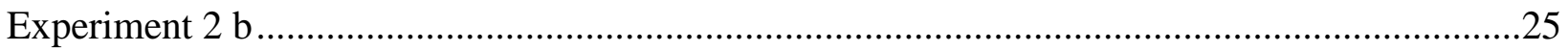

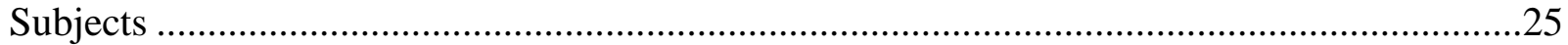

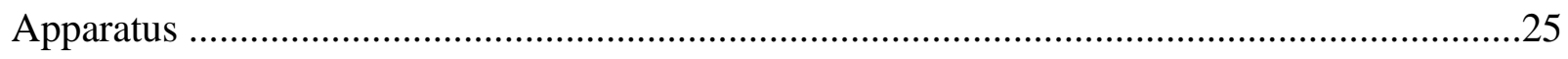

Procedure

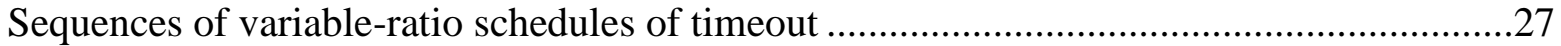

Variable-interval schedules of timeout and variable-ratio replications..................................27

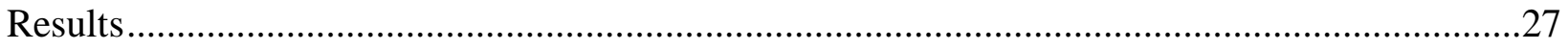

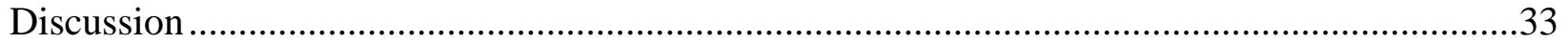

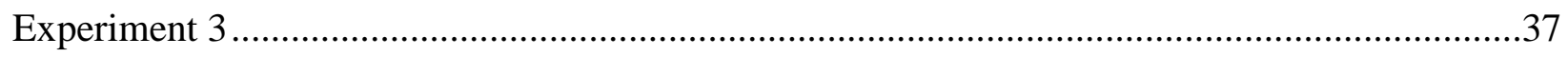

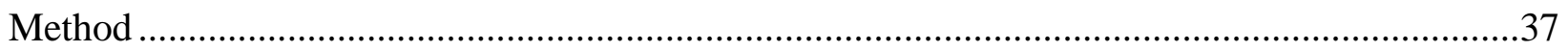

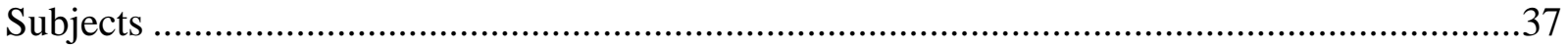

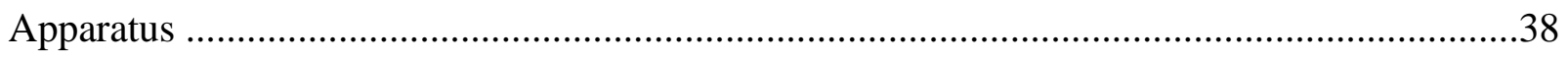

Procedure

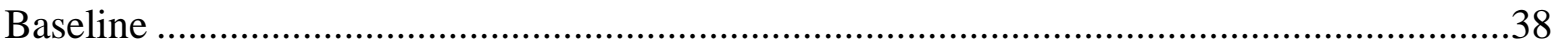

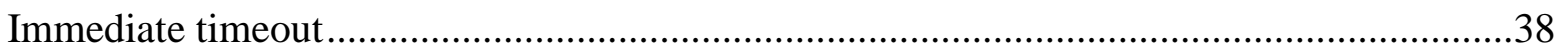

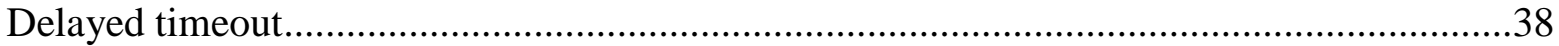

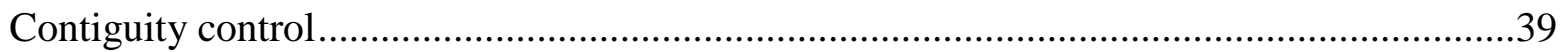

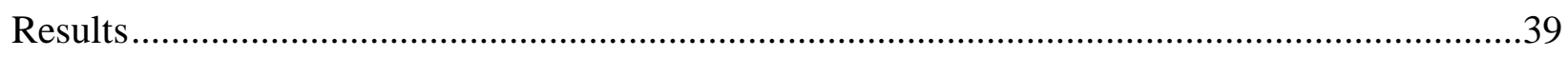

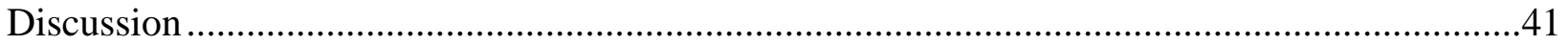

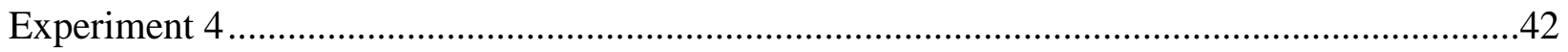

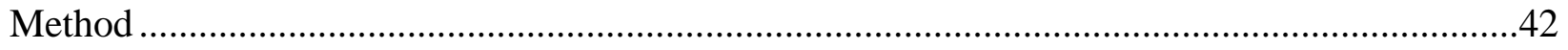

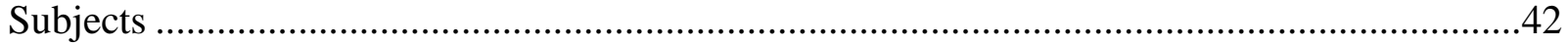

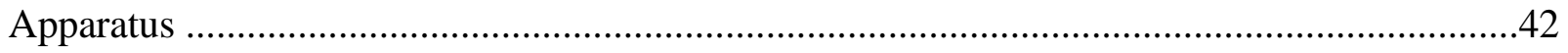

Procedure

Immediate timeout .......................................................................................................

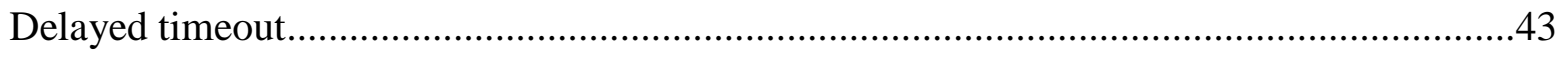

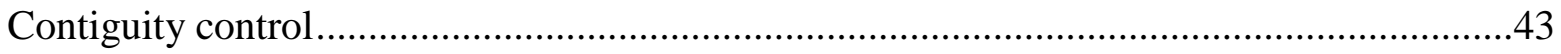

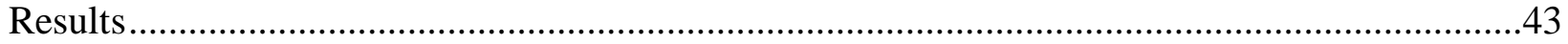

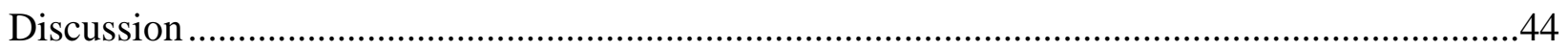

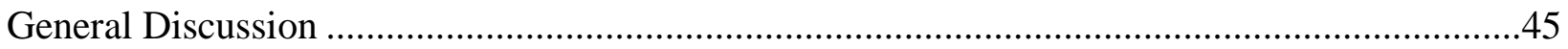

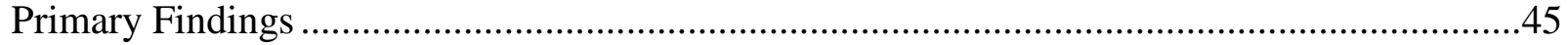


Methodological Considerations in the Analysis of Timeout-Punishment Effects Revisited .....47

Schedule Effects of Timeout Punishment in Relation to Positive Punishment........................51

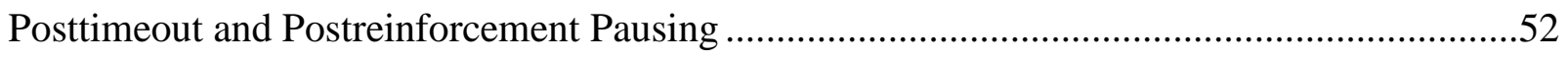

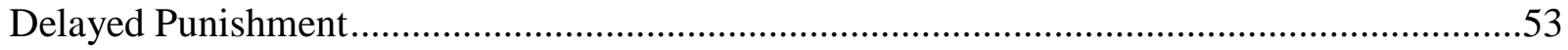

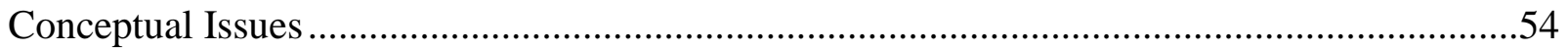

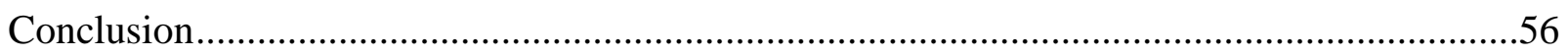

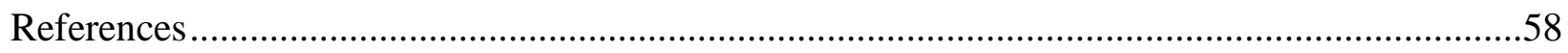




\section{List of Tables}

Table 1. The sequence of conditions, number of sessions, reinforcers (Reinf) per min, and timeouts (TO) per min for the last six stable sessions for each pigeon in Experiment 1

Table 2. The sequence of conditions, number of sessions, reinforcers (Reinf) per min, and timeouts (TO) per min for the last six stable sessions for each pigeon in Experiment 2 a.....

Table 3. The sequence of conditions, number of sessions, reinforcers (Reinf) per min, and timeouts (TO) per min for the last six stable sessions for each pigeon in Experiment $2 \mathrm{~b}$.

Table 4. The unadjusted and adjusted response rates for all VI-timeout conditions in Experiment 2.

Table 5. The unadjusted and adjusted response rates for all VR-timeout conditions in Experiment 2

Table 6. The sequence of conditions, number of sessions, reinforcers (Reinf) per min, and timeouts (TO) per min for the last six stable sessions for each pigeon in Experiment 3

Table 7. The sequence of conditions, number of sessions, reinforcers (Reinf) per min, and timeouts (TO) per min for the last six stable sessions for each pigeon in Experiment 4. 


\section{List of Figures}

Figure 1. Mean responses per min for the last six stable sessions of each condition for Experiment 1

Figure 2. Suppression ratios plotted as a function of timeout component for each pigeon in Experiment 1

Figure 3. Suppression ratios plotted as a function of the median punished IRTs in Experiment 1

Figure 4. Interresponse times (IRTs) plotted in successive 0.2-s bins for the VR and YI components for each pigeon and condition in Expet 1

Figure 5. Mean responses per min from the last six stable sessions of each condition for pigeons in the VI sequence in Experiment 2 a

Figure 6. Mean responses per min for the last six stable sessions of each condition for pigeons in the VR sequence in Experiment $2 \mathrm{~b}$

Figure 7. Timeouts per minute and suppression ratios for pigeons in Experiment 2 a

Figure 8. Individual-subject data for timeouts per minute and suppression ratios for pigeons in Experiment $2 \mathrm{~b}$

Figure 9. Mean proportion of total session time spent pausing following timeouts during the last six stable sessions for each individual pigeon (top two graphs) and the mean of all pigeons (bottom graph) for the aggregated VI conditions

Figure 10. Mean proportion of total session time spent pausing following timeouts during the last six stable sessions for each individual pigeon (top two graphs) and the mean of all pigeons (bottom graph) for the aggregated VR conditions

Figure 11. Mean proportion of total session time spent pausing following reinforcers during the last six stable sessions for each individual pigeon (top two graphs) and the mean of all pigeons (bottom graph) for the aggregated VI conditions

Figure 12. Mean proportion of total session time spent pausing following reinforcers during the last six stable sessions for each individual pigeon (top two graphs) and the mean of all pigeons (bottom graph) for the aggregated VR conditions

Figure 13. Suppression ratios plotted as a function of median punished IRTs in Experiment 2 .91

Figure 14. Proportion of interresponse times (IRTs) plotted in successive 0.2-s bins for the first baseline (BL; left most column) and the response-independent timeout components for the 
highest mean nominal VI and VR timeout conditions for each pigeon in Experiment $2 \mathrm{a}$ in Experiment 2

Figure 15. Proportion of interresponse times (IRTs) plotted in successive 0.2-s bins for the first baseline (BL; left most column) and the response-independent timeout components for the highest mean nominal VI and VR timeout conditions for each pigeon in Experiment $2 \mathrm{~b}$

Figure 16. The median obtained delays to timeout in the response-independent timeout components in Experiment 2

Figure 17. Mean responses per min for the last six stable sessions of each condition for the pigeons in Experiment 3 .....

Figure 18. Median and ranges of the obtained delays to timeouts in Experiment 3

Figure 19. Mean responses per min for the last six stable sessions of each condition for pigeons in Experiment 4 


\section{Introduction}

The process of punishment is defined as a decrease in the future probability of a response as a result of an environmental change that is dependent on the response (Azrin \& Holz, 1966). Punishment occurs frequently in everyday situations, across a variety of settings, and is used to effect behavior change (DeFulio \& Hackenberg, 2007; Skinner, 1953). A commonly used punisher is a timeout (Cooper, Heron, \& Heward, 2007; Everett, Hupp, \& Olmi, 2010; DeFulio \& Hackenberg). Punishment by timeout involves a response-dependent stimulus change accompanied by cessation of positive reinforcement for a predefined period, typically no more than a few minutes with humans and less with nonhumans (Azrin \& Holz; Ferster, 1958; Ferster \& Skinner, 1957). If the timeout thus presented is indeed a punisher then it will decrease the future probability of the response that produced the timeout.

Timeout, in application, often is a less objectionable punisher than other physical events that have served as unconditioned punishers in basic behavioral research such as shock, slaps, and air puffs (Hake \& Azrin, 1963; Terris \& Barnes, 1969). Timeout therefore is considered a more ethical procedure for reducing behavior when compared to forms of corporal punishment (Lerman \& Vorndran, 2002) and often is used, and has been shown effective, across a variety of settings (Burchard \& Barrera, 1972; Clark, Rowbury, Baer, \& Baer, 1973; Hobbs, Forehand \& Murray, 1978; Lerman, Iwata, Shore, \& DeLeon, 1997; White, Nielsen, \& Johnson, 1972). Merely demonstrating that timeout works is insufficient for understanding the variables related to how timeout reduces responding (DeFulio \& Hackenberg, 2007). Given that timeout punishment is among the most commonly reported disciplinary procedures (Barkin, Scheindlin, Ip, Richardson, \& Finch, 2007) it is surprising that experiments of timeout in application and in basic research have been limited in regard to evaluating variables that can decrease the 
effectiveness of timeout punishment: variable schedules of timeout, delay to timeout, and the response-timeout dependency (Azrin \& Holz, 1966). The aim of the following series of experiments was to investigate the preceding variables in relation to timeout punishment and to add to the data analysis techniques used to evaluate the effects of timeout punishment.

How response rates change during punishment depends in part on the environmental context in which the punishers are arranged (Azrin \& Holz, 1966). Isolating the punishing effects of timeout from other variables that can decrease responding is important in an experimental analysis of timeout punishment. The first section of the literature review addresses methodological issues involved in interpreting response decreasing effects during timeout punishment. A review of research on schedules of timeout, both in human and animal experiments follows next. Finally, experiments using variable schedules of positive punishment are reviewed and followed with a discussion of delayed punishment.

\section{Literature Review}

\section{Methodological Considerations in the Analysis of Timeout-Punishment Effects}

A timeout presentation meets the definition of a punisher if responding decreases as a result of the response-dependent presentation of the timeout. This seemingly straightforward definition has posed a challenge to researchers studying timeouts because response reduction cannot often be unequivocally attributed directly to the timeout. Indeed other variables may contribute to or even supplant timeout as the reason for the decrease in responding resulting from response-dependent timeouts from positive reinforcement. These methodological considerations are examined in this section.

Reviewing research on timeout from positive reinforcement, Leitenberg (1965) commented on several methodological considerations that arise in timeout experiments. One is 
whether response reduction is a direct effect of the introduction of the timeout or occurs indirectly because of accompanying reductions in reinforcement rates. If a timeout is indeed a punisher, then response reductions should be attributable specifically to the timeout presentation. If, however, a procedure allows for a concomitant change in the reinforcement rate for either the punished or other, competing responses, this confounds the attribution of response reduction to the timeout. For example, two human subjects in an experiment by Holz, Azrin, and Ayllon (1963) completely ceased responding to a timeout-punished alternative when an unpunished alternative was concurrently available. In this instance, subjects could respond exclusively to the unpunished alternative. Responding to the timeout-punished alternative decreased the obtained reinforcement rate within a session; a potential indirect response-decreasing effect of timeout presentations.

To further examine this methodological limitation in the interpretation of timeout punishment raised by Leitenberg (1967), Kaufman and Baron (1968, Experiment 1) investigated the effects of timeout when the introduction of the timeout resulted in a net decrease in obtained positive reinforcement. Kaufman and Baron controlled for increases in the reinforcement rate that can occur when another reinforced alternative was made available during punishment (as in Holz, Azrin, \& Ayllon, 1963) and that had been observed during demonstrations of successful timeout avoidance (Thomas, 1965). Sweetened condensed milk reinforcers were delivered to rats following the first and second responses of a three-response sequence. A 2-min timeout was delivered following every third response of the sequence. The latencies between the second and third responses increased relative to a no-punishment condition where no consequence followed the third response of the sequence. This procedure decreased overall reinforcement rate, but left unanswered whether the longer latencies were a function of the delay to the next reinforcer 
availability that the timeout introduced (see Lattal [2010] for a review of delay-of-reinforcement effects).

The concurrent availability of punished and unpunished alternatives can engender more frequent responding to the unpunished alternative, thereby decreasing responding to the punished alternative, even when relative reinforcement rate is controlled between the two alternatives. An example of this type of preparation is evident in an experiment conducted by Thomas (1968). Thomas maintained pigeons' key pecking on two concurrently available variable-interval (VI) 180-s schedules of food delivery. Thirty- or 120-s timeouts were scheduled across separate conditions according to a descending series of fixed-ratio (FR) timeout presentation schedules in one of the concurrent schedule components. Across conditions, every fiftieth, twenty-fifth, tenth, or second response produced a timeout. Responding during the timeout components decreased as the frequency of timeout increased and responding increased during the unpunished component. Thomas concluded that the response reduction was a direct effect of the introduction of the timeout independently of any concomitant increase in reinforcement rate for the alternative response because relative reinforcement rates (reinforcers per minute) between both components of the concurrent schedules were comparable within each timeout condition. Although valid, his conclusion does not address whether the decreased absolute reinforcement rate (total component time including timeout time) resulted in decreased responding to the punished component.

The experiments by Thomas (1968) and Kaufmann and Baron (1968) highlight a need for a procedure that controls for concomitant changes in absolute reinforcement rates when imposing timeouts. Such a procedure is necessary to further understand the effects of timeout punishment separable from indirect effects of changes in reinforcement rate. Branch, Nicholson, and 
Dworkin (1977) used such a control procedure to determine whether response reduction observed during timeout punishment was an indirect effect of reduced reinforcement rate resulting from timeout introductions. Key pecking by pigeons was maintained under a multiple random-interval (RI) 1-min RI 6-min schedule of food delivery. Following baseline, a random ratio (RR) schedule of 20-s timeouts (house light and key light turned off and no food delivery following key pecks) was conjointly introduced in the RI 1-min component. A timeout was arranged for approximately every third key peck, on average (RR 3). Timeouts reduced responding in the RI 1-min component by approximately 35 to $50 \%$ of the preceding no-timeout baseline and there was a slight increase in responding to the unpunished component. As a control procedure for reduced session reinforcement rate, in a subsequent condition, Branch et al. delivered timeouts independently of responding, but with a similar temporal distribution as in the response-dependent timeout condition. Responding was not decreased by these responseindependent timeouts indicating that response reduction was a function of response-dependent timeouts, not of reductions in overall session reinforcement rate.

The procedure used by Branch et al. (1977) was not specifically designed as an experimental analysis of timeout from positive reinforcement, rather, they produced equivalent baseline rates of punished responding by timeout and shock as baselines to assess the effects of different doses of pentobarbital. Their procedure nevertheless demonstrated that the responsereducing effects of timeout presentations are separable from the indirect effects of decreased session reinforcement rate (see also Carlson, 1972, for control procedures in a concurrent chains schedule). Their results, by extension, also show that the dependency between the response and the timeout it produces is an important component of punishment by timeout. Further schedule effects of timeout presentations will be reviewed in the following section. 


\section{Schedules of Timeout Punishment}

Azrin and Holz (1966) noted that the schedule of punishment can affect the extent of response reduction. Some early experiments of timeout punishment focused on the accuracy of matching-to-sample performance when incorrect responses were punished by timeout (e.g., Ferster \& Appel, 1961; Zimmerman \& Ferster, 1963). Percentage correct responses in discretetrial preparations increase with the frequency of punished incorrect responses; continuous punishment of incorrect responses generally produces higher accuracy than intermittent punishment (Zimmerman \& Ferster). Free-operant experiments of timeout punishment (e.g. Branch et al., 1977) move beyond percentage-correct dependent measures and allow schedule effects of punishment to be studied on ongoing behavior. Whether characteristic patterns of responding typical of those seen with schedules of positive reinforcement (Ferster \& Skinner, 1957; Zeiler, 1984) occur with schedules of timeout punishment has not been systematically explored. What follows expands on intermittent timeout-punishment experiments described in the prior section.

An early experiment evaluating the effects of variable punishment by timeout was conducted by Clark et al. (1973). Variable-ratio (VR) schedules of timeout were used to decrease disruptive behavior of an 8-year old girl. Initially, responses were continuously punished by timeouts (an FR 1 schedule) and disruptive behavior was reduced to near-zero. Following FR 1 timeout, VR 4, VR 8, and VR 3 schedules of timeout were implemented across conditions. The VR 3 schedule similarly reduced responses to that observed during the FR 1 schedule of timeout and the VR 4 schedule resulted in lower levels of responses relative to baseline, although slightly elevated above the responding observed during the VR 3 condition. During the VR 8 schedule, rates of disruptive behavior were similar to those during the 
unpunished baseline. Clark et al. used a release contingency during the timeout that required 15 s of quiet before the timeout could end, which increased the minimum 3-min duration of timeout time. The potential for variation in timeout duration is not necessarily a limitation of their experiment, but was noted by the authors as an uncontrolled variable. Irrespective of this uncontrolled variable, as a higher frequency of the target response was punished, greater response reduction occurred.

Other schedule effects of punishment were studied by Lerman et al. (1997). Following an FR 1 schedule of punishment, Lerman et al. implemented fixed-interval (FI) schedules of timeout to decrease hand mouthing for one of five participants with profound mental retardation. The FI schedule resulted in a timeout following the first instance of hand mouthing after a fixed period of time. Low levels of hand mouthing continued as the duration of the FI schedule increased from $30 \mathrm{~s}$ to $300 \mathrm{~s}$. Similar to the experiment by Clark et al. (1973), a release criterion of $10 \mathrm{~s}$ free of hand mouthing had to occur prior to the end of the 20 -s timeout. Data were not presented on how this contingency affected the overall duration of timeout for this participant. A positive punishment procedure, in which hands-down restraint resulted in a time-out, was implemented according to a similar sequence (FR 1 followed by FI increases) for the remaining participants. Increasing the duration of the FI yielded mixed levels of response reduction across participants. Increasing the FI duration resulted in similar to baseline levels of injurious behavior for two of the participants and sustained but lower levels of injurious behavior for two others. Lerman et al. proposed that the delivery of the hands-down punishment functioned as a discriminative stimulus that signaled an upcoming period of punishment-free time, thus leading to increases in self-injurious behavior in two participants. Similar results have occurred in animal experiments of FI positive punishment whereby a high rate of responding occurs early in 
the interval and decreases as the time to punishment nears (Azrin, 1956). Such responding can be characterized as negatively accelerating, in contrast to positively accelerating patterns of responding typically seen during FI schedules of positive reinforcement.

Lerman et al. (1997) used FI schedules of punishment on the assumption that it would be easier for caregivers to keep track of the passage of fixed-time periods than continuous response monitoring (as in FR or VR schedules) once response reduction was achieved. Variable-interval schedules were described as potentially being more difficult to implement because they require more frequent monitoring because of the varying time intervals. There have been few systematic evaluations of variable schedules of timeout from positive reinforcement in application or in basic animal research (see Clark et al., 1973 and Donaldson \& Vollmer, 2012 for VR timeout). The few basic-research experiments that have used VI timeout have done so only incidentally to the primary purpose of the experiment.

In an experiment on delayed reinforcement with pigeons, Ferster (1953, Exp. 3) used a procedure to control for the introduction of blackouts that served as signaled delays preceding a reinforcer delivery (the term "blackout" does not differ from the definition of a timeout offered thus far). Ferster introduced response-dependent and response-independent blackouts that were not correlated with reinforcement. A VI 60-s baseline schedule of reinforcement maintained responding and was alternated with two other conditions: conjointly operating VI 60-s schedules of response-dependent and response-independent 60-s blackouts. Responding during both the response-dependent and response-independent blackout conditions was unchanged relative to baseline. Lattal (1984) systematically replicated Ferster's findings. Pigeon's key pecking was maintained by a VI 50-s schedule of reinforcement in baseline. Two conditions, conjoint VI 50-s schedule of response-independent and conjoint VI 50-s schedule of response-dependent 20-s 
blackouts, were alternated with baseline conditions where the blackouts did not occur. Response rates were similar between the response-independent and response-dependent conditions, but response rates in both conditions were elevated relative to the preceding baseline condition. The experiments by Ferster and Lattal indicate that response reduction did not occur during VI 60and VI 50-s schedules of response-dependent and independent blackouts.

Dunn (1990) maintained pigeons' key pecking to left and right keys by VI 45-s and VI 90-s food reinforcement schedules, respectively. A changeover-key concurrent schedule (cf. Findley, 1958) was used such that either the left or right key was active; the pigeon could activate the other key by pecking 4 times on a center key. Variable-interval schedules of 20-s timeouts were introduced to both keys according to equal VI 45-, 90-, and 180-s schedules across conditions. Responding decreased to each alternative relative to baseline levels; the greatest relative decrease in response rates occurred to the VI 45-s key during the VI 45-s timeout condition. Despite this decrease in relative response rates to the VI 45-s key there were no systematic differences in response rates between the VI 180-s and VI 90-s timeout conditions. This finding is in contrast to the results by Thomas (1968) when timeouts were presented according to FR schedules (see prior section for experimental details).

In summary, responding varies with the schedule of timeout in effect; the effect being demonstrated with FR, VR and FI schedules. Generally, intermittent-timeout punishment can reduce responding to levels similar to that of continuous punishment when the schedule of punishment is relatively rich (Clark et al., 1973; Lerman et al., 1997). What remains unknown is how responding changes across different values of VR and VI timeout schedules and whether comparable rates of timeout between the two schedule types result in equivalent response reduction. It is possible that a richer schedule of VI timeout than those described above may 
serve as an effective schedule of punishment, however, the time-plus-response requirement of VI schedules (as in FI schedules) can allow responding to occur at higher rates during intertimeout intervals, potentially leading to higher response rates when compared to VR schedules of punishment. Said another way, schedule differences could occur because the numbers of responses per timeout are set at some mean value during VR schedules of timeout, but responses per timeout are not constrained during VI schedules of timeout. The aforementioned experiments and the latter considerations warrant further analysis of intermittent schedules of timeout.

\section{Variable-Ratio and Variable-Interval Schedules of Positive Punishment}

The response-dependent presentation of an unconditioned punisher such as electric shock has been designated as a form of positive punishment in contrast to negative punishment defined as the response-dependent cessation of positive reinforcement (Catania, 1998; Cooper, Heron, \& Heward, 2007; Skinner, 1953). The functional definition of punishment offered by Azrin and Holz (1966) is general in that it does not specify any particular property of the punishing stimulus that serves to decrease the future probability of a given response producing the punisher. Similarly, Michael (1975) described the distinction, or potential lack thereof, between positive and negative reinforcement by stating that,

Perhaps they [positive and negative reinforcement] have different temporal properties, or different relations with other independent variables. . . It is quite true that the various environmental changes that function as reinforcement each have unique properties that one must know about in order to predict or control behavior effectively. However, these properties seem just as relevant to the distinctions among the various kinds of positive reinforcements as between positive and negative reinforcement (1975, p. 41). 
It is possible that the distinction between positive and negative punishment serves merely a pedagogical function rather than distinguishing behavioral processes. The behavioral effect of both putative punishment processes should be similar; the future probability of a response will decrease relative to unpunished responding. Whether positive and negative punishment processes actually operate similarly can be determined in part by experimentally determined functional relations. This section extends the prior discussion of VR and VI punishment by reviewing results from experiments using shock as a punishing stimulus.

Relatively few systematic evaluations of variable schedules of timeout punishment have been made, but, by contrast, a number of experiments have evaluated variable schedules of electric-shock punishment. For example, using a group design, Filby and Appel (1966) maintained lever pressing by rats by VI 30-, 60-, and 180-s schedules of reinforcement by a sweetened milk solution. They introduced VI schedules of 0.2-, 0.4-, and 0.6-mA of shock according to the same mean frequency of milk presentation in each group. Responding of rats in the VI 30- and 60-s groups increased relative to the no-punishment baseline during $0.2 \mathrm{~mA}$ shocks, but no systematic change relative to baseline occurred at $0.4 \mathrm{~mA}$ shock, and response rates decreased for the VI 180-s group during the $0.4 \mathrm{~mA}$ shock relative to the $0.2 \mathrm{~mA}$ shock. There were no within-subject comparisons of the different VI schedules of food and punishment and, as noted by the authors, comparisons across groups were confounded by the different rates of food reinforcement. Filby and Appel showed that response rates can increase during VI schedules of shock when the intensity of the shock is relatively low. The results highlight the need for further within-subject analyses of VI punishment schedules to answer the question of whether responding would have decreased during 0.2-mA shock if a richer VI punishment schedule was used. 
Lande (1981) maintained pigeons' key pecking by a VI 60-s schedule of reinforcement prior to introducing VR schedules of electric shock. The mean frequency of VR punishment was varied across conditions as follows: 100, 400, 800,400, 100, and 10. Response rates varied inversely as a function of the mean VR punishment schedule for each subject. Similar to the results of Filby and Appel (1966), response rate increases relative to no-shock baselines were observed and were correlated with increases in the proportion of short interresponse times (IRTs; the time between successive responses) for 7 of 12 pigeons for one or more of the shockintensity conditions used (range of $2.5-16 \mathrm{~mA}$ ). Ida and Kimora (2005) also found that rats' lever pressing maintained by a VI 60-s schedule of reinforcement also varied as a function of the mean VR schedule of shock (3.5, 4, and $5 \mathrm{~mA}$ shock). Ida and Kimora studied a lower range of VR schedule values than that of Lande; values varied between subjects, but ranged from VR 12 to VR 90. A positive correlation was found between the punishment ratio (response / punishment) and the relative response rate.

Azrin (1956) studied the effects of VI schedules of response-dependent and responseindependent schedules of shock delivery on pigeons' key pecking maintained by a VI 180-s schedule of positive reinforcement. Shocks always were presented every 2 min on average during an orange key light presentation interspersed with a stimulus presentation associated with the absence of punishment. Responding during the stimulus uniquely correlated with the schedule of punishment was decreased to a very low, but uniform, level of responding. The same frequency of shock presented as an FI schedule resulted in a negatively accelerated pattern of responding during the punishment stimulus. Hymowitz (1973) also studied FI and VI schedules of electric shock with rats as subjects. Responding was maintained by a VI 35-s schedule of food and FI 60- and 240-s schedules of shock decreased responding more than the 
same mean values of shock presented as a VI schedule. Hymowitz noted that differences in response reduction between the schedule types would not likely maintain beyond the 10 observed sessions because responding was not deemed stable and was showing an increasing trend (habituation to the shock) across the last 5 sessions of each shock condition.

During VR and VI schedules of shock presentation, responding sometimes is increased relative to baseline responding when the intensity of the shock is low (Galbicka \& Branch, 1981; Filby \& Appel, 1966; Lande, 1981) and sometimes is decreased (Azrin, 1956) or increased relative to fixed schedules of equivalent mean durations (Hymowitz, 1973). The results are not surprising given the variety of experimental arrangements and intensities of shock used. Timeout presentations may also show similar response increasing or decreasing effects if the frequency of timeout functions similarly to shock.

\section{Delayed Punishment}

The temporal interval between a response and punisher is another critical variable that can determine the effect of punishment (Azrin \& Holz, 1966). Delay-to-punishment gradients have been demonstrated using electric shock (Baron, 1965; Baron, Kauffman, \& Fazzini, 1969; Kamin, 1959; Trenholme \& Baron, 1975) and timeout (Carlson, 1972) as punishers. With both shock and timeout, response rates typically increase with increasing delays to the punisher. Carlson, for example, maintained lever pressing of rhesus monkeys on a concurrent-chains schedule in which the last response of a VI 15-s initial link on one lever produced a 15-s timeout. In some conditions the timeout immediately preceded the terminal-link entry or was delayed and presented 3, 9, or $15 \mathrm{~s}$ into the terminal link. Responses to both levers were roughly equivalent during no punishment conditions and the lowest number of responses occurred during the initial link lever during timeout conditions when the timeout immediately preceded the terminal link 
(i.e., no delay). During delayed timeout conditions, responses to the timeout lever increased as the delay to timeout increased. The reinforcement rate in the terminal links were roughly equivalent in Carlson's experiment, indicating that there was a punishing effect of the timeout independent of concomitant increases or subsequent deceases in reinforcement rate. As previously mentioned, most punishment experiments have used shock as the punisher and experiments of delayed punishment are not an exception. A free-operant analysis of delayed timeout from positive reinforcement has yet to be conducted.

\section{Statement of the Problem}

Punishment is relatively understudied in comparison to reinforcement, and within the experimental analysis of punishment, relatively more is known about the effects of positive than negative punishment. Basic research on punishment by timeout from positive reinforcement will contribute to the literature on punishment in general and add to the knowledge of punishing stimuli beyond unconditioned punishers such as shock. Studying schedules of timeout and response-timeout relations is also warranted to further a theoretical understanding of punishment, to determine how timeout-punishment effects compare to similar variables affecting positively reinforced responding, and to allow comparisons to other punishing stimuli. No experiments have attempted direct comparisons of timeout schedules, and few have attempted to control for decreases in reinforcement rate during immediate timeout or decreases in timeout rate during delayed timeout (but see Branch et al., 1977, and Kaufman \& Baron, 1968). It is currently unknown what frequency of VI timeout may be necessary to produce response reductions relative to unpunished baselines in a free-operant preparation. Likewise, it is currently not known what schedule values, of both VI and VR timeout, might lead to response rate increases 
relative to unpunished baselines, and how distributions of IRTs may be changed during response rate decreases and potential increases.

The following series of experiments were designed to examine how timeouts function under the following conditions: 1) direct comparisons of VR and VI schedules of timeout while attempting to equate timeout rate between the two schedule types, 2) separate parametric analyses of VI and VR schedules of timeout using a within-subject control for reductions in reinforcement rate that occur during timeout, and 3) delays to punishment using the same withinsubject control for reductions in reinforcement rate as well as additional controls for reductions in timeout rate that occur during delay conditions. 


\section{Experiment 1}

The purpose of Experiment 1 was to investigate the effects of VR and yoked-interval (YI) schedules of timeout, within individual subjects, while attempting to equate both the rate and distribution of timeouts between the two schedule types. In the case of positive reinforcement, direct comparisons of the characteristic patterns of responding generated by VR and by VI schedules have been studied by using yoking procedures that equate overall reinforcement rate between the VR and VI schedules (Ferster \& Skinner, 1957; Peele, Casey, \& Silberberg, 1984). Typically a higher response rate is generated by VR and a lower relative response rate by VI; shorter and longer reinforced IRTs occurring between the schedule types, respectively. Direct comparisons of VR and VI schedule effects of timeout have not been systematically studied in both basic research and application. It is possible that responding during timeout presentations will come under schedule-specific control, potentially leading to differences in response reduction and punished IRTs. The schedule values, VR 2 and VR 10, were investigated because they were both more and less frequent than have been used in prior experiments of timeout and would likely result in yoked-interval schedules of timeout more frequent than the VI 50-s schedule used by Lattal (1984).

\section{Method}

\section{Subjects}

Three White Carneau pigeons served. Each had a prior history of responding to schedules of positive reinforcement. The pigeons were maintained at approximately $80 \%$ of their free-feeding body weight by feedings that occurred at least $30 \mathrm{~min}$ after sessions. Each pigeon was housed individually with continuous access to water and health grit as necessary in a vivarium with a 12:12 hr light/dark cycle. 


\section{Apparatus}

Three sound-attenuating operant chambers were used. The first chamber was $31 \mathrm{~cm}$ long, $27 \mathrm{~cm}$ wide, and $31 \mathrm{~cm}$ high. The chamber was equipped with three response keys, each 2 $\mathrm{cm}$ in diameter, the bottom edges $22 \mathrm{~cm}$ from the floor, and $7.5 \mathrm{~cm}$ apart, center to center. The left key was the only operative key in this chamber. Two exposed $28 \mathrm{vdc}$ bulbs were located at the top rear ceiling of the chamber and provided general illumination. The second and third chambers were $30 \mathrm{~cm}$ long, $30 \mathrm{~cm}$ wide, and $38 \mathrm{~cm}$ high. Three response keys, each $2 \mathrm{~cm}$ in diameter, were on the fronts of both work panels. The keys were $10 \mathrm{~cm}$ apart, center to center, with the lower edges of each key $25 \mathrm{~cm}$ from the floor. The center key was operative in the second chamber and the right key was operative in the third. A house light located behind a translucent plastic panel, $4.5 \mathrm{~cm}$ wide and $4 \mathrm{~cm}$ high, with the lower edge $3 \mathrm{~cm}$ from the floor and the right edge $3.5 \mathrm{~cm}$ from the right wall, provided general illumination for the second and third chambers. In in all three chambers, Purina pigeon pellets were made available through an aperture, $5 \mathrm{~cm}$ wide and $5 \mathrm{~cm}$ high, $4 \mathrm{~cm}$ from the floor, and located in the midline of the work panel below the response keys. During reinforcement, the response key and house light were extinguished, an unfiltered 28 -vdc bulb located above the top of the aperture and behind the work panel was illuminated, and a hopper was raised to provide 3-s access to food. White noise masked extraneous sound and a computer located outside of the experimental room ran MedPC 7 software, controlled the experimental procedures, and recorded data.

\section{Procedure}

Sessions occurred at approximately the same time each day, seven days a week, and started with a 3-min blackout in the operant chamber. Pigeons responded on a two-component multiple schedule of reinforcement with a specific key color correlated with each component. 
Each component occurred twice within a session and strictly alternated. Each component lasted $10 \mathrm{~min}$, excluding reinforcement time and timeouts. All timeouts were $20 \mathrm{~s}$ in duration with the key light and house light extinguished. Components were separated by a 30-s intercomponent interval (ICI) where the key light was extinguished and the house light remained on. Responding during all timeouts and ICI's had no programmed consequences, but were recorded. Each condition was in effect for a minimum of 14 sessions and until the following relative stability criteria were met for both components: the difference between the mean response rate of the first three and last three most recent sessions was divided by the grand mean of the most recent six sessions and the resulting percentage could be no greater than or less than $\pm 5 \%$. Response rates for each session were calculated as responses per min during the total time in for each component (20 minutes total summed across both alternations of a component and exclusive of food and timeout durations). All pigeons started immediately on the baseline condition because of a prior history of responding. Table 1 shows the sequence of conditions, number of sessions for each condition, reinforcement rate, and timeout rate in Experiment 1. The conditions are described below.

Baseline. Key pecking in each component was maintained by a VI 45-s schedule of reinforcement. Successive interreinforcer intervals for each component were drawn without replacement from two independent lists of 12 intervals derived from the distribution described by Fleshler and Hoffman (1962). The first response after an interval timed out extinguished the key light and the house light, illuminated the food aperture, and provided 3-s access to food.

Variable-ratio and yoked-interval timeout. Across conditions, two VR schedules of timeout operated conjointly with the VI 45-s schedule of reinforcement in the first and third components of the multiple schedule. The ratios were selected without replacement from a 
single list comprised of 12 values. The ratio values were generated using a Fleshler and Hoffman (1962) distribution and the values were rounded to the nearest integer to produce ratios. Each key peck was counted toward the selected ratio value for timeouts, but key pecks that resulted in reinforcement were not counted toward the ratio value for timeouts. The intertimeout intervals (the time between the end of one timeout and the start of the following timeout) from the first and third components were recorded and played back to occur as interval schedules of timeout (yoked interval - YI) in the second and fourth components, respectively. The first response following the lapse of the recorded intertimeout interval produced the timeout.

\section{Results}

All analyses were based on the last six (stable) sessions from each condition. The time-in reinforcement rates were similar and had minimal session-to-session variability for all pigeons and conditions. Figure 1 shows the response rates in each component across all conditions for each pigeon. Response rates of each pigeon during all conditions, for both the VR and YI components, were reduced relative to the preceding no-punishment baseline. Response rates in the YI components were higher than in the VR components during the VR 2 condition for Pigeons 849 and 4365. Timeouts per minute between the VR and YI components during the VR 2 conditions were not equated using the yoking procedure.

Suppression ratios plotted as a function of timeout condition and with the obtained timeout rate (unfilled bars) are shown in Figure 2. The suppression ratio is a quantitative measure of response reduction relative to the preceding baseline. The mean response rates during each timeout condition were divided by the sum of the mean response rate in the preceding baseline and the mean response rate during each timeout condition. The equation is as follows:

Suppression Ratio $=\frac{\text { Punishment }}{\text { Baseline }+ \text { Punishment }}$ 
The designation of punishment and baseline represent the mean response rates. Suppression ratios of 0.50 indicate no change in response rates, ratios higher than 0.50 indicate increased rates, and ratios below 0.50 indicate decreased response rates. The biggest difference in the rate of timeout between components, within a condition, occurred during the VR 2 conditions for all pigeons. The suppression ratios in the VR components were lower than the suppression ratios during the YI components indicating greater response reduction relative to the preceding baseline during VR timeout components than in YI. This relation held regardless of the relative timeout rates in the two components.

The punished IRT is the time between two successive responses that immediately preceded the timeout. Suppression ratios plotted as a function of the median punished IRTs are shown in Figure 3. The punished IRTs in the VR components for each pigeon were shorter than the punished IRTs in the corresponding YI components within each condition. Thus, the punished IRTs varied as a function of timeout schedule type. Figure 4 shows the proportions of all IRTs plotted in successive 0.2-s bins for both components in each condition. An IRT was excluded from the proportion calculation when timeouts or reinforcers intervened between two successive responses. The proportion of IRTs in the first bin for both punishment conditions and components were decreased relative to baselines for Pigeons 4365 and 828. For Pigeon 849, there was an overall leftward shift in the IRT distributions and an increase in the proportion of IRTs in the first bin. The VR 2 condition showed the most response reduction despite the increase in the proportion of short IRTs for Pigeon 849. Overall, there were no systematic differences in the distributions between components, and therefore VR and YI schedule types, for either timeout condition.

\section{Discussion}


Response rates relative to the preceding baseline typically decreased with increases in the rate of timeout, replicating prior experiments that varied the rate of timeout (Clark et al., 1973; Thomas, 1968; Zimmerman \& Ferster, 1963). These results also extend prior experiments using interval schedules of timeout. Ferster (1953) and Lattal (1984) found no reduction in responding during VI schedules of response-dependent timeouts. Their experiments scheduled timeouts according to relatively lean schedules (mean intertimeout intervals were $60 \mathrm{~s}$ and $50 \mathrm{~s}$, respectively) and this likely contributed to their finding of no response reduction. Dunn (1990) maintained responding of pigeons using a concurrent VI 45 VI 90-s schedule arrangement and then conjointly punished responding using VI 45-, 90-, and 180-s schedules of 20-s timeouts to both response alternatives across conditions. Dunn found response reduction relative to notimeout conditions for all three schedules of timeout. The finding that interval schedules of timeout can decrease response rates within a multiple schedule arrangement adds to the generality of response reduction by timeout punishment.

In prior experiments, differences in the punished IRTs have not only increased or decreased response rates, but also changed particular classes of IRTs dependent on whether short or long IRTs are targeted for punishment (Arbuckle \& Lattal, 1992; Everly \& Perone, 2012; Galbicka \& Branch, 1981). For example, Everly and Perone found that shock dependent on long IRTs generally increased response rates and, conversely, when shock was dependent on short IRTs response rates decreased; the IRTs targeted in each procedure were susceptible to punishment. The current experiment did not specifically target IRTs for punishment; nevertheless, shorter punished IRTs occurred for VR than for YI timeouts. The decreases in proportion of IRTs in the shortest bins were correlated with decreases in response rate for two of 
the three pigeons; a greater proportion of shorter IRTs, and therefore a greater likelihood of shorter punished IRTs occurred for only one pigeon.

The 20-s timeouts functioned as punishers with both schedule types, but the differences in the rate of timeout, and therefore also total reinforcement rate between components, between the VR and YI components in the VR 2 conditions were limitations of the direct comparison attempted in Experiment 1. The high number of yoked intertimeout intervals from the preceding VR components, and the time-plus-response requirement necessary to produce the timeout in the YI components contributed to fewer timeouts during the YI components. The duration of each component was set at 10 min of time-in and therefore some recorded intertimeout intervals were not presented within a session. Such a difference in timeout rate is a confounding variable for a within-subject analysis of schedule effects of timeout. The differences in suppression ratios observed between the VR and YI components in the VR 2 condition for each pigeon cannot, therefore, be attributed directly to schedule effects. Despite this confound, the results of Experiment 1 provided preliminary evidence of schedule differences in the punished IRT, showed that YI schedules of timeout decreased responding, and identified parameter values to further evaluate schedule effects of timeout presentations in Experiment 2. 


\section{Experiment 2}

Experiment 2 was designed to evaluate schedule effects of VR and VI timeout without the limitation of the direct comparisons attempted in Experiment 1. The degree of response reduction that occurred as a function of the programmed (VR) and obtained (YI) timeouts per min in Experiment 1 were used to inform the schedule values used in this experiment. The experimental design used in Experiment 1 had two features: 1) responding in the previous VRtimeout components determined the rate of YI timeout in the following components and 2) the time-plus response requirement necessary to produce the YI timeouts limited the number of timeouts that were obtained in each YI component. Experiment 2 changed the experimental design used in Experiment 1 by independently evaluating both higher and lower rates of VI and VR schedules of timeout in two parametric analyses, presented as Experiment $2 \mathrm{a}$ and Experiment $2 \mathrm{~b}$, respectively. The procedure allowed greater control over the rates of interval timeout than occurred using the within-subject direct comparison of timeout schedules in Experiment 1. The mean nominal VI value in Experiment 2 was determined by experimental condition rather than individual-subject performance.

Control components were introduced such that the distribution and rate of responseindependent timeouts presented in the second and fourth components were yoked to the response-dependent (VI and VR) timeouts obtained in the first and third components. This within-session yoking procedure (e.g. Pietras, Brandt, \& Searcy, 2010) was used to evaluate the effects of response-independent timeouts and served as a potential control for reductions in total component reinforcement rate that occurred during the response-dependent timeout components within a session (McMillan, 1967; Pietras \& Hackenberg, 2005; Willoughby, 1969). Branch et al. (1977) used similar response-independent timeout control conditions, although in a separate 
experimental condition, and found no response reduction. Their results implicate a direct punishing effect of timeout. Experiment 2, therefore, also served as an evaluation of the withinsession timeout-control component.

\section{Experiment 2 a}

\section{Subjects}

The three pigeons used in Experiment 1 were used. A fourth pigeon that had a history of responding to schedules of positive reinforcement was added. All were maintained as in Experiment 1.

\section{Apparatus}

Four sound-attenuating operant chambers were used. The first three chambers were the ones used in Experiment 1. The fourth chamber was $30 \mathrm{~cm}$ long, $30 \mathrm{~cm}$ wide, and $38 \mathrm{~cm}$ high. Two response keys were located on the front panel. Both keys were $2 \mathrm{~cm}$ in diameter, separated by $15 \mathrm{~cm}$ center to center, with the bottom edges $22 \mathrm{~cm}$ from the floor. The right key was the operative key in the fourth chamber. The house light for the fourth chamber was $4 \mathrm{~cm}$ in diameter and was located $3.5 \mathrm{~cm}$ from the right wall, the bottom edge $3 \mathrm{~cm}$ from the floor. Illumination, reinforcement procedures, white noise, and data collection were as described in Experiment 1.

\section{Procedure}

The schedule of reinforcement, timeout duration, and intercomponent intervals were as described in Experiment 1. The multiple-schedule arrangement (time-in component time and component alternations) was similar to that described in Experiment 1 except that the second and fourth components served as response-independent timeout control conditions. The intertimeout intervals from the first and third components of each session were recorded and played back to 
occur independently of responding in the second and fourth components, respectively. Table 2 shows the sequence of conditions, number of sessions, reinforcers per min, and timeouts per min for all conditions in Experiment 2 a.

Baseline. The baseline was as in Experiment 1.

Sequences of variable-interval schedules of timeout. Timeouts were delivered according to VI schedules that operated conjointly with the VI 45-s schedule of reinforcement in the first and third components of the multiple schedule. Successive timeout intervals for each component were drawn without replacement from a list of 12 intervals derived from the distribution described by Fleshler and Hoffman (1962). Mean interval values for the timeouts were presented sequentially across conditions in an ascending series for 2 pigeons and a descending series for the other 2 pigeons.

Variable-ratio schedules of timeouts and variable-interval replications. Following returns to baseline, each pigeon was exposed to VR 2 and VR 5 schedules of timeout across conditions. Following a subsequent return to baseline, each pigeon underwent at least three VI condition replications.

\section{Experiment 2 b}

\section{Subjects}

Four White Carneau pigeons with histories of responding to schedules of positive reinforcement, but different than those used in Experiment 2 a, were used. The pigeons were maintained as in Experiment 1.

\section{Apparatus}

Three sound-attenuating operant chambers were used. Each was $30 \mathrm{~cm}$ long, $30 \mathrm{~cm}$ wide, and $38 \mathrm{~cm}$ high. In the first chamber, two response keys, each $2 \mathrm{~cm}$ in diameter, were 
centered on the front work panel. The keys were $12 \mathrm{~cm}$, center to center, with the lower edge of each key $25 \mathrm{~cm}$ from the floor. Only the right response key was used. In the second chamber, three response keys, each $2 \mathrm{~cm}$ in diameter, were centered on the front work panel. The keys were $10 \mathrm{~cm}$ apart, center-to-center, and the lower edge of each key $25 \mathrm{~cm}$ from the floor. The center response key was the only operative key. In the third chamber, one response key, $2 \mathrm{~cm}$ in diameter, was centered on the work panel with the lower edge $24 \mathrm{~cm}$ from the floor. Filtered 28vdc bulbs (blue, orange, green, red, or white) were located behind the operative response key in each chamber. A house light located behind a translucent plastic panel, $4.5 \mathrm{~cm}$ wide and $4 \mathrm{~cm}$ high, with the lower edge $3 \mathrm{~cm}$ from the floor and the right edge $3.5 \mathrm{~cm}$ from the right wall, provided general illumination for the first, second, and third chamber. The house light in the third chamber was located behind a translucent plastic panel, $4 \mathrm{~cm}$ wide and $4 \mathrm{~cm}$ high, on the midline of the work panel, $4 \mathrm{~cm}$ from the floor. Food in the first, and second chambers was made available through an aperture, $5 \mathrm{~cm}$ wide and $5 \mathrm{~cm}$ high, and located in the midline of the work panel below the response keys. Food in the third chamber was made available through an aperture, $5 \mathrm{~cm}$ wide and $6 \mathrm{~cm}$ high, located $9 \mathrm{~cm}$ from the floor and $4 \mathrm{~cm}$ from the right wall.

\section{Procedure}

The schedule of reinforcement, timeout duration, and intercomponent intervals were as described in Experiment 1. The multiple-schedule arrangement was the same as described in Experiment 2 a. Table 3 shows the sequence of conditions, number of sessions, reinforcers per min, and timeouts per min for all conditions in Experiment $2 \mathrm{~b}$.

Sequences of variable-ratio schedules of timeout. Timeouts were delivered according to VR schedules that operated conjointly with the VI 45-s schedule of reinforcement in the first and third components of the multiple schedule. The ratio values were selected without 
replacement from a single list comprised of 12 values. These values were generated using a Fleshler and Hoffman (1962) distribution and the values were rounded to the nearest integer. Each key peck was counted toward the selected ratio value for timeouts except for those key pecks resulting in reinforcement. Mean ratio values for the timeouts were presented sequentially across conditions in an ascending series for 2 pigeons and a descending series for the other 2 pigeons.

Variable-interval schedules of timeout and variable-ratio replications. Following a return to baseline, Pigeons 521 and 10 were exposed to VI 2.5-s and VI 5-s schedules of timeout followed by subsequent returns to baseline and then two VR condition replications. Pigeon 1782 was euthanized for health reasons following the final VR timeout condition in the initial VR sequence. Following the first return to baseline, VR conditions were replicated with Pigeon 975, and a VR 40 condition was conducted.

In summary, the pigeons in Experiment 2 a received the VI sequence first, followed by VR 2 and VR 5 timeout and VI replications. The pigeons in Experiment $2 \mathrm{~b}$ received the VR sequence first, followed by VI 2.5 and VI 5 timeout and VR replications. All pigeons, with exceptions noted, received the two most frequent VI and VR schedules of timeout.

\section{Results}

All analyses are based on the last six (stable) sessions of each condition. The time-in reinforcement rates for all pigeons were similar, with minimal session-to-session variability across conditions. Figure 5 shows the component response rates for each pigeon that went through the sequence of VI schedules of timeout (Experiment 2 a). Response rates in the response-dependent timeout components (filled circles) typically were reduced relative to the preceding baselines during the three most frequent VI-timeout conditions for each pigeon. For 
Pigeons 4365, 2403, and 849, the lowest response rates occurred during the VR 2 timeout conditions. Replications resulted in similar levels of response reduction in the responsedependent components for all pigeons. Three exceptions to replication were the VI 20-s condition for Pigeons 4365 and 849, and the VI 5-s replication for Pigeon 2403. Response rates during the response-independent timeout components (open circles) in the VI timeout conditions were idiosyncratic to each pigeon. Response rates in the response-independent components were elevated above the response-dependent components in 16 out of the 34 total VI conditions. Response-independent component response rates were considered higher in a condition if five out of the six response rate data points were higher than the response-dependent timeout component data points.

Figure 6 shows the response rates in each component for the pigeons that went through the sequence of VR schedules of timeout first (Experiment $2 \mathrm{~b}$ ). Response rates in the responsedependent timeout components of each VR 2 condition were decreased relative to the preceding baseline for each pigeon. Response rates in the response-dependent timeout components during the VR 5 condition decreased relative to the preceding baseline for five out of the seven conditions. Response rates for Pigeon 521 in the response-dependent components of the VR 10, 15 , and 20 conditions were unchanged relative to the preceding baseline, but were elevated above baselines for Pigeons 1782 and 10. Response rates in the response-dependent components during the VR 10, 15, and 20 conditions for Pigeon 975 were each decreased relative to the preceding baseline. A replication at VR 20 and subsequent exposure to a VR 40 condition still showed lower response rates relative to both preceding baselines in the response-dependent components for Pigeon 975. Response rates in the response-independent components were 
elevated above the response-dependent components in 21 out of the 27 total VR conditions (the same decision criteria used in Figure 5 applied here).

The data shown in Figures 7 and 8 show suppression ratios (filled data points) plotted with the timeout rate (bars) for both components and each condition in Experiments $2 \mathrm{a}$ and $2 \mathrm{~b}$, respectively. The suppression ratios in the response-dependent timeout components varied inversely with the rate of timeout. Responding decreased the most during the VR 2 timeout conditions. During VI timeout, more suppression ratios fell below 0.50, and at lower timeout rates, when compared to the VR timeout. Suppression ratios for the response-independent timeout components followed the pattern noted in the prior sections describing overall response rates; that is, suppression ratios more often were lower in the response-dependent timeout components for the VR conditions than for the VI conditions.

The data for the remaining analyses were aggregated across all VI and VR conditions. That is, all VI conditions are shown in the same graphs and all VR conditions are shown in the same graphs. The latency to respond, or the pause, following a timeout contributes to decreases in overall response rates independently of changes in the overall distribution of IRTs. The pause following timeouts can make up a large proportion of the total component time (the denominator in the response rate calculation) especially if the rate of timeout is high. The topmost graphs in Figures 9 and 10 show the mean proportion of session time spent pausing following a timeout for both the response-dependent and response-independent timeout components for the aggregated VI and VR conditions, respectively. The mean proportion of session time spent pausing following response-dependent timeouts varied inversely with the mean schedule value for both timeout schedule types. That is, the mean proportion of the session time spent pausing following response-dependent timeouts increased as the mean schedule value of timeout decreased. The 
correlation coefficients for the proportion of session time spent pausing following responsedependent timeouts plotted as a function of obtained timeout rate (figure not shown) revealed a positive correlation for both schedule types (VI, $r=0.61$; VR, $r=0.67$ ). The bottom left graph in Figures 9 and 10 shows a side-by-side comparison of the grand means of both components. The mean proportion of session time spent pausing following timeouts in the responseindependent timeout components (unfilled bars) were all below the mean proportions shown for the response-dependent timeout components. Overall, a greater mean proportion of session time was spent pausing following timeouts when they were response dependent than response independent.

The posttimeout pauses contributed to the response rate decreases found during the most frequent timeout conditions, for both VI and VR timeout. If the punishment effect extended beyond the posttimeout pause and response rates remained decreased thereafter, then subtracting the posttimeout pause from the overall response-rate calculation will give a clearer picture of the contribution of the posttimeout pause to the observed punishment effects. For example, if the adjusted response rates are lower than the response rates in the unpunished baselines, this indicates that response reduction occurred beyond that resulting from the absence of responding during the posttimeout pause in the punishment conditions. If the adjusted rates are similar to or higher than the unpunished baselines, then this indicates that the punishment effect can be accounted for by the latencies to respond following timeouts. To adjust for the posttimeout pauses, the total time spent in the posttimeout pause was subtracted from the total time-in session time for the last six stable sessions for each timeout condition. Additionally, because the first response following a timeout ends the time of the pause and starts the new adjusted time-in, it was excluded from the analysis. The response ending the pause was also excluded because the 
response rate contribution of the removed response increased with the rate of timeout, when the most response reduction occurred.

Tables 4 and 5 show the unadjusted and adjusted response rates for all VI and VR conditions, respectively. The baseline response rate shown is the mean of all baselines for each pigeon. The values in italics represent the adjusted response rates of the values immediately above them, and the second set of unadjusted and adjusted values are the replication of a condition. The bolded adjusted values indicate response rates that are below the mean of the baseline conditions for a pigeon. Out of 38 total VI timeout conditions, the adjusted response rates for 20 conditions remained lower than the baseline mean. Out of 35 total VR timeout conditions, the adjusted response rates for 12 conditions remained lower than the baseline mean. There were 10 conditions for the VI and 12 conditions for the VR where the unadjusted rates showed a punishment effect and the adjusted rates were higher than the mean baseline rate.

Figures 11 and 12 show the mean proportion of session time spent pausing following a reinforcer delivery for both the response-dependent and response-independent timeout components for the aggregated VI and VR conditions, respectively. The proportion of session time spent pausing following a reinforcer delivery increased as the rate of timeout increased for both the VR timeout conditions during the response-dependent timeout components, but not for the VI timeout conditions. The proportion of session time spent pausing following a reinforcer delivery in the response-independent timeout components increased as the frequency of timeouts decreased. The available sample of postreinforcement pausing in the response-independent timeout components during the richest timeout conditions was smaller than in the corresponding response-dependent timeout conditions because timeouts occurred frequently and interrupted pauses. 
Figure 13 shows suppression ratios plotted as a function of punished IRTs for the aggregated VI and VR conditions in Experiment 2. The punished IRTs for the VI conditions were less than $0.5 \mathrm{~s}$ for 5 out of 38 conditions and the punished IRTs for the VR conditions were less than $0.5 \mathrm{~s}$ for 27 out of 35 conditions. These results replicate and extend the schedulespecific effects of timeout presentation found in Experiment 1; shorter punished IRTs occurred during VR timeout. A Pearson correlation coefficient was calculated for both VI and VR data series and indicated that there was a strong negative correlation $(r=-0.78)$ between suppression ratio and punished IRTs for the VI conditions and a weak negative correlation $(r=-0.13)$ between suppression ratio and punished IRTs for the VR conditions. The results for the VI conditions provide support for an association between the punished IRT and level of response reduction because the median punished IRTs became longer with greater response reduction. The punished IRT data for the VR conditions indicate that response reduction was not always correlated with the punished IRT. The suppression ratios plotted with timeout rate in Figures 7 and 8 indicate that the VR 2 conditions resulted in the greatest response reduction per rate of timeout when compared to the VI conditions. The median punished IRTs for 8 out of the 10 VR 2 conditions shown in Figure 13 were less than $0.5 \mathrm{~s}$. Independence between the punished IRT and rate of VR timeout was observed. That is, the punished IRT remained similar across all values of the independent variable.

The proportion of IRTs are shown for the first baseline condition for each pigeon and the highest nominal VI and VR conditions, and replications, for each pigeon for the responsedependent timeout components for Experiments $2 \mathrm{a}$ and $2 \mathrm{~b}$ in Figures 14 and 15, respectively. For 8 out of the 10 total VR 2 conditions, there was a leftward shift in the IRT distribution relative to the first baseline and an increase in the proportion of IRTs within the first bin. The 
same result occurred for 6 out of the 9 most frequent nominal VI timeout conditions. The exceptions to the above results were for Pigeons 2403 and 828. The proportion of shortest IRTs during the VI 2.5 and VR 2 timeout conditions were decreased relative to the first baseline for Pigeons 2403 and 828.

In summary, the primary findings in Experiment 2 were that: 1) orderly relations between timeout schedule value and response rates were generally obtained for each pigeon in the VR sequence (but see VR 20 for Pigeon 975), but were not obtained for 2 pigeons in the VI sequence, 2) VI schedules of timeout resulted in more response reduction at lower rates of timeout compared to VR schedules of timeout, however, VR schedules resulted in the most response reduction of either schedule type, 3) the proportion of session time spent in the posttimeout pause varied as a function of timeout rate and dependency for both schedule types, 4) the latency to respond following a timeout was a determinant of response rate reduction in some, but not all timeout conditions, 5) the proportion of session time spent in the postreinforcement pause increased with the rate of timeout in response-dependent timeout components and conversely increased as the rate of timeout became less frequent in the response-independent timeout components, 6) leftward shifts in IRT distributions occurred and the proportion of short IRTs increased during the most frequent nominal timeout conditions, and 7) longer punished IRTs were correlated with lower suppression ratios (i.e. less response reduction) for VI schedules of timeout and there was no correlation between punished IRT and suppression ratios for VR schedules of timeout.

\section{Discussion}

The results of Experiment 2 replicate and extend the results of Experiment 1 and prior experiments using VR and VI schedules of timeout and shock (Branch et al. 1977; Clark et al., 
1973; Filby \& Appel, 1966; Ferster, 1953; Lattal, 1984; Sadowsky, 1973). Response reduction, facilitation, and no change relative to the preceding baselines were observed during responsedependent and response-independent timeout presentations. More response reduction occurred when response-dependent timeouts were more frequent. The data analyses in Experiment 2 implicate contributions to response reduction during timeout that have not been described in prior experiments. That is, the latencies to respond following timeouts and reinforcers both contributed to response reduction. One potential contribution to the greater proportion of session time spent pausing during response-dependent timeout components than in the responseindependent timeout components during VR conditions is that the probability of a punished response following each timeout increased across conditions. For example, the programmed probability of a response being punished following each timeout was 0.5 during VR 2 conditions. The probability of a response being punished increased with the passage of time during the VI conditions and could have similarly contributed to longer pauses across conditions as the probability of a punished response following a timeout increased. The removal of the responsetimeout dependency, and therefore the absence of a probability of a response producing a timeout immediately following a just-produced timeout, resulted in less pausing following response-independent timeouts.

Increases in the proportion of short IRTs were not always correlated with increased response rates. The proportion of the shortest IRTs increased relative to unpunished baselines for 14 of 19 timeout conditions with the highest mean nominal timeout rate (where the most response reduction was observed) were observed for both VI and VR schedules. These findings contrast with increases in the proportions of short IRTs found during presentations of shock (Arbuckle \& Lattal, 1992; Galbicka \& Branch, 1981; Lande, 1981), however, the frequencies of 
timeouts presented herein were quite extreme in relation to those that have been used in experiments with shock. Likewise, the numbers of available IRTs for analysis were relatively low in the VR 2 timeout conditions; half the ratios were FR 1 and limited the available IRTs for analysis.

Within-session yoking of response-independent timeouts to the deliveries of responsedependent timeouts in the preceding components has not been previously established as an appropriate control procedure for the reduction in overall reinforcement rate that occurs during timeout punishment. Branch et al. (1977) found no response reduction when timeouts were delivered independently of responding in separate control conditions rather than within session. Response rates in the response-independent timeout components in Experiment 2 were not always higher than the corresponding response-dependent timeout components when response reduction was observed in the response-dependent components, particularly during VI timeout. Pietras and Hackenberg (2005, Experiment 2, Yoked Complete) arranged a similar within-session yoking procedure during response-cost punishment procedures with pigeons as subjects. In one component, a conjoint FR 10 token removal and random interval 30-s schedule of token production occurred. In the second, yoked-control component, tokens were removed independently of responding according to token-removal intervals obtained in the first component (token production and exchange ratios were yoked to the first component). Response rates for 3 of 4 pigeons were generally lower in the response-dependent token-loss components relative to the response-independent (yoked control) token-loss components. Response rates in both components were decreased relative to no punishment baselines. These results are similar to those obtained in Experiment 2 in that lower response rates in the response-dependent components indicates a punishment effect independent of decreased reinforcement rate; 
however, lower response rates in the response-dependent components relative to the yokedcontrol components were not uniformly obtained.

One potential contributing factor for similar levels of response reduction during responseindependent timeout as in response-dependent timeout is that the contiguity between responses and timeouts were sufficiently close as to allow the response-independent timeouts to be indistinguishable from response-dependent timeouts. Figure 16 shows that the median obtained delays to timeout, the time between timeouts and the immediately preceding responses, for the response-independent timeout components for each VI (top graph) and VR (bottom graph) condition in Experiment 2. No systematic relation between the obtained delay to timeout and response reduction was found because the obtained delays were mostly shorter during VR 2 and VR 5 timeout conditions, where response rates in the response-independent timeout components were typically elevated above their corresponding response-dependent components. Experiment 3 was designed to systematically assess the role of delay to timeout by introducing programmed delays during VR timeout. 


\section{Experiment 3}

Azrin and Holz (1966) describe punishment dependency and immediacy as "critical determinants in the degree of response reduction obtained" (pgs. 395-396). In Experiment 2, response rates during the response-independent timeout conditions were not always higher than the corresponding response-dependent timeout components. Response rates typically increase, relative to immediate punishment, when the punisher is delayed from the response that produces the punisher (Baron, 1965; Baron, Kauffman, \& Fazzini, 1969; Carlson, 1972; Kamin, 1959; Trenholme \& Baron, 1975). The purpose of Experiment 3 was to assess the effects of responsedependency, response contiguity, and rate of timeout in the context of delays to timeout with the same response-independent timeout yoking procedure used in Experiment 2.

Reduction in timeout rate is a potential confound in interpreting the potential responseincreasing effects of delayed timeout using the current free-operant procedure. The intervening time between a response initiating the delay to timeout and the presentation of the timeout, not present during immediate timeout, contributes to less timeout per unit of time. Attributing response reduction to the introduction of the delay cannot occur because it is confounded with decreased timeout rate given a free operant procedure. A control procedure, detailed below, was used in Experiment 3 such that the rate of timeout in delayed-timeout conditions and immediatetimeout conditions were similar. Variable-ratio schedules of timeout (VR 2 and VR 3) were chosen to evaluate the effects of delays to timeout because of the replicability of response reduction observed in Experiments 1 and 2. Two delay values, 0.5 and $5 \mathrm{~s}$, were chosen to maximize the likelihood of maintaining and abolishing response reduction, respectively. 


\section{Method}

\section{Subjects}

Four White Carneau pigeons, different than those used in Experiments 1 and 2, with prior histories of responding to schedules of positive reinforcement were maintained as described in the Experiment 1.

\section{Apparatus}

Chambers 1 and 3 from Experiment 1, the fourth chamber described in Experiment 2 a, and the first chamber described in Experiment $2 \mathrm{~b}$ were used.

\section{Procedure}

The general procedure was identical to that described in Experiment 2. Each component, however, was 5 min instead of 10 min, excluding reinforcement and timeout time. The distribution of intertimeout intervals in the first and second components were recorded and played back to occur independently of responding in the second and fourth components, respectively. The sequences of conditions, number of sessions, reinforcers per min, and timeouts per min for each pigeon are shown in Table 6.

Baseline. The baseline conditions were arranged as in Experiment 1, except that the components were 5 min.

Immediate timeout. The immediate timeout conditions were arranged as in Experiment 2, except that the components were $5 \mathrm{~min}$.

Delayed timeout. The delays to timeout $(0.5,1$, and $5 \mathrm{~s})$ were arranged by a tandem VR fixed-time (FT) schedule. The FT delays were nonresetting and were presented following the completion of the current VR value for timeout. Responses were recorded during the delays, the component timer continued to time, and reinforcers could be obtained. The FT timer was paused 
at the start of reinforcement and resumed after the offset of reinforcement. The 0.5- and 5-s delay conditions were counterbalanced among the 4 pigeons. Pigeon 2 received only the 0.5 -s delay condition and did not complete the experiment (the 5-s delay sequence) because of a recurring wing injury. An additional 1-s delay condition was conducted for Pigeon 691 only.

Contiguity control. Introduction of the delayed timeouts resulted in decreases in overall rate of timeout when compared to the immediate timeout conditions. During the contiguity control condition, food was delivered according to the same schedule as described in the previous experiments and timeouts were arranged using a tandem VR FI schedule. An FI timer started following the completion of the current VR ratio whereby the next response following the lapse of the FI timer resulted in timeout. This procedure allowed contiguity between responses and timeouts with comparable timeout rates to those obtained in the delayed timeout conditions. Responses during the FI schedule were recorded, the component timer continued to time, and reinforcers could be obtained. The FI timer was paused at the start of reinforcement and resumed after the offset of reinforcement.

\section{Results}

Reinforcers per min of time-in, shown if Table 6, were similar between components and within sessions across all experimental conditions. The rate of timeout decreased during the delayed and contiguity control conditions relative to the immediate punishment conditions for each pigeon; however, there were minimal differences in the rate of timeout between the delay and contiguity control conditions for all pigeons.

Figure 17 shows response rates in all conditions in Experiment 3. The condition labels are as follows: BL indicates no punishment baselines, VR (3 and 2) indicates the immediate timeout conditions, FT (0.5, 1, and 5) indicates delay conditions, and FI (0.5 and 5) indicates 
contiguity-control conditions. Response rates were decreased in the immediate punishment conditions (VR 3 and VR 2) relative to the unpunished baselines for each pigeon. The introduction of the delays, both $0.5 \mathrm{~s}$ and $5 \mathrm{~s}$ (FT 0.5 and FT 5), increased responding relative to the immediate-punishment conditions for all pigeons except during the first 0.5 -s delay condition for Pigeon 2 and the replication of the 0.5-s delay condition for Pigeon 691 (the return to immediate punishment was lower than the replication of the delay). Response rates in the response-independent timeout components typically were higher than their corresponding response-dependent timeout components during the immediate timeout, 0.5 -s delay, and 0.5-s contiguity control conditions. The only exception was for Pigeon 8964 during the 0.5 -s contiguity control condition, the replication of the 0.5 -s delay condition, and replications of immediate timeout.

Response rate increases during delay conditions cannot solely be attributed to the introduction of the delay because there were concomitant decreases in the overall rate of timeout relative to the immediate timeout conditions. The contiguity control conditions (FI 0.5 and FI 5 in the figures) were conducted to control for such decreases in timeout rate. Similar rates and temporal distributions of timeouts were obtained relative to the delay conditions. Despite this control, response rates increased for six out of the seven conducted contiguity control conditions. The only exception was for Pigeon 2. This finding was replicable not only between subjects, but also within subjects by using an A-B-A design (delay-control-delay) for both delay values embedded between the two immediate timeout conditions and the unpunished baselines.

Figure 18 shows the median obtained delays during the response-dependent timeout components and the response-independent timeout components. The obtained delay is the time between the delivery of a timeout and the immediately preceding response. The obtained delays 
during the 0.5 -s delay conditions were lower than the obtained delays in the 5-s delay conditions for each pigeon. The median obtained delays were also lower in the response-dependent components than in the response-independent timeout components within the 0.5 -s delay conditions.

\section{Discussion}

The response reduction during immediate timeout found in Experiments 1 and 2 were replicated in Experiment 3 using shorter time-in component durations. Response rates remained decreased relative to baselines for each pigeon during the 0.5 -s delay condition. When the response-timeout dependency resulted in relatively frequent timeouts, as in the 0.5 -s delay conditions, response reduction relative to baselines was maintained. When the timeouts were delivered response-independently (no dependency), during the same 0.5 -s delay conditions, response rates were higher than when the dependency was maintained. Increasing the delay duration to $5 \mathrm{~s}$ resulted in large decreases in timeout rate and also resulted in response rates that were higher than unpunished baselines. The mean schedule of timeout was the same in both delay conditions, but the 5-s delay introduced a much longer period of time in which no timeouts occurred, thereby decreasing the total timeout rate.

The contribution of the response-timeout contiguity in maintaining response reduction is difficult to interpret given the results of the contiguity control in Experiment 3. Response rates increased during the contiguity-control conditions even though similar rates of timeout were obtained as in the delayed-timeout conditions. The variable that did change between the delay and contiguity-control conditions was that there was an increase in the number of dependent responses necessary to produce the timeout. It is possible that the behavioral sensitivity to such a small change in dependency, one that does not appreciably alter the obtained rate of timeout, 
could account for the increased response rates during the contiguity-control conditions. This possibility was explored in Experiment 4.

\section{Experiment 4}

The purpose of Experiment 4 was to determine if the increase in response rates during the contiguity-control conditions in Experiment 3 were the result of an extra dependent response. If the increase in the number of dependent responses resulted in the increased response rate, then removing one response requirement from each ratio in the VR list during the control conditions should attenuate the response-increasing effect. Also, if response rates in the new contiguitycontrol conditions are lower than in the preceding delayed-timeout conditions, this would indicate that the delay resulted in increased response rates rather than reductions in timeout rates.

\section{Method}

\section{Subjects}

Pigeons 21331 and 8964 from Experiment 3 served.

\section{Apparatus}

The third chamber described in Experiment 1 and the fourth chamber described in Experiment 2 a were used.

\section{Procedure}

The same general procedure and baseline described in Experiment 3 were used, with the exceptions noted below. The sequences of conditions, number of sessions, reinforcers per min and timeouts per min for each pigeon in Experiment 4 are shown in Table 7.

Immediate timeout. Modified VR 3 schedules of timeout were used for both pigeons. The modified schedule was arranged such that a single response could be subtracted from each ratio during the subsequent contiguity control condition, thereby maintaining an equivalent 
number of dependent responses per timeout between the immediate, delayed, and contiguity control conditions. The original VR 3 list was comprised of the following 12 ratios: $1,1,1,1,1$, $2,2,3,4,5,6,9$. The modified VR 3 list was comprised of the following 12 ratios: 2, 2, 2, 2, 2, $2,2,2,3,4,5,8$. The mean value of both lists is 3 .

Delayed timeout. The modified VR 3 ratios were used and FT unsignaled-nonresetting delays to timeout were arranged according to the same procedure described in Experiment 3. Both delay values were replicated for Pigeon 21331, although in the reverse order as presented in Experiment 3. Only the 0.5 -s delay condition was evaluated for Pigeon 8964.

Contiguity control. A tandem VR FI schedule arranged timeouts in a similar manner as described in Experiment 3. One response was subtracted from each ratio in the VR list such that the number of responses in the ratio, with the addition of the subsequent FI response, equaled the same number of dependent responses in the modified VR 3 immediate-timeout condition. The FI timer was initiated after completion of the following ratios: $1,1,1,1,1,1,1,1,2,3,4$, and 7.

\section{Results}

Response rates, shown in Figure 18, were decreased relative to baseline when using the modified VR 3 immediate schedule of timeout for both pigeons. Similar levels of response reduction were obtained for Pigeon 21331 as in Experiment 3 despite the absence of any singleresponse produced timeouts given the modified VR 3 schedule (see VR 3 conditions in Figures 16 and 18). Response rates for Pigeon 8964, VR 3 condition in Figure 18, were slightly increased over the VR 2 immediate-timeout condition in Experiment 3 (VR 2 condition in Figure 16). Response rate increases during the FI 0.5 -s contiguity-control condition were attenuated for Pigeon 21331, relative to the results obtained in Experiment 3. Response rates in the FI 0.5-s contiguity-control conditions were lower than the FT 0.5-s delay conditions for Pigeon 8964. 
Response rates in the FI 5-s contiguity-control condition were lower than the 5-s delay conditions for Pigeon 21331. These results replicate the immediate and delayed timeout effects observed in Experiment 3 and implicate the additional dependent response as the controlling variable for the increased response rate during the contiguity-control conditions in Experiment 3.

\section{Discussion}

The results of Experiment 4 confirmed that response rates during punishment by timeout from positive reinforcement are sensitive to small changes in the response-timeout dependency. Correcting for the increase in the number of dependent responses per timeout attenuated and eliminated the response rate increasing effect observed in Experiment 3. Response rates were decreased in two of the contiguity-control conditions relative to the preceding delayed-timeout conditions. Similar tandem control procedures have been used in delayed-reinforcement experiments to maintain equivalent rates of reinforcement between immediate and delayed conditions (Lattal, 1987). These results provide limited evidence that the introductions of the delay, and not solely the decrease in timeout rate, resulted in increased response rates during the delay conditions. Overall, reductions in timeout rate appear to primarily contribute to increases in response rates during delay conditions in Experiments 3 and 4. 


\section{General Discussion}

To date, few basic-research experiments have been conducted on punishment by timeout from positive reinforcement. As a result, relatively little was known about the schedule parameters of timeout that do or do not lead to response reduction relative to unpunished conditions. Potential confounds in prior experiments and some inconsistencies in findings of response reduction during timeout presentations were the major reasons for conducting the current experiments. Response rate decreases and increases occurred during timeout presentations across a range of variable-timeout schedules and response-timeout relations. The greatest response reduction relative to baselines typically occurred when immediate responsedependent timeouts were scheduled most frequently (i.e., VR 2, VR 3, VI 2.5, VI 5) Response rate increases or no change relative to baselines typically occurred when timeouts were less frequent and, occasionally when timeouts occurred independently of responding.

The results provide new evidence of possible behavioral mechanisms underlying the timeout-punishment effect. The posttimeout and postreinforcement pause analyses indicated that the response reduction was occurring primarily after timeouts and reinforcements. The results are the first to show that increases in the proportion of shortest IRT's during the most frequent VI and VR timeout were, with but few exceptions, correlated with the most response reduction. Taken together, these two findings provide an account of how punishment by timeout from positive reinforcement decreases responding. As such, they indicate that the organization of IRTs does not always follow a predictable pattern. That is, decreases in the proportion of the shortest IRTs were not always correlated with decreases in response rates.

\section{Primary Findings}


The current series of experiments arranged variable schedules of timeout from positive reinforcement within a multiple-schedule arrangement when the timeouts were responsedependent, response-independent, and delayed. Experiment 1 used a within-subject yoking procedure to compare schedules of VR and YI timeouts. Experiment 2 evaluated schedule effects of VR and VI timeout without the limitation of the direct comparisons attempted in Experiment 1. Control components delivering response-independent timeouts were introduced in Experiment 2 that served as a comparison for the response-dependent timeout components within a condition. Experiment 3 introduced timeout delays and used the same responseindependent timeout yoking as in Experiment 2. Conditions were embedded in the experimental sequence in Experiment 3 to control for decreases in timeout frequency that occurred during the introduction of the delays. Response rates increased during the control conditions and the potential confounding effects of an additional dependent response were explored in Experiment 4.

The four experiments contribute to the understanding of timeout punishment in several ways. Response-dependent VR 2 timeout resulted in the most overall response reduction, but had the highest rates of timeout; this result was replicated across the majority of pigeons in all 4 experiments. The most frequent schedules of VI timeout reduced responding relative to baselines across multiple mean schedule values. Response rate increases during responsedependent timeout components relative to preceding baselines, occurred in Experiment 2, for both VI and VR timeout, and in Experiments 3 and 4 during 5-s delays and corresponding contiguity-control conditions. Response rates during the response-independent timeout components typically were higher than their corresponding response-dependent timeout components during the most frequent timeout conditions for both VR and VI timeout in 
Experiment 2. Response reduction was shown to be a function of the timeout dependency and not decreased component reinforcement rates. The posttimeout and postreinforcement pauses contributed to the observed response reduction in Experiment 2. Schedule-specific effects of the punished IRT were observed in Experiments 1 and 2, and increases in the proportion of the shortest IRTs were observed during the most frequent timeout conditions in Experiment 2. Response rates were sensitive to small changes in the number of dependent responses per timeout (the response requirement) in Experiments 3 and 4, but response rate increases could not be fully attributed to the introduction of the delays to timeout independently of decreases in timeout rates.

The results of this series of experiments are consistent with prior findings of punishment using both VR and VI schedules of timeout from positive reinforcement. In general, greater reductions in responding were observed when response-dependent timeouts were more frequent. The results also align with prior experiments where the frequency of the punishing stimulus was varied (Timeout: Clark et al., 1973; Thomas, 1968; McMillan, 1967; Zimmerman \& Ferster, 1963. Shock: Azrin, Holz, \& Hake 1963; Filby \& Appel, 1966; Mcmillan 1967. Response cost: Pietras, Brandt, \& Searcy, 2010). Few experiments have attempted to control for reinforcement rate reductions that occur during free-operant punishment by timeout from positive reinforcement. The results found in the response-independent timeout components in Experiment 2, 3, and 4 are consistent with and extend what has been found in prior experiments in which timeouts were delivered independently of responding (Branch et al., 1977; Ferster, 1953; Lattal, 1984; Sadowsky, 1973). The following sections will explore the major findings and implications of each experiment in more detail. 
Response reductions during the response-dependent timeout components are considered relative to response rates during unpunished baselines, and also relative to the responseindependent timeout components within a condition. If response rates during the responseindependent timeout components are undifferentiated from, or lower than, the responsedependent components, this suggests that other variables are operating independently of a direct punishing effect of the timeout. These aforementioned results occurred in Experiments 2, 3, and 4.

Interaction effects, notably contrast and induction, are two labels given to response rate increases and decreases in unpunished components during multiple schedule arrangements. Reynolds (1961a) defined an interaction as "a change in the rate of responding during the presentation of one stimulus, brought about by changing the schedule of reinforcement associated with a different stimulus" (p. 107). Typically, interaction effects have been assessed in the context of reinforcement procedures using either multiple or concurrent schedules where reinforcement rates are differentiated between components, reinforcement is alternated with extinction, or different reinforcement schedules are alternated (Reynolds, 1961a; Sadowsky, 1973; see Williams, 1983, for a detailed discussion). Interactions as a function of differences in reinforcement rate between components were not possible in the current experiments because the reinforcement rates were equivalent for all conditions and pigeons.

When Sadowsky (1973) alternated 3-min periods of VI reinforced responding with 3-min periods of nonreinforcement (as a blackout of the chamber, extinguished response key, or changed key color), response rates increased during the reinforcement components. This is similar to the within-component alternations of time in and timeout in the current experiments. The response-independent timeouts in Experiments 2, 3, and 4 were more frequent, but of a 
shorter duration than those studied by Sadowsky. Despite this difference, it is plausible that within-component positive contrast occurred in components where the response rates were elevated above unpunished baselines. Between-component, but schedule-specific, interaction effects possibly contributed to the differences in response rates between VR and VI condition response-independent timeout components in Experiment 2 (see Figures 5 and 6). Response rates during the response-independent timeout components within VI conditions were more often lower than the VR response-independent timeout components. What occurred in the preceding component seemed to influence the response rate during the following components.

An example of punishment induction is when responding is punished in one component of a two-component multiple schedule, and response rates decrease in the unpunished component (Crosbie, Williams, Lattal, Anderson, \& Brown, 1997; Reynolds, 1961a). There were concomitant decreases in response rates that were observed in some response-independent timeouts conditions (unpunished conditions) in Experiments 2, 3, and 4. For a punishment induction account to hold in the present series of experiments, delivering response-independent timeouts in the absence of a prior punishment contingency should not result in decreases in responding. Research conducted following the conclusion of the present series of experiments used variable-time (VT) 5-s schedules of timeout (i.e., timeouts were delivered independently of responding after an average of $5 \mathrm{~s}$ ), presented in the first and third components of a twocomponent multiple schedule, identical to that used in Experiments 2, 3, and 4. The VT timeouts typically resulted in either no change or increases in response rate for 4 of 6 pigeons relative to no-timeout baselines. These results, taken together, indicate that within-component contrast and between-component punishment induction were possible in the present experiments (see Crosbie et al., 1997, for experiments on punishment contrast and induction). 
A difference in the discriminability between components is another potential variable that contributed to the differences found between response-dependent and independent presentations of timeouts during the VR and VI conditions. Both the VI response-dependent and responseindependent timeout schedules shared similar temporal properties in that both delivered timeouts as a function of elapsed time. In contrast, the VR response-dependent timeout components arranged timeouts for a certain mean number of responses, on average, within a condition. Response-independent timeouts more closely resemble the delivery of VI timeouts than do VR timeouts, which could have increased the likelihood of punishment induction during the VI timeout conditions.

The indirect effect of reduced reinforcement rate per total unit of session time could have resulted in response reduction in both the response-dependent and response-independent timeout components for some pigeons. The reinforcement rate, calculated as the number of food presentations delivered during time in, is different from the overall component reinforcers delivered per unit of session time (total component time inclusive of the sum of all timeout durations). The difference can be understood in relation to the unpunished baseline conditions. Approximately 13 reinforcers were delivered, on average, per each 10-min component across all conditions. When considering the intervening timeouts during response-dependent and independent conditions, the reinforcement per unit of session time was greatly reduced.

In summary, the experimental design (a multiple schedule arrangement) as well as other potentially uncontrolled variables (reduced total session reinforcement rate) likely contributed to response reduction during response-independent timeout components in Experiments 2, 3, and 4. The timeous can be said to function as a punisher given prior results of punishment by timeout from positive reinforcement using similar control procedures (Branch et al., 1977), and because 
response rates in the response-dependent timeout components in the current experiments were generally lower than their corresponding response-independent timeout components.

\section{Schedule Effects of Timeout Punishment in Relation to Positive Punishment}

The results of the current series of experiments indicated that the punished IRTs varied by schedule type: IRTs less than $0.5 \mathrm{~s}$ were more likely to be punished during VR timeout and IRTs greater than $1 \mathrm{~s}$ were more likely to be punished during VI timeout. Previous punishment experiments have emphasized the role of the punished IRT as a controlling variable when response rates decrease or increase relative to unpunished baselines (Arbuckle \& Lattal, 1992, Galbicka \& Branch, 1981; Lande, 1981). Galbicka and Branch (1981), for example, suggested that "interval schedules of punishment may differentially punish long IRTs" therefore resulting in a greater proportion of short IRTs, leading to increases in response rate (p. 320). More recently, Everly and Perone (2012) showed that increases or decreases in response rates during shock punishment may be multiply determined by the schedule values of punishment and reinforcement, the duration and intensity of the shock, and the IRTs followed by shock.

Response facilitation, increases relative to unpunished baselines, occurred during immediate and delayed timeout for 5 of the 8 pigeons in Experiment 2 and for 3 of 4 pigeons in Experiment 3, respectively. Order effects, or decreasing the mean value of timeout across conditions, may account for some, but not all instances of response rate increases (see overall response rates for Pigeons 10 and 521 for examples of order effects during VR timeout and the initial VI sequence for Pigeon 4365 and the VI replication conditions for Pigeon 2403). Multiple variables potentially contributed to the response facilitation, such as: the reinforcement schedule maintaining responding, the duration of timeout, and lower frequencies of timeout (see Everly \& Perone, 2012 for similar variables related to shock deliveries). Less frequent timeout is a 
contributing factor in the present experiments because the 5-s delay and corresponding contiguity control conditions in Experiment 3 consistently resulted in response rate facilitation and were correlated with largest decreases in timeout rate relative to immediate punishment.

The leftward shifts in IRT distributions like those observed in Experiments 1 and 2, as well as increases in the proportion of IRTs in the shortest IRT bin, were reported in prior punishment experiments (Galbicka \& Branch, 1981; Lande, 1981). In the current experiments, however, these results occurred during both the VI and VR conditions, and typically with the most frequent rates of timeout and where the most response rate decreases were observed (except the VI 2.5-s condition for Pigeon 521). These results are novel because such changes in IRT distributions have not been reported in experiments using timeout from positive reinforcement as the punisher. These results indicate that other variables contributed to response reduction independently of decreases in short IRTs. These variables are reviewed in the next section.

\section{Posttimeout and Postreinforcement Pausing}

The proportion of session time spent in the posttimeout pause and postreinforcement pause are potential mechanisms by which timeouts functioned to decrease responding in the current experiments. The results replicate and extend findings by Branch et al. (1977) that "the latencies between the end of a timeout and a key peck entered significantly into the calculation of rate" (p. 292) during a punishment condition. Branch et al. argued that if the latencies to respond following a timeout were influenced by the pigeon being further away from the operandum during the blackout, then this would undermine the use of response rates as a dependent measure during their comparisons of shock and timeout. The finding of no response reduction during response-independent timeout presentations during their experiment showed that response 
reduction during response-dependent timeouts was not merely the result of the pigeon being further away from the response key following a timeout.

The posttimeout pause and postreinforcement pause in the current experiments contributed to the overall response reduction. The response rate adjustments shown in Tables 4 and 5 indicate that the punishment effect for some pigeons can be fully attributed to the posttimeout pause. Response rates, calculated excluding the posttimeout pause were no different, or actually higher than unpunished baselines in some cases. This finding was not consistent between pigeons. The proportion of session time spent in the posttimeout pauses during response-independent timeout conditions were all lower than or equivalent to (VI 45 s) the response-dependent conditions. The median durations of the posttimeout pauses did not increase with the mean rate of timeout. Kaufman and Baron (1968) found increased latencies to produce timeouts, measured as the IRT that preceded the timeout, when timeout duration increased. If the posttimeout pause duration is not sensitive to changes in the frequency of timeout using the present experimental arrangement, it may be that changes in the duration of timeout, or the maintaining schedule of reinforcement, would lead to orderly functional relations in pausing after the timeout.

\section{Delayed Punishment}

Prior research has found that delayed punishment results in attenuation of immediate punishment effects as a function of increasing delay values (Baron, 1965; Baron, Kaufman, \& Fazzini, 1969; Kamin, 1959; Trenholme \& Baron, 1975). The results of Experiments 3 and 4 replicated the attenuation effect of delayed punishment and extended the findings to timeout punishment. A qualification of the effects of delayed punishment in the current experiments is that the delay to timeout decreased the obtained timeout rate relative to immediate-timeout 
conditions. Response rates increased in 6 out of 7 conditions when similar punishment rates to those obtained during delayed timeout conditions were arranged in the contiguity-control conditions in Experiment 3.

Response rate increases during delay conditions cannot be fully attributed to the delays in Experiments 3 and 4. The reduction in timeout rate during delay conditions relative to immediate timeout, as well as changes in the number of dependent responses per timeout (the response requirement necessary to produce the timeout) were controlling variables in response reduction, or lack thereof, found in Experiments 3 and 4. Response reduction was sensitive to the addition, or subtraction, of a single dependent response. The contiguity between responses and timeout data during the response-independent timeout components in Experiments 2, 3, and 4 does not, however, fully support for this interpretation. The median contiguity between responses and the timeouts was less than $1 \mathrm{~s}$ across most conditions. If the contiguity of a response to timeout, in the absence of response dependency, functioned similarly to delayed timeout, then response reduction should be maintained. This was observed in some conditions, but alternative accounts for the decreases were proposed in the prior section.

\section{Conceptual Issues}

Alternative accounts of the concept of punishment have been proposed and should be considered in the interpretation of the present results. For example, the distinction between positive and negative punishment, particularly in reference to timeout from positive reinforcement, can seem arbitrary when defined in the following way,

In negative punishment, and environmental change occurs such that a stimulus is removed subsequent to the performance of a behavior, and the corresponding future frequency of the preceding behavior is reduced. By contrast, in positive punishment, a 
stimulus is presented, and the corresponding future frequency of that behavior is reduced (Cooper, Heron, \& Heward, 2007, p.329).

It may be easier to teach distinctions between positive and negative punishment in this way, because timeout necessarily involves removing an existing reinforcing stimulus situation. A similar distinction between positive and negative reinforcement also can be made. Maintenance of avoidance responding (avoidance of shock or timeout) can be conceptualized as the result of either the removal of the punisher or the production of periods free of the punisher (Baron \& Galizio, 2005; Michael, 1975). Michael expanded on this distinction between presentation and removal by stating that:

We seem to use 'present' when we wish to implicate the postchange condition as the one most relevant to behavior, or the most in need of specification. We use 'remove' when the pre-change condition is the most significant one. Similarly (but not exactly) we use 'present' when the characteristics of the prechange condition can be taken for granted: 'remove' when the postchange conditions can be taken for granted (p. 40).

When timeout is considered as a stimulus, it is unclear whether the current classification of negative punishment over positive punishment aligns with the experimental evidence suggesting that timeout from positive reinforcement acts similarly to other unconditioned punishers (DeFulio \& Hackenberg, 2007; Holtyn, 2012; Pietras \& Hackenberg, 2000).

Response reduction during punishment can also be conceptualized as negative reinforcement for not responding, rather than of punishment of responding (Dinsmoor, 1954, 1977). Two competing responses can be identified in the current experiment: 1) discrete key pecks and 2) all other (unmeasured) behavior. Considering punishment as simply a case of reinforcement for not responding is certainly more parsimonious in that it eliminates allusion to 
the punishment process per se. Pietras and Hackenberg (2000) stated that there are a variety of variables that could lead to reinforcing, response reducing, or neutral functions of timeout from positive reinforcement in avoidance contexts. The same can be said about timeout-punishment procedures. It is difficult to argue against negative reinforcement for nonresponding herein because unobserved, but, more importantly, unmeasured behavior is needed to support such an approach (Galbicka \& Branch, 1981; Rachlin \& Herrnstein, 1969).

No appeal to unmeasured behavior was made in the current experiments and therefore the results were framed in terms of a punishment process. It can be argued that evidence of negative reinforcement of response omission occurred in the current experiments following the delivery of a timeout and also a reinforcer. The experiments were not designed to differentiate between primary punishing effects of timeout from positive reinforcement and indirect negative reinforcement for not responding (see Arbuckle \& Lattal, 1987, for such an experimental design). The colloquial and pedagogical distinctions of timeout as a punishment procedure, and specifically a negative-punishment process, respectively support the continued need for a distinction between positive and negative punishment.

\section{Conclusion}

Timeout from positive reinforcement served as a punishing stimulus in specific conditions within each of the four experiments presented herein. Future experiments on punishment by timeout from positive reinforcement should consider using an experimental design that minimized the likelihood of interaction effects between punished and unpunished components. Arranging a simple schedule of punishment and separate control conditions (as in Branch et al. 1977) is one, time-intensive, solution to minimizing interaction effects. 
The duration of timeout was not systematically evaluated in the present experiments, and is of interest because it may be positively related to the length of the posttimeout pause. Additionally, response reduction might have occurred across the range of schedule values studied herein if the maintaining reinforcement schedule was leaner. Leaning the maintaining schedule of reinforcement across successive sessions, or potentially within sessions, could help determine interaction effects of punishment schedules with the maintaining schedules of positive reinforcement. Further research is needed to fully understand the controlling variables responsible for the response rate increases seen during variable schedules of timeout. The current experiments provides information necessary to continue a systematic evaluation of response facilitation, differential schedule effects, and interactions between punished and unpunished responding during punishment by timeout from positive reinforcement. 


\section{References}

Appel, J. B. (1968). Fixed-interval punishment. Journal of the Experimental Analysis of Behavior, 11, 803-808.

Azrin, N. H. (1956). Some effects of two intermittent schedules of immediate and nonimmediate punishment. Journal of Psychology, 42, 3-21.

Azrin, N. H., \& Holz, W. C. (1966). Punishment. In W. K. Honig (Ed.), Operant behavior: Areas of research and application (pp. 380-447). New York: Appleton-Century-Crofts.

Arbuckle, J. L., \& Lattal, K. A. (1987). A role for negative reinforcement of response omission in punishment? Journal of the Experimental Analysis of Behavior, 48, 407-416.

Arbuckle, J. L., \& Lattal, K. A. (1992). Molecular contingencies in schedules of intermittent punishment. Journal of the Experimental Analysis of Behavior, 58, 361-375.

Barkin, S., Scheindlin, B., Ip, E. H., Richardson, I., \& Finch, S. (2007). Determinants of parental discipline practices: A national sample from primary care practices. Clinical Pediatrics, 46, 64-69.

Baron, A. (1965). Delayed punishment of a runway response. Journal of Comparative and Physiological Psychology, 60, 131-134.

Baron, A., Kaufman, A., \& Fazzini, D. (1969). Density and delay of punishment of free-operant avoidance. Journal of the Experimental Analysis of Behavior, 12, 1029-1037.

Baron, A., \& Galizio, M. (2005). Positive and negative reinforcement: Should the distinction be preserved? The Behavior Analyst, 28, 85-98.

Branch, M. N., Nicholson, G., \& Dworkin, S. I. (1977). Punishment-specific effects of pentobarbital: Dependency on the type of punisher. Journal of the Experimental Analysis of Behavior, 28, 285-293. 
Burchard, J. D., \& Barrera, F. (1972). An analysis of timeout and response cost in a programmed environment. Journal of Applied Behavior Analysis, 5, 271-282.

Carlson, J. (1972). Timeout punishment: Rate of reinforcement and delay of timeout. Learning and Motivation, 3, 31-43.

Catania, A. C. (1998). Learning (4th ed.). New Jersey: Prentice-Hall Inc.

Clark, H. B., Rowbury, T., Baer, A. M., \& Baer, D. M. (1973). Timeout as a punishing stimulus in continuous and intermittent schedules. Journal of Applied Behavior Analysis, 6, 443455.

Cooper, J. O., Heron, T. E., \& Heward, W. L. (2007). Applied behavior analysis (2nd ed.). Upper Saddle River, NJ: Pearson.

Crosbie, J., Williams, A. M., Lattal, K. A., Anderson, M. M., \& Brown, S. M. (1997). Schedule interactions involving punishment with pigeons and humans. Journal of the Experimental Analysis of Behavior, 68, 161-175.

Donaldson, J. M., \& Vollmer, T. R. (2012). A procedure for thinning the schedule of time-out. Journal of Applied Behavior Analysis, 45, 625-630.

DeFulio, A., \& Hackenberg, T. D. (2007). Timeout from reinforcement: Restoring a balance between analysis and application. Mexican Journal of Behavior Analysis, 33, 37-44.

Dinsmoor, J. A. (1954). Punishment: I. The avoidance hypothesis. Psychological Review, 61, 3446.

Dinsmoor, J. A. (1977). Escape, avoidance, punishment: Where do we stand? Journal of the Experimental Analysis of Behavior, 28, 83-95.

Dunn, R. (1990). Timeout from concurrent schedules. Journal of the Experimental Analysis of Behavior, 53, 163-174. 
Everette, G. E., Hupp, S. D. A., Olmi, D. J. (2010). Time-out with parents: A descriptive analysis of 30 years of research. Education and Treatment of Children, 33, 235-259.

Everly, J. B., Perone, M. (2012). Suppressive and facilitative effects of shock intensity and interresponse times followed by shock. Journal of the Experimental Analysis of Behavior, 98, 311-340.

Ferster, C. B. (1953). Sustained behavior under delayed reinforcement. Journal of Experimental Psychology, 45, 218-224.

Ferster, C. B. (1958). Control of behavior in chimpanzees and pigeons by time out from positive reinforcement. Psychological Monographs: General and Applied, 72, Whole No. 461.

Ferster, C. B., \& Appel, J. B. (1961). Punishment of $\mathrm{S}^{\Delta}$ responding in matching to sample by timeout from positive reinforcement. Journal of the Experimental Analysis of Behavior, $4,45-56$.

Ferster, C. B., \& Skinner, B. F. (1957). Schedules of reinforcement. New York: AppletonCentury-Crofts.

Filby, Y., Appel, J. B. (1966). Variable-interval punishment during variable-interval reinforcement. Journal of the Experimental Analysis of Behavior, 9, 521-527.

Findley, J. D. (1958). Preference and switching under concurrent scheduling. Journal of the Experimental Analysis of Behavior, 1, 123-144.

Fleshler, M., \& Hoffman, H. S. (1962). A progression for generating variable-interval schedules. Journal of the Experimental Analysis of Behavior, 5, 529-530.

Galbicka, G., \& Branch, M. N. (1981). Selective punishment of interresponse times. Journal of the Experimental Analysis of Behavior, 35, 311-322. 
Hake, D. F., \& Azrin, N. H. (1963). An apparatus for delivering pain shock to monkeys. Journal of the Experimental Analysis of Behavior, 6, 297-298.

Hobbs, S. A., Forehand, R., \& Murray, R. G. (1978). Effects of various durations of timeout on the noncompliant behavior of children. Behavior Therapy, 9, 652-656.

Holtyn, A. F. (2012). Avoidance of timeout from response-independent schedules of food or sucrose water with and without a limited hold on consumption. (Doctoral dissertation). Available from ProQuest Dissertations and Theses database. (UMI No. 35330312).

Holz, W. C., Azrin, N. H., \& Ayllon, T. (1963). Elimination of behavior of mental patients by response-produced extinction. Journal of the Experimental Analysis of Behavior, 6, 407412.

Ida, N., \& Kimura, H. (2005). The effects of variable-ratio punishment on rats' lever pressing maintained by variable-interval reinforcement. The Japanese Journal of Animal Psychology, 55, 71-75.

Kamin, L. J. (1959). The delay-of-punishment gradient. Journal of Comparative and Physiological Psychology, 52, 434-437.

Kaufman, A., \& Baron, A. (1968). Suppression of behavior by timeout punishment when suppression results in loss of positive reinforcement. Journal of the Experimental Analysis of Behavior, 11, 595-607.

Lande, S. D. (1981). An interresponse time analysis of variable-ratio punishment. Journal of the Experimental Analysis of Behavior, 35, 55-67.

Lattal, K. A. (1984). Signal function in delayed reinforcement. Journal of the Experimental Analysis of Behavior, 42, 239-253. 
Lattal, K. A. (1987). Considerations in the experimental analysis of reinforcement delay. In M.L. Commons, J. Mazur, J.A. Nevin, \& H. Rachlin (Eds.), Quantitative studies of operant behavior: The effect of delay and of intervening events on reinforcement value (pp. 107-123). New York: Erlbaum

Lattal, K. A. (2010). Delayed reinforcement of operant behavior. Journal of the Experimental Analysis of Behavior, 93, 129-139.

Leitenberg, H. (1965). Is time-out from positive reinforcement an aversive event? Psychological Bulletin, 64, 428-441.

Lerman, D. C., Iwata, B. A., Shore, B. A., \& DeLeon, I. G. (1997). Effects of intermittent punishment on self-injurious behavior: An evaluation of schedule thinning. Journal of Applied Behavior Analysis, 30, 187-201.

Lerman, D. C. \& Vorndran, C. M. (2002). On the status of knowledge for using punishment: Implications for treating behavior disorders. Journal of Applied Behavior Analysis, 35, 431-464.

Michael, J. (1975). Positive and negative reinforcement, a distinction that is no longer necessary; or a better way to talk about bad things. Behaviorism, 3, 33-44.

McMillan, D. E. (1967). A comparison of the punishing effects of response-produced shock and response-produced time out. Journal of the Experimental Analysis of Behavior, 10, 439449.

Peele, D. B., Casey, J., \& Silberberg, A. (1984). Primacy of Interresponse-time reinforcement in accounting for rate differences under variable-ratio and variable-interval schedules. Journal of the Experimental Analysis of Behavior, 10, 149-167. 
Pietras, C. J., Brandt, A. E. \& Searcy, G. D. (2010). Human responding on random-interval schedules of response-cost punishment: The role of reduced reinforcement density. Journal of the Experimental Analysis of Behavior, 93, 5-26.

Pietras, C. J., \& Hackenberg, T. D. (2000). Timeout postponement without increased reinforcement frequency. Journal of the Experimental Analysis of Behavior, 74, 147-164.

Pietras, C. J., \& Hackenberg, T. D. (2005). Response-cost punishment via token loss with pigeons. Behavioural Processes, 69, 343-356.

Rachlin, H., \& Herrnstein, R. J. (1969). Hedonism revisited: On the negative law of effect. In B. A. Campbell \& R. M. Church (Eds.), Punishment and aversive behavior. New York: Appleton-Century-Crofts.

Reynolds, G. S. (1961a). An analysis of interactions in a multiple schedule. Journal of the Experimental Analysis of Behavior, 4, 107-117.

Sadowsky, S. (1973). Behavioral contrast with timeout, blackout, or extinction as the negative condition. Journal of the Experimental Analysis of Behavior, 19, 499-507.

Skinner, B. F. (1953). Science and human behavior. New York: Macmillan.

Terris, W., \& Barnes, M. (1969). Learned resistance to punishment and subsequent responsiveness to the same and novel punishers. Psychonomic Science, 15, 49-50.

Thomas, J. R. (1965). Discriminated time-out avoidance in pigeons. Journal of the Experimental Analysis of Behavior, 8, 329-338.

Thomas, J. R. (1968). Fixed-ratio punishment by timeout of concurrent variable-interval behavior. Journal of the Experimental Analysis of Behavior, 11, 609-616.

Trenholme, I. A., \& Baron, A. (1975). Immediate and delayed punishment of human behavior by loss of reinforcement. Learning and Motivation, 6, 62-79. 
White, G. D., Nielsen, G., \& Johnson, S. M. (1972). Timeout duration and the suppression of deviant behavior in children. Journal of Applied Behavior Analysis, 5, 111-120.

Williams, B. A. (1983). Another look at contrast in multiple schedules. Journal of the Experimental Analysis of Behavior, 39, 345-384.

Willoughby, R. H. (1969). The effects of time-out from positive reinforcement on the operant behavior of preschool children. Journal of Experimental Child Psychology, 7, 299-313.

Zeiler, M. D. (1984). The sleeping giant: Reinforcement schedules. Journal of the Experimental Analysis of Behavior, 42, 485-493.

Zimmerman, J., \& Ferster, C. B. (1963). Intermittent punishment of $\mathrm{S}^{\Delta}$ responding in matching to sample. Journal of the Experimental Analysis of Behavior, 6, 349-356. 
Table 1

The sequence of conditions, number of sessions, reinforcers (Reinf) per min, and timeouts (TO) per min for the last six stable sessions for each pigeon in Experiment 1. The standard deviations are shown in parentheses. The conditions, except no-timeout baselines $(B L)$ are named by the mean variable-ratio (VR) timeout schedule in effect. YI = the corresponding yoked-interval timeout components for a condition.

\begin{tabular}{|c|c|c|c|c|c|c|}
\hline \multirow[b]{2}{*}{ Pigeon } & \multirow[b]{2}{*}{ Condition } & \multirow[b]{2}{*}{ Sessions } & \multicolumn{2}{|c|}{ Reinf per min } & \multicolumn{2}{|c|}{ TO per min } \\
\hline & & & VR & YI & VR & YI \\
\hline \multirow[t]{8}{*}{4365} & $\mathrm{BL}$ & 15 & 1.32 & 1.34 & & \\
\hline & & & $(0.08)$ & $(0.08)$ & & \\
\hline & VR 2 & 32 & 1.27 & 1.23 & 10.78 & 8.58 \\
\hline & & & $(0.05)$ & $(0.04)$ & $(1.2)$ & (1.19) \\
\hline & VR 10 & 19 & 1.28 & 1.32 & 5.19 & 4.77 \\
\hline & & & $(0.05)$ & $(0.10)$ & $(0.27)$ & $(0.25)$ \\
\hline & $\mathrm{BL}$ & 14 & 1.30 & 1.33 & & \\
\hline & & & $(0.05)$ & $(0.04)$ & & \\
\hline \multirow[t]{8}{*}{849} & $\mathrm{BL}$ & 14 & 1.35 & 1.36 & & \\
\hline & & & $(0.04)$ & $(0.10)$ & & \\
\hline & VR 10 & 21 & 1.33 & 1.30 & 6.06 & 5.37 \\
\hline & & & (0.09) & $(0.04)$ & $(5.07)$ & $(0.42)$ \\
\hline & VR 2 & 16 & 1.33 & 1.34 & 18.00 & 13.63 \\
\hline & & & $(0.07)$ & $(0.04)$ & $(0.50)$ & $(0.30)$ \\
\hline & BL & 31 & 1.28 & 1.33 & & \\
\hline & & & $(0.04)$ & $(0.05)$ & & \\
\hline \multirow[t]{8}{*}{828} & $\mathrm{BL}$ & 15 & 1.30 & 1.31 & & \\
\hline & & & $(0.07)$ & $(0.10)$ & & \\
\hline & VR 10 & 21 & 1.33 & 1.27 & 3.72 & 3.40 \\
\hline & & & $(0.06)$ & $(0.03)$ & $(0.22)$ & $(0.23)$ \\
\hline & VR 2 & 60 & 1.28 & 1.24 & 7.68 & 5.87 \\
\hline & & & $(0.08)$ & $(0.10)$ & $(1.50)$ & $(1.32)$ \\
\hline & BL & 14 & 1.31 & 1.32 & & \\
\hline & & & $(0.04)$ & $(0.07)$ & & \\
\hline
\end{tabular}


Table 2

The sequence of conditions, number of sessions, reinforcers (Reinf) per min, and timeouts (TO) per min for the last six stable sessions for each pigeon in Experiment 2 a. The standard deviations are shown in parentheses. The conditions, except no-timeout baselines (BL), are named by the mean variable-interval (VI) or variable-ratio (VR) timeout schedule in effect. Dep. $=$ response-dependent timeout. Ind. = response-independent timeout .

\begin{tabular}{|c|c|c|c|c|c|c|}
\hline \multirow[b]{2}{*}{ Pigeon } & \multirow[b]{2}{*}{ Condition } & \multirow[b]{2}{*}{ Sessions } & \multicolumn{2}{|c|}{ Reinf per min } & \multicolumn{2}{|c|}{ TO per min } \\
\hline & & & Dep. & Ind. & Dep. & Ind. \\
\hline \multirow[t]{31}{*}{4365} & $\mathrm{BL}$ & 14 & 1.30 & 1.33 & & \\
\hline & & & $(0.05)$ & $(0.04)$ & & \\
\hline & VI 3 & 51 & 1.28 & 1.31 & 12.48 & 12.44 \\
\hline & & & $(0.05)$ & $(0.08)$ & $(0.61)$ & $(0.59)$ \\
\hline & VI 5 & 24 & 1.30 & 1.29 & 9.55 & 9.52 \\
\hline & & & $(0.06)$ & $(0.07)$ & $(0.11)$ & $(0.15)$ \\
\hline & VI 10 & 17 & 1.28 & 1.33 & 5.49 & 5.49 \\
\hline & & & $(0.07)$ & $(0.04)$ & $(0.12)$ & $(0.12)$ \\
\hline & VI 20 & 14 & 1.23 & 1.33 & 2.80 & 2.80 \\
\hline & & & $(0.04)$ & $(0.04)$ & $(0.10)$ & $(0.10)$ \\
\hline & VI 45 & 14 & 1.32 & 1.30 & 1.3 & 1.3 \\
\hline & & & $(0.06)$ & $(0.07)$ & $(0.05)$ & $(0.05)$ \\
\hline & BL & 14 & 1.33 & 1.28 & & \\
\hline & & & $(0.07)$ & $(0.06)$ & & \\
\hline & VR 5 & 14 & 1.26 & 1.29 & 11.84 & 11.80 \\
\hline & & & $(0.04)$ & $(0.05)$ & $(1.00)$ & $(1.00)$ \\
\hline & VR 2 & 21 & 1.26 & 1.32 & 13.39 & 13.33 \\
\hline & & & $(0.04)$ & $(0.05)$ & (1.19) & (1.18) \\
\hline & BL & 17 & 1.34 & 1.30 & & \\
\hline & & & $(0.05)$ & $(0.08)$ & & \\
\hline & VI 5 & 20 & 1.28 & 1.36 & 9.46 & 9.45 \\
\hline & & & $(0.08)$ & $(0.02)$ & $(0.46)$ & $(0.46)$ \\
\hline & VI 3 & 35 & 1.30 & 1.25 & 11.95 & 11.92 \\
\hline & & & $(0.10)$ & $(0.06)$ & $(0.71)$ & $(0.71)$ \\
\hline & BL & 29 & 1.34 & 1.23 & & \\
\hline & & & $(0.09)$ & $(0.04)$ & & \\
\hline & VI 20 & 15 & 1.31 & 1.30 & 2.79 & 2.78 \\
\hline & & & $(0.09)$ & $(0.04)$ & $(0.07)$ & $(0.08)$ \\
\hline & VI 45 & 16 & 1.32 & 1.27 & 1.23 & 1.23 \\
\hline & & & $(0.08)$ & $(0.03)$ & $(0.04)$ & $(0.04)$ \\
\hline & BL & 14 & 1.28 & 1.32 & & \\
\hline
\end{tabular}




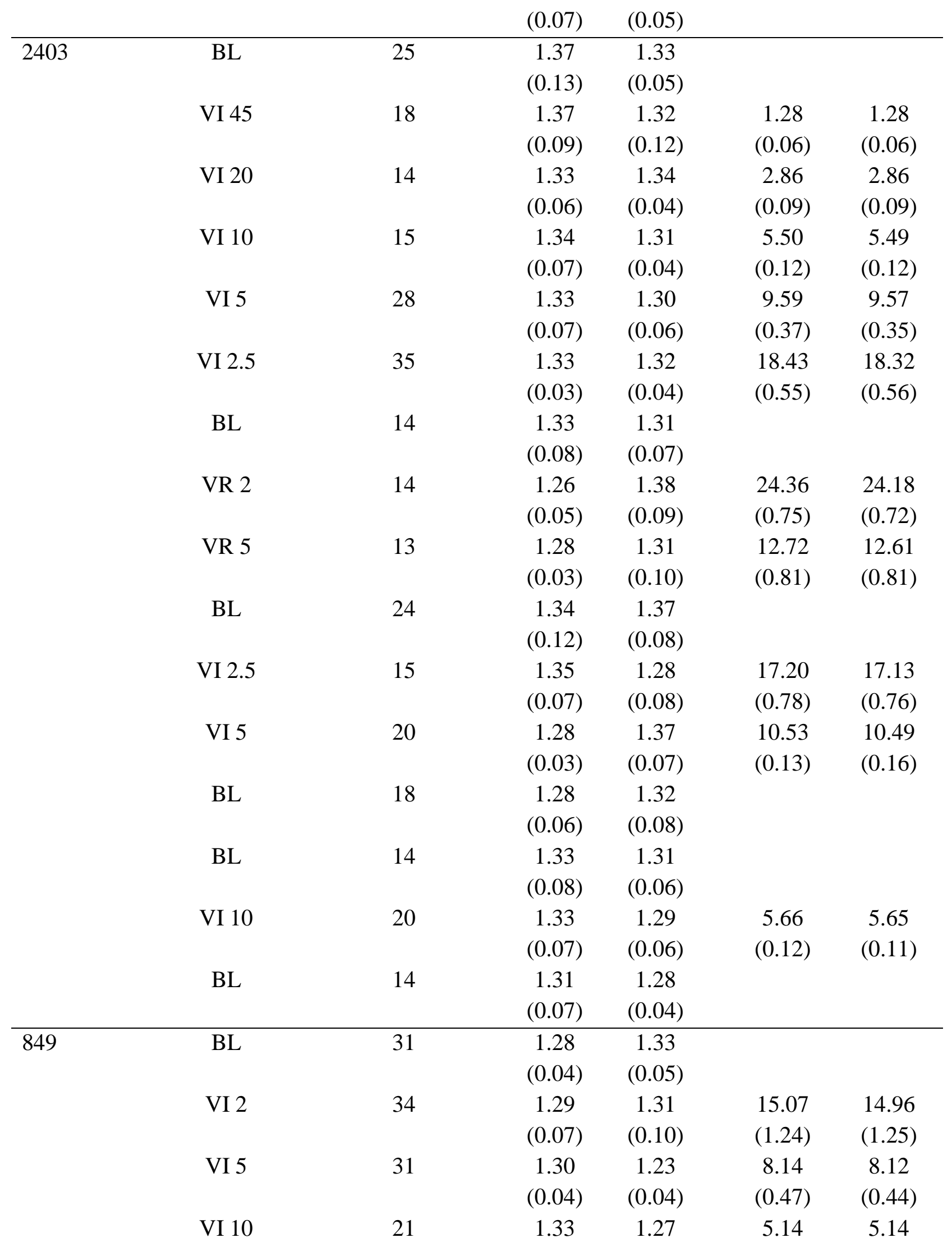




\begin{tabular}{|c|c|c|c|c|c|c|}
\hline & & & $(0.10)$ & $(0.06)$ & $(0.12)$ & $(0.12)$ \\
\hline & VI 20 & 17 & 1.33 & 1.31 & 2.74 & 2.73 \\
\hline & & & $(0.08)$ & $(0.08)$ & $(0.11)$ & $(0.12)$ \\
\hline & VI 45 & 15 & 1.29 & 1.25 & 1.29 & 1.25 \\
\hline & & & $(0.07)$ & $(0.04)$ & $(0.07)$ & $(0.04)$ \\
\hline & BL & 38 & 1.33 & 1.29 & & \\
\hline & & & $(0.10)$ & (0.06) & & \\
\hline & VR 5 & 33 & 1.32 & 1.15 & 13.27 & 13.18 \\
\hline & & & $(0.06)$ & $(0.15)$ & $(0.70)$ & $(0.69)$ \\
\hline & VR 2 & 16 & 1.25 & 1.31 & 16.69 & 16.63 \\
\hline & & & $(0.03)$ & (0.09) & (1.04) & (1.00) \\
\hline & BL & 17 & 1.32 & 1.30 & & \\
\hline & & & $(0.07)$ & $(0.07)$ & & \\
\hline & VI 5 & 15 & 1.26 & 1.27 & 8.87 & 8.84 \\
\hline & & & $(0.04)$ & $(0.05)$ & $(0.32)$ & $(0.34)$ \\
\hline & VI 2 & 24 & 1.26 & 1.28 & 15.09 & 15.04 \\
\hline & & & $(0.05)$ & $(0.09)$ & (1.10) & (1.07) \\
\hline & BL & 14 & 1.37 & 1.28 & & \\
\hline & & & $(0.06)$ & (0.04) & & \\
\hline & VI 45 & 19 & 1.32 & 1.28 & 1.30 & 1.30 \\
\hline & & & $(0.07)$ & (0.07) & $(0.05)$ & $(0.05)$ \\
\hline & VI 20 & 15 & 1.28 & 1.30 & 2.75 & 2.75 \\
\hline & & & $(0.10)$ & $(0.09)$ & $(0.10)$ & $(0.10)$ \\
\hline & BL & 15 & 1.36 & 1.29 & & \\
\hline & & & $(0.11)$ & $(0.07)$ & & \\
\hline 828 & BL & 14 & 1.31 & 1.32 & & \\
\hline & & & $(0.04)$ & $(0.07)$ & & \\
\hline & VI 45 & 24 & 1.28 & 1.26 & 1.33 & 1.33 \\
\hline & & & $(0.07)$ & $(0.06)$ & $(0.08)$ & $(0.08)$ \\
\hline & VI 20 & 16 & 1.29 & 1.31 & 2.83 & 2.83 \\
\hline & & & $(0.07)$ & (0.08) & $(0.07)$ & $(0.07)$ \\
\hline & VI 10 & 60 & 1.29 & 1.24 & 4.94 & 4.93 \\
\hline & & & $(0.07)$ & $(0.04)$ & $(0.18)$ & (0.19) \\
\hline & VI 5 & 48 & 1.23 & 1.18 & 6.32 & 6.31 \\
\hline & & & $(0.03)$ & $(0.04)$ & $(0.47)$ & $(0.48)$ \\
\hline & VI 2.5 & 14 & 1.16 & 1.18 & 6.79 & 6.78 \\
\hline & & & $(0.04)$ & $(0.09)$ & $(0.37)$ & $(0.37)$ \\
\hline & BL & 25 & 1.25 & 1.26 & & \\
\hline & & & $(0.04)$ & 0.06) & & \\
\hline & VR 2 & 14 & 1.28 & 1.23 & 8.21 & 8.18 \\
\hline
\end{tabular}




\begin{tabular}{|c|c|c|c|c|c|}
\hline & & $(0.08)$ & $(0.06)$ & $(0.67)$ & $(0.67)$ \\
\hline \multirow[t]{2}{*}{ VR 5} & 18 & 1.27 & 1.25 & 4.13 & 4.12 \\
\hline & & $(0.04)$ & $(0.08)$ & $(0.38)$ & $(0.39)$ \\
\hline \multirow[t]{2}{*}{ BL } & 14 & 1.27 & 1.33 & & \\
\hline & & $(0.05)$ & $(0.03)$ & & \\
\hline \multirow[t]{2}{*}{ VI 10} & 22 & 1.28 & 1.28 & 4.45 & 4.44 \\
\hline & & $(0.04)$ & $(0.04)$ & $(0.17)$ & $(0.17)$ \\
\hline \multirow[t]{2}{*}{ VI 45} & 20 & 1.33 & 1.26 & 1.33 & 1.33 \\
\hline & & $(0.05)$ & $(0.04)$ & $(0.06)$ & $(0.06)$ \\
\hline \multirow[t]{2}{*}{ VI 90} & 18 & 1.33 & 1.30 & 0.66 & 0.66 \\
\hline & & $(0.08)$ & $(0.06)$ & $(0.07)$ & $(0.07)$ \\
\hline \multirow[t]{2}{*}{ BL } & 20 & 1.31 & 1.33 & & \\
\hline & & $(0.09)$ & $(0.07)$ & & \\
\hline
\end{tabular}


Table 3

The sequence of conditions, number of sessions, reinforcers (Rein) per min, and timeouts (TO) per min for the last six stable sessions for each pigeon in Experiment $2 \mathrm{~b}$. The standard deviations are shown in parentheses. The conditions, except no-timeout baselines $(B L)$, are named by the mean variable-ratio (VR) or variable-interval (VI) timeout schedule in effect. Dep. = response-dependent timeout. Ind. = response-independent timeout.

\begin{tabular}{|c|c|c|c|c|c|c|}
\hline \multirow[b]{2}{*}{ Pigeon } & \multirow[b]{2}{*}{ Condition } & \multirow[b]{2}{*}{ Sessions } & \multicolumn{2}{|c|}{ Reinf per min } & \multicolumn{2}{|c|}{ TO per min } \\
\hline & & & Dep. & Ind. & Dep. & Ind. \\
\hline \multirow[t]{12}{*}{1782} & $\mathrm{BL}$ & 32 & 1.33 & 1.30 & & \\
\hline & & & $(0.05)$ & $(0.04)$ & & \\
\hline & VR 20 & 15 & 1.28 & 1.30 & 3.80 & 3.78 \\
\hline & & & $(0.07)$ & $(0.10)$ & $(0.19)$ & $(0.18)$ \\
\hline & VR 15 & 14 & 1.34 & 1.30 & 5.15 & 5.14 \\
\hline & & & $(0.04)$ & $(0.10)$ & $(0.24)$ & $(0.24)$ \\
\hline & VR 10 & 18 & 1.30 & 1.28 & 6.83 & 6.80 \\
\hline & & & (0.09) & $(0.04)$ & $(0.32)$ & $(0.33)$ \\
\hline & VR 5 & 18 & 1.29 & 1.28 & 8.81 & 8.73 \\
\hline & & & $(0.06)$ & $(0.10)$ & $(0.66)$ & $(0.64)$ \\
\hline & VR 2 & 20 & 1.25 & 1.28 & 13.37 & 13.28 \\
\hline & & & $(0.06)$ & (0.07) & (1.39) & (1.36) \\
\hline \multirow[t]{19}{*}{975} & $\mathrm{BL}$ & 22 & 1.25 & 1.31 & & \\
\hline & & & $(0.06)$ & $(0.06)$ & & \\
\hline & VR 2 & 21 & 1.27 & 1.33 & 12.64 & 12.59 \\
\hline & & & $(0.05)$ & $(0.06)$ & $(0.78)$ & $(0.80)$ \\
\hline & VR 5 & 14 & 1.28 & 1.21 & 10.45 & 10.43 \\
\hline & & & (0.09) & $(0.11)$ & $(0.28)$ & $(0.28)$ \\
\hline & VR 10 & 65 & 1.30 & 1.31 & 7.98 & 7.98 \\
\hline & & & $(0.04)$ & $(0.06)$ & $(0.83)$ & $(0.83)$ \\
\hline & VR 15 & 23 & 1.18 & 1.31 & 5.85 & 5.85 \\
\hline & & & $(0.17)$ & (0.09) & $(0.81)$ & $(0.81)$ \\
\hline & VR 20 & 35 & 1.25 & 1.20 & 3.21 & 3.21 \\
\hline & & & $(0.04)$ & $(0.00)$ & $(0.34)$ & $(0.34)$ \\
\hline & BL & 18 & 1.29 & 1.37 & & \\
\hline & & & $(0.07)$ & $(0.07)$ & & \\
\hline & VR 5 & 21 & 1.18 & 1.27 & 5.25 & 5.25 \\
\hline & & & $(0.06)$ & $(0.06)$ & $(0.48)$ & $(0.48)$ \\
\hline & VR 20 & 31 & 1.25 & 1.27 & 2.58 & 22.58 \\
\hline & & & $(0.05)$ & (0.07) & $(0.43)$ & $(0.43)$ \\
\hline & VR 40 & 23 & 1.24 & 1.23 & 1.80 & 1.80 \\
\hline
\end{tabular}




\begin{tabular}{|c|c|c|c|c|c|c|}
\hline & \multirow{3}{*}{ BL } & \multirow{3}{*}{14} & $(0.05)$ & $(0.07)$ & \multirow[t]{3}{*}{ (0.10) } & \multirow[t]{3}{*}{$(0.10)$} \\
\hline & & & 1.33 & 1.32 & & \\
\hline & & & $(0.05)$ & $(0.08)$ & & \\
\hline \multirow[t]{26}{*}{521} & $\mathrm{BL}$ & 20 & 1.29 & 1.31 & & \\
\hline & & & $(0.10)$ & $(0.07)$ & & \\
\hline & VR 20 & 31 & 1.33 & 1.32 & 4.31 & 4.30 \\
\hline & & & $(0.09)$ & $(0.06)$ & (0.16) & $(0.17)$ \\
\hline & VR 15 & 14 & 1.32 & 1.29 & 5.89 & 5.88 \\
\hline & & & $(0.09)$ & $(0.07)$ & $(0.37)$ & $(0.36)$ \\
\hline & VR 10 & 14 & 1.31 & 1.24 & 8.38 & 8.36 \\
\hline & & & $(0.10)$ & $(0.04)$ & $(0.42)$ & $(0.43)$ \\
\hline & VR 5 & 20 & 1.33 & 1.26 & 12.47 & 12.41 \\
\hline & & & $(0.08)$ & $(0.05)$ & (1.01) & (0.99) \\
\hline & VR 2 & 19 & 1.25 & 1.27 & 12.38 & 12.32 \\
\hline & & & $(0.08)$ & $(0.08)$ & (1.76) & (1.75) \\
\hline & BL & 17 & 1.36 & 1.30 & & \\
\hline & & & $(0.08)$ & $(0.06)$ & & \\
\hline & VI 2.5 & 14 & 1.30 & 1.35 & 12.73 & 12.67 \\
\hline & & & $(0.04)$ & $(0.09)$ & $(0.88)$ & (0.87) \\
\hline & VI 5 & 22 & 1.28 & 1.33 & 9.44 & 9.40 \\
\hline & & & $(0.07)$ & $(0.05)$ & $(0.20)$ & $0.20)$ \\
\hline & BL & 19 & 1.29 & 1.33 & & \\
\hline & & & $(0.08)$ & $(0.08)$ & & \\
\hline & VR 2 & 14 & 1.28 & 1.32 & 14.09 & 14.04 \\
\hline & & & $(0.07)$ & $(0.09)$ & $(0.93)$ & $(0.91)$ \\
\hline & VR 5 & 22 & 1.28 & 1.32 & 13.15 & 13.08 \\
\hline & & & $(0.08)$ & $(0.08)$ & (1.13) & (1.09) \\
\hline & BL & 21 & 1.30 & 1.35 & & \\
\hline & & & (0.09) & $(0.05)$ & & \\
\hline \multirow[t]{11}{*}{10} & $\mathrm{BL}$ & 13 & 1.36 & 1.28 & & \\
\hline & & & $(0.08)$ & $(0.09)$ & & \\
\hline & VR 2 & 22 & 1.30 & 1.28 & 20.48 & 20.34 \\
\hline & & & $(0.11)$ & $(0.11)$ & $(0.54)$ & $(0.53)$ \\
\hline & VR 5 & 19 & 1.28 & 1.28 & 16.91 & 16.80 \\
\hline & & & $(0.05)$ & $(0.07)$ & $(1.32)$ & (1.30) \\
\hline & VR 10 & 15 & 1.33 & 1.28 & 10.63 & 10.61 \\
\hline & & & $(0.08)$ & $(0.04)$ & $(0.40)$ & $(0.39)$ \\
\hline & VR 15 & 15 & 1.33 & 1.36 & 7.11 & 7.11 \\
\hline & & & $(0.04)$ & $(0.07)$ & $(0.40)$ & $(0.40)$ \\
\hline & VR 20 & 19 & 1.34 & 1.28 & 5.45 & 5.44 \\
\hline
\end{tabular}




\begin{tabular}{|c|c|c|c|c|c|}
\hline & & $(0.09)$ & $(0.03)$ & $(0.10)$ & $(0.09)$ \\
\hline \multirow[t]{2}{*}{ BL } & 20 & 1.28 & 1.30 & & \\
\hline & & $(0.07)$ & $(0.03)$ & & \\
\hline \multirow[t]{2}{*}{ VI 5} & 14 & 1.29 & 1.28 & 10.29 & 10.24 \\
\hline & & $(0.06)$ & $(0.03)$ & $(0.22)$ & $(0.21)$ \\
\hline \multirow[t]{2}{*}{ VI 2.5} & 34 & 1.30 & 1.29 & 16.25 & 16.15 \\
\hline & & $(0.06)$ & $(0.05)$ & $(0.53)$ & $(0.53)$ \\
\hline \multirow[t]{2}{*}{ BL } & 15 & 1.32 & 1.37 & & \\
\hline & & $(0.09)$ & $(0.09)$ & & \\
\hline \multirow[t]{2}{*}{ VR 5} & 14 & 1.25 & 1.37 & 17.88 & 17.75 \\
\hline & & $(0.03)$ & $(0.10)$ & $(0.58)$ & $(0.54)$ \\
\hline \multirow[t]{2}{*}{ VR 2} & 23 & 1.26 & 1.29 & 17.18 & 17.09 \\
\hline & & $(0.04)$ & (0.09) & (1.90) & (1.89) \\
\hline \multirow[t]{2}{*}{ BL } & 15 & 1.34 & 1.31 & & \\
\hline & & $(0.09)$ & (0.09) & & \\
\hline
\end{tabular}


Table 4

The unadjusted and adjusted response rates for all VI-timeout conditions in Experiment 2.

\begin{tabular}{|c|c|c|c|c|c|c|c|c|c|}
\hline \multicolumn{10}{|c|}{ Condition } \\
\hline Pigeon & $\mathrm{BL}$ & VI 2 & VI 2.5 & VI 3 & VI 5 & VI 10 & VI 20 & VI 45 & VI 90 \\
\hline \multirow[t]{4}{*}{4365} & 77.32 & & & 47.63 & 61.72 & 76.89 & 77.18 & 85.63 & \\
\hline & $(8.56)$ & & & 90.20 & 86.17 & 85.13 & 82.57 & 87.00 & \\
\hline & & & & 44.89 & 71.51 & & 103.04 & 83.13 & \\
\hline & & & & 81.26 & 100.39 & & 109.58 & 84.70 & \\
\hline \multirow[t]{4}{*}{2403} & 104.73 & & 76.35 & & 53.19 & 66.07 & 92.00 & 105.18 & \\
\hline & $(7.16)$ & & 70.21 & & 49.39 & 69.60 & 93.01 & 105.94 & \\
\hline & & & 69.35 & & 73.03 & 79.50 & & & \\
\hline & & & 69.65 & & 68.82 & 77.22 & & & \\
\hline \multirow[t]{4}{*}{849} & 74.07 & 49.28 & & & 49.78 & 51.64 & 75.21 & 61.02 & \\
\hline & (8.76) & 120.75 & & & 75.93 & 60.25 & 81.58 & 63.56 & \\
\hline & & 48.61 & & & 45.68 & & 61.90 & 58.46 & \\
\hline & & 129.27 & & & 65.47 & & 68.53 & 60.61 & \\
\hline \multirow[t]{4}{*}{828} & 61.02 & & 9.13 & & 13.38 & 27.24 & 38.78 & 38.90 & 42.45 \\
\hline & (10.03) & & 14.71 & & 19.53 & 31.94 & 41.41 & 39.23 & 43.10 \\
\hline & & & & & & 18.26 & & 34.00 & \\
\hline & & & & & & 23.06 & & 35.41 & \\
\hline \multirow[t]{2}{*}{521} & 62.59 & & 74.97 & & 118.07 & & & & \\
\hline & $(12.93)$ & & 212.40 & & 192.17 & & & & \\
\hline \multirow[t]{2}{*}{10} & 102.35 & & 95.12 & & 109.57 & & & & \\
\hline & $(21.21)$ & & 224.62 & & 160.89 & & & & \\
\hline
\end{tabular}

Note: The baseline response rates are the means for the last six sessions of all baseline conditions for each pigeon. The standard deviations are shown in parentheses. The values in italics show the adjusted response rates of the values immediately above them. The bolded values indicate adjusted rates that are lower than the mean of the respective baseline conditions (see text for additional details). The second pair of unadjusted and adjusted response rates are replications of the condition. 
Table 5

The unadjusted and adjusted response rates for all VR-timeout conditions in Experiment 2.

\begin{tabular}{|c|c|c|c|c|c|c|c|}
\hline \multicolumn{8}{|c|}{ Condition } \\
\hline Pigeon & $\mathrm{BL}$ & VR 2 & VR 5 & VR 10 & VR 15 & VR 20 & VR 40 \\
\hline \multirow[t]{2}{*}{1782} & 58.22 & 27.42 & 44.61 & 68.65 & 77.79 & 77.73 & \\
\hline & & 67.93 & 54.25 & 72.76 & 82.31 & 80.68 & \\
\hline \multirow[t]{4}{*}{975} & 109.79 & 25.79 & 52.76 & 79.75 & 89.51 & 64.81 & 73.40 \\
\hline & (16.80) & 80.96 & 144.94 & 148.29 & 135.18 & 86.67 & 87.55 \\
\hline & & & 26.38 & & & 50.75 & \\
\hline & & & 56.08 & & & 66.97 & \\
\hline \multirow[t]{4}{*}{521} & 62.59 & 25.36 & 62.90 & 83.38 & 88.45 & 86.59 & \\
\hline & (12.93) & 90.18 & 128.40 & 123.76 & 116.55 & 100.50 & \\
\hline & & 28.79 & 65.95 & & & & \\
\hline & & 90.35 & 156.94 & & & & \\
\hline \multirow[t]{4}{*}{10} & 102.35 & 41.71 & 84.92 & 107.13 & 106.63 & 110.06 & \\
\hline & $(21.21)$ & 98.28 & 158.10 & 132.97 & 125.70 & 122.95 & \\
\hline & & 34.98 & 89.78 & & & & \\
\hline & & 123.11 & 185.81 & & & & \\
\hline \multirow[t]{2}{*}{4365} & 77.32 & 27.35 & 59.66 & & & & \\
\hline & $(8.56)$ & 83.91 & 106.04 & & & & \\
\hline \multirow[t]{2}{*}{2403} & 104.73 & 49.42 & 64.08 & & & & \\
\hline & $(7.16)$ & 52.15 & 60.45 & & & & \\
\hline \multirow[t]{2}{*}{849} & 74.07 & 34.04 & 66.78 & & & & \\
\hline & $(8.76)$ & 88.94 & 138.26 & & & & \\
\hline \multirow[t]{2}{*}{828} & 61.02 & 17.04 & 21.14 & & & & \\
\hline & (10.03) & 26.51 & 25.74 & & & & \\
\hline
\end{tabular}

Note: The baseline response rates are the means for the last six sessions of all baseline conditions for each pigeon. The standard deviations are shown in parentheses. The values in italics show the adjusted response rates of the values immediately above them. The bolded values indicate adjusted rates that are lower than the mean of the respective baseline conditions (see text for additional details). The second pair of unadjusted and adjusted response rates are replications of the condition. 
Table 6

The sequence of conditions, number of sessions, reinforcers (Reinf) per min, and timeouts (TO) per min for the last six stable sessions for each pigeon in Experiment 3. The standard deviations are shown in parentheses. The conditions, except no-timeout baselines (BL), are named by the mean variable-ratio (VR) timeout schedule in effect, the tandem delay value (FT 5 or 0.5), and the tandem fixed-interval value (FI 5 or 0.5). Dep. = response-dependent timeout. Ind. = response-independent timeout.

\begin{tabular}{|c|c|c|c|c|c|c|}
\hline \multirow[b]{2}{*}{ Pigeon } & \multirow[b]{2}{*}{ Condition } & \multirow[b]{2}{*}{ Sessions } & \multicolumn{2}{|c|}{ Reinf per min } & \multicolumn{2}{|c|}{ TO per min } \\
\hline & & & Dep. & Ind. & Dep. & Ind. \\
\hline \multirow[t]{22}{*}{21331} & $\mathrm{BL}$ & 16 & 1.30 & 1.28 & & \\
\hline & & & $(0.09)$ & $(0.12)$ & & \\
\hline & VR 3 & 18 & 1.33 & 1.32 & 23.50 & 23.32 \\
\hline & & & $(0.18)$ & $(0.12)$ & (1.29) & (1.24) \\
\hline & FT 5 & 15 & 1.38 & 1.25 & 8.87 & 8.80 \\
\hline & & & $(0.20)$ & $(0.08)$ & $(0.10)$ & $(0.15)$ \\
\hline & FI 5 & 14 & 1.38 & 1.35 & 8.72 & 8.68 \\
\hline & & & $(0.15)$ & $(0.14)$ & $(0.08)$ & $(0.10)$ \\
\hline & FT 5 & 15 & 1.35 & 1.28 & 8.77 & 8.77 \\
\hline & & & $(0.14)$ & $(0.08)$ & $(0.08)$ & $(0.08)$ \\
\hline & VR 3 & 14 & 1.27 & 1.28 & 28.25 & 27.92 \\
\hline & & & $(0.05)$ & $(0.08)$ & $(1.25)$ & $(1.25)$ \\
\hline & FT 0.5 & 14 & 1.35 & 1.32 & 21.58 & 21.40 \\
\hline & & & $(0.08)$ & $(0.12)$ & $(0.54)$ & $(0.58)$ \\
\hline & FI 0.5 & 14 & 1.32 & 1.25 & 20.02 & 19.85 \\
\hline & & & $(0.12)$ & $(0.08)$ & $(0.67)$ & $(0.63)$ \\
\hline & FT 0.5 & 14 & 1.32 & 1.33 & 20.08 & 19.98 \\
\hline & & & $(0.13)$ & $(0.14)$ & $(0.81)$ & $(0.89)$ \\
\hline & VR 3 & 14 & 1.32 & 1.30 & 23.05 & 22.82 \\
\hline & & & $(0.12)$ & $(0.09)$ & $(0.58)$ & $(0.57)$ \\
\hline & $\mathrm{BL}$ & 15 & 1.28 & 1.32 & & \\
\hline & & & $(0.12)$ & $(0.10)$ & & \\
\hline \multirow[t]{8}{*}{8964} & $\mathrm{BL}$ & 14 & 1.28 & 1.27 & & \\
\hline & & & $(0.12)$ & $(0.08)$ & & \\
\hline & VR 2 & 18 & 1.35 & 1.32 & 31.25 & 30.97 \\
\hline & & & $(0.08)$ & $(0.10)$ & (1.69) & (1.66) \\
\hline & FT 0.5 & 19 & 1.23 & 1.27 & 22.10 & 21.95 \\
\hline & & & $(0.05)$ & $(0.05)$ & $(0.92)$ & $(0.94)$ \\
\hline & FI 0.5 & 16 & 1.32 & 1.32 & 22.17 & 21.98 \\
\hline & & & $(0.12)$ & $(0.10)$ & $(0.37)$ & $(0.37)$ \\
\hline
\end{tabular}




\begin{tabular}{|c|c|c|c|c|c|c|}
\hline & FT 0.5 & 16 & 1.32 & 1.35 & 23.77 & 23.58 \\
\hline & & & $(0.08)$ & $(0.10)$ & $(0.54)$ & $(0.56)$ \\
\hline & VR 2 & 15 & 1.30 & 1.30 & 31.03 & 30.77 \\
\hline & & & $(0.06)$ & $(0.11)$ & $(1.21)$ & (1.16) \\
\hline & FT 5 & 14 & 1.27 & 1.33 & 8.50 & 8.48 \\
\hline & & & $(0.05)$ & $(0.12)$ & $(0.09)$ & $(0.08)$ \\
\hline & FI 5 & 15 & 1.33 & 1.35 & 8.35 & 8.32 \\
\hline & & & $(0.12)$ & $(0.08)$ & $(0.05)$ & $(0.08)$ \\
\hline & FT 5 & 14 & 1.33 & 1.30 & 8.53 & 8.53 \\
\hline & & & $(0.14)$ & $(0.09)$ & $(0.15)$ & $(0.15)$ \\
\hline & VR 2 & 16 & 1.27 & 1.30 & 28.30 & 28.08 \\
\hline & & & $(0.08)$ & $(0.13)$ & $(0.72)$ & (0.69) \\
\hline & BL & 16 & 1.27 & 1.37 & & \\
\hline & & & $(0.05)$ & $(0.16)$ & & \\
\hline 691 & $\mathrm{BL}$ & 7 & 1.33 & 1.30 & & \\
\hline & & & $(0.10)$ & $(0.09)$ & & \\
\hline & VR 2 & 21 & 1.33 & 1.28 & 16.27 & 16.20 \\
\hline & & & $(0.12)$ & $(0.04)$ & (1.19) & (1.17) \\
\hline & FT 5 & 15 & 1.23 & 1.27 & 7.80 & 7.80 \\
\hline & & & $(0.05)$ & $(0.10)$ & $(0.15)$ & $(0.15)$ \\
\hline & FI 5 & 14 & 1.22 & 1.22 & 8.27 & 8.22 \\
\hline & & & $(0.04)$ & $(0.04)$ & $(0.14)$ & $(0.10)$ \\
\hline & FT 5 & 14 & 1.35 & 1.30 & 8.55 & 8.53 \\
\hline & & & $(0.10)$ & $(0.09)$ & $(0.15)$ & (0.16) \\
\hline & VR 2 & 22 & 1.25 & 1.33 & 22.22 & 22.05 \\
\hline & & & $(0.05)$ & $(0.10)$ & $(2.22)$ & (2.19) \\
\hline & FT 0.5 & 15 & 1.37 & 1.37 & 18.27 & 18.17 \\
\hline & & & $(0.12)$ & $(0.14)$ & (1.49) & (1.44) \\
\hline & FI 0.5 & 15 & 1.33 & 1.38 & 16.52 & 16.43 \\
\hline & & & $(0.10)$ & $(0.17)$ & (1.35) & (1.33) \\
\hline & FT 0.5 & 20 & 1.23 & 1.25 & 15.13 & 15.08 \\
\hline & & & $(0.05)$ & $(0.08)$ & (1.78) & (1.79) \\
\hline & VR 2 & 22 & 1.28 & 1.23 & 16.07 & 15.97 \\
\hline & & & $(0.12)$ & $(0.05)$ & $(1.24)$ & (1.24) \\
\hline & FT 1 & 17 & 1.30 & 1.28 & 13.70 & 13.67 \\
\hline & & & $(0.06)$ & $(0.08)$ & (1.29) & (1.32) \\
\hline & VR 2 & 14 & 1.25 & 1.30 & 15.12 & 15.02 \\
\hline & & & $(0.05)$ & $(0.06)$ & (1.09) & (1.06) \\
\hline & BL & 17 & 1.30 & 1.38 & & \\
\hline & & & (0.09) & $(0.12)$ & & \\
\hline
\end{tabular}




\begin{tabular}{ccccccc}
\hline 2 BL & 21 & 1.38 & 1.28 & & \\
& & $(0.17)$ & $(0.12)$ & & \\
VR 3 & 31 & 1.28 & 1.27 & 11.47 & 11.40 \\
& & $(0.04)$ & $(0.10)$ & $(1.16)$ & $(1.15)$ \\
FT 0.5 & 16 & 1.32 & 1.35 & 9.43 & 9.43 \\
& & $(0.10)$ & $(0.10)$ & $(0.78)$ & $(0.78)$ \\
& FI 0.5 & 21 & 1.28 & 1.27 & 7.85 & 7.83 \\
& & $(0.10)$ & $(0.12)$ & $(1.04)$ & $(1.07)$ \\
& & 1.25 & 1.25 & 12.42 & 12.33 \\
& & 16 & $(0.08)$ & $(0.08)$ & $(0.55)$ & $(0.54)$ \\
& & 1.32 & 1.23 & 11.62 & 11.58 \\
& & & $(0.14)$ & $(0.05)$ & $(1.21)$ & $(1.23)$ \\
\hline
\end{tabular}


Table 7

The sequence of conditions, number of sessions, reinforcers (Reinf) per min, and timeouts (TO) per min for the last six stable sessions for each pigeon in Experiment 4. The standard deviations are shown in parentheses. The conditions, except no-timeout baselines $(B L)$, are named by the mean variable-ratio (VR) timeout schedule in effect, the tandem delay value (FT 5 or 0.5), and the tandem fixed-interval value (FI 5 or 0.5). Dep. = response-dependent timeout. Ind. = response-independent timeout.

\begin{tabular}{|c|c|c|c|c|c|c|}
\hline \multirow[b]{2}{*}{ Pigeon } & \multirow[b]{2}{*}{ Condition } & \multirow[b]{2}{*}{ Sessions } & \multicolumn{2}{|c|}{ Reinf per min } & \multicolumn{2}{|c|}{ TO per min } \\
\hline & & & Dep. & Ind. & Dep. & Ind. \\
\hline \multirow[t]{16}{*}{21331} & VR 3 & 14 & 1.37 & 1.42 & 23.57 & 23.42 \\
\hline & & & $(0.08)$ & $(0.16)$ & (1.19) & $(1.16)$ \\
\hline & FT 0.5 & 14 & 1.25 & 1.25 & 19.67 & 19.53 \\
\hline & & & $(0.08)$ & $(0.08)$ & $(0.39)$ & $(0.40)$ \\
\hline & FI 0.5 & 14 & 1.33 & 1.37 & 20.30 & 20.20 \\
\hline & & & $(0.12)$ & $(0.10)$ & $(0.41)$ & $(0.46)$ \\
\hline & FT 0.5 & 16 & 1.28 & 1.32 & 19.17 & 19.02 \\
\hline & & & $(0.08)$ & $(0.08)$ & $(0.40)$ & $(0.38)$ \\
\hline & VR 3 & 17 & 1.35 & 1.28 & 21.15 & 21.03 \\
\hline & & & $(0.14)$ & $(0.08)$ & $(0.41)$ & $(0.42)$ \\
\hline & FT 5 & 15 & 1.38 & 1.37 & 7.80 & 7.80 \\
\hline & & & $(0.08)$ & $(0.14)$ & $(0.17)$ & $(0.17)$ \\
\hline & FI 5 & 40 & 1.30 & 1.37 & 7.50 & 7.48 \\
\hline & & & $(0.09)$ & $(0.16)$ & $(0.13)$ & $(0.12)$ \\
\hline & FT 5 & 20 & 1.35 & 1.37 & 7.73 & 7.73 \\
\hline & & & $(0.10)$ & $(0.12)$ & $(0.15)$ & $(0.15)$ \\
\hline \multirow[t]{12}{*}{8964} & VR 3 & 15 & 1.28 & 1.27 & 25.00 & 24.75 \\
\hline & & & $(0.08)$ & $(0.08)$ & $(0.83)$ & $(0.82)$ \\
\hline & FT 0.5 & 22 & 1.28 & 1.25 & 20.17 & 20.02 \\
\hline & & & $(0.08)$ & $(0.08)$ & $(0.90)$ & $(0.87)$ \\
\hline & FI 0.5 & 18 & 1.20 & 1.35 & 20.08 & 19.98 \\
\hline & & & $(0.00)$ & $(0.10)$ & $(0.67)$ & $(0.65)$ \\
\hline & FT 0.5 & 27 & 1.32 & 1.35 & 19.32 & 19.22 \\
\hline & & & $(0.08)$ & $(0.16)$ & $(0.33)$ & $(0.36)$ \\
\hline & VR 3 & 16 & 1.27 & 1.28 & 25.23 & 25.02 \\
\hline & & & $(0.08)$ & $(0.08)$ & $(0.63)$ & $(0.64)$ \\
\hline & BL & 14 & 1.40 & 1.40 & & \\
\hline & & & (0.09) & $(0.15)$ & & \\
\hline
\end{tabular}




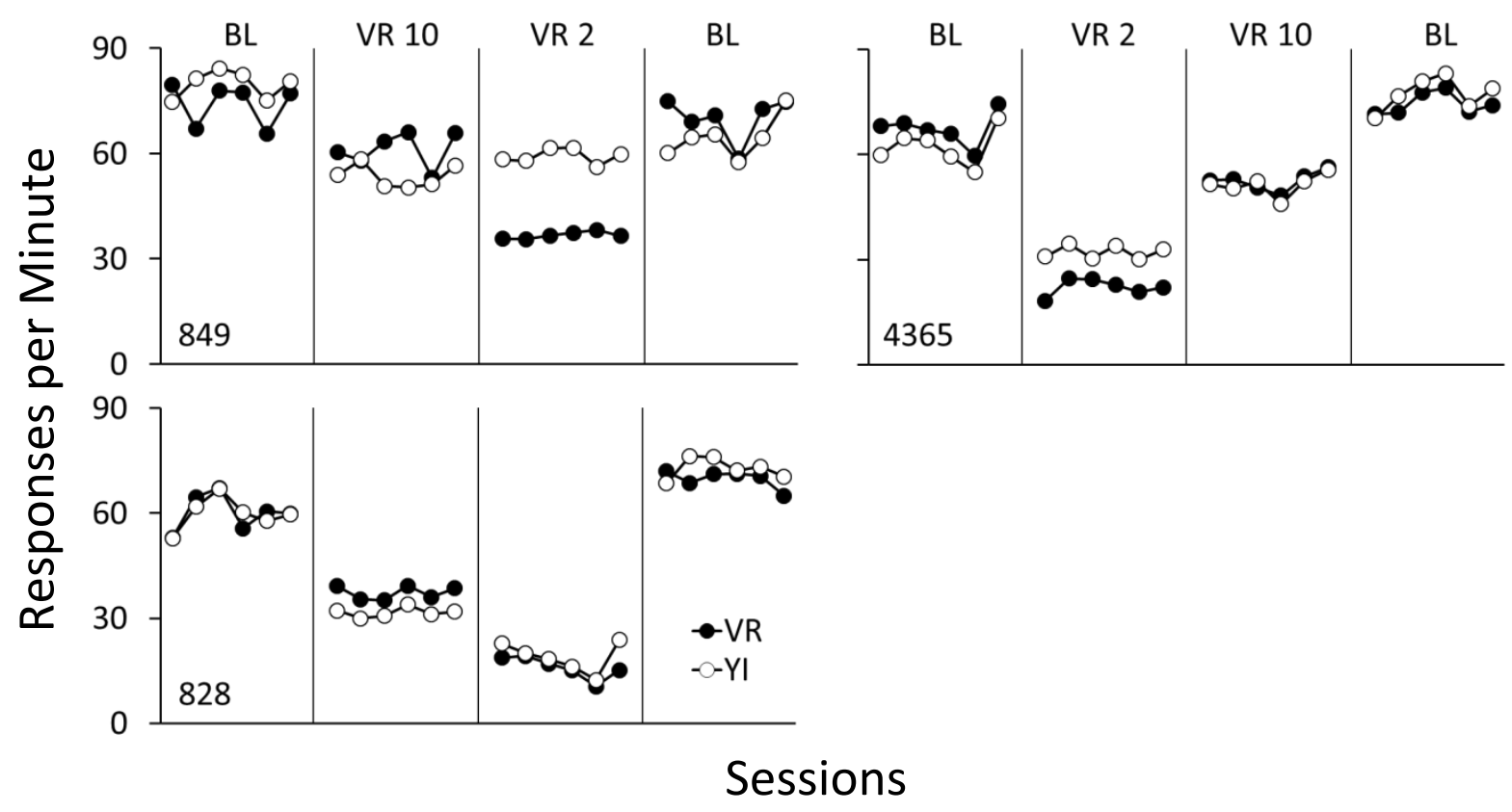

Figure 1. Mean responses per min for the last six stable sessions of each condition for Experiment 1. The filled data points indicate variable ratio (VR) components and unfilled data points indicate yoked-interval (YI) components. 


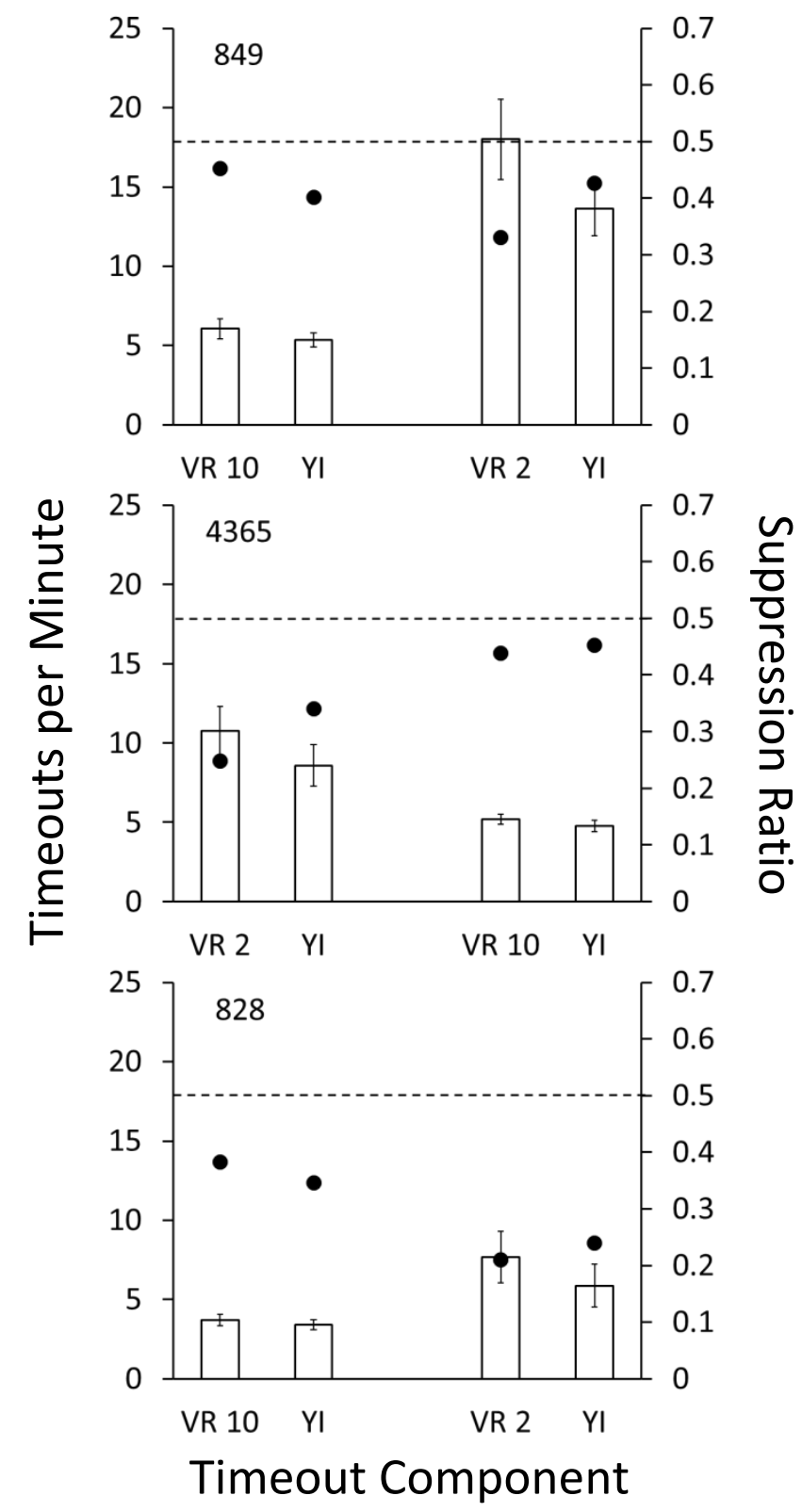

Figure 2. Suppression ratios plotted as a function of timeout component for each pigeon in Experiment 1 . The bars indicate the timeout rate. The error bars are the standard deviations. The filled data points indicate suppression ratios for both the variable-ratio (VR) and corresponding yoked-interval (YI) components for both timeout conditions. The dashed line at 0.50 indicates no change in responding relative to the preceding unpunished baseline. 


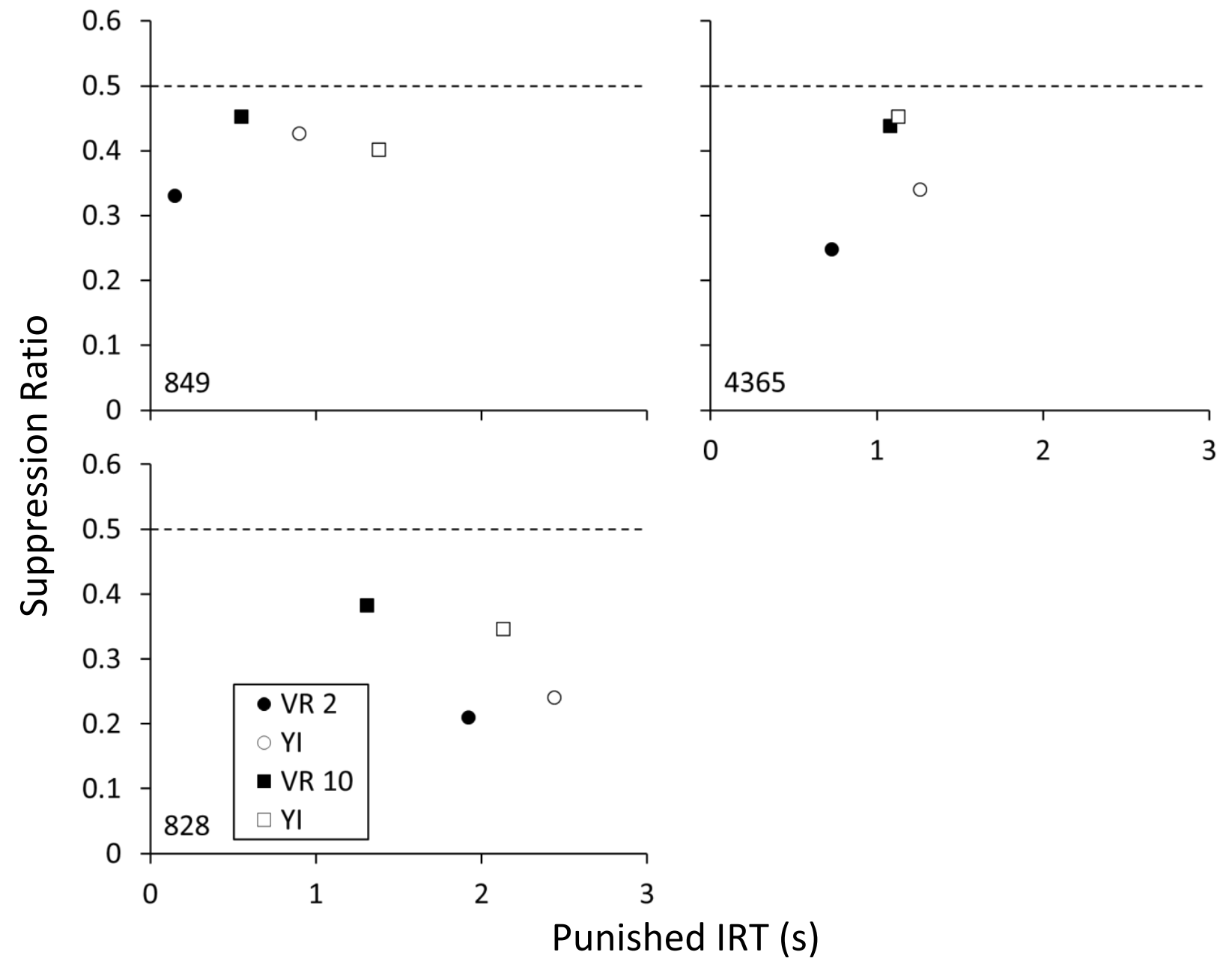

Figure 3. Suppression ratios plotted as a function of the median punished IRTs in Experiment 1. The filled data points are for the variable-ratio (VR) timeout components and the unfilled data points are for the corresponding yoked-interval timeout components. 

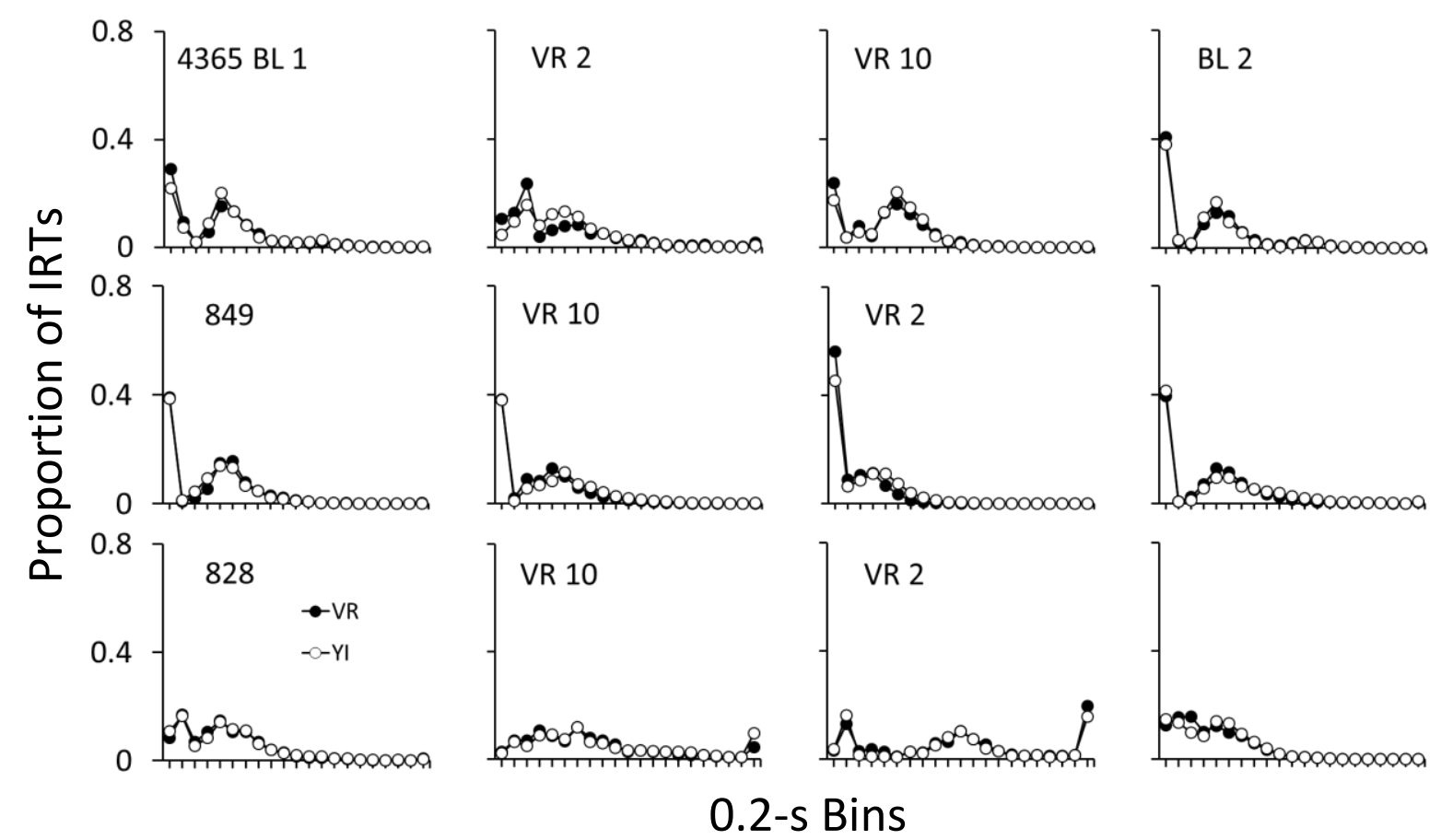

Figure 4. Interresponse times (IRTs) plotted in successive 0.2-s bins for the VR (filled data points) and YI (unfilled data points) components for each pigeon and condition in Experiment 1. The last bin is the overflow bin for IRTs greater than $4 \mathrm{~s}$. BL indicates baselines and the timeout conditions are listed within the innermost graphs. 


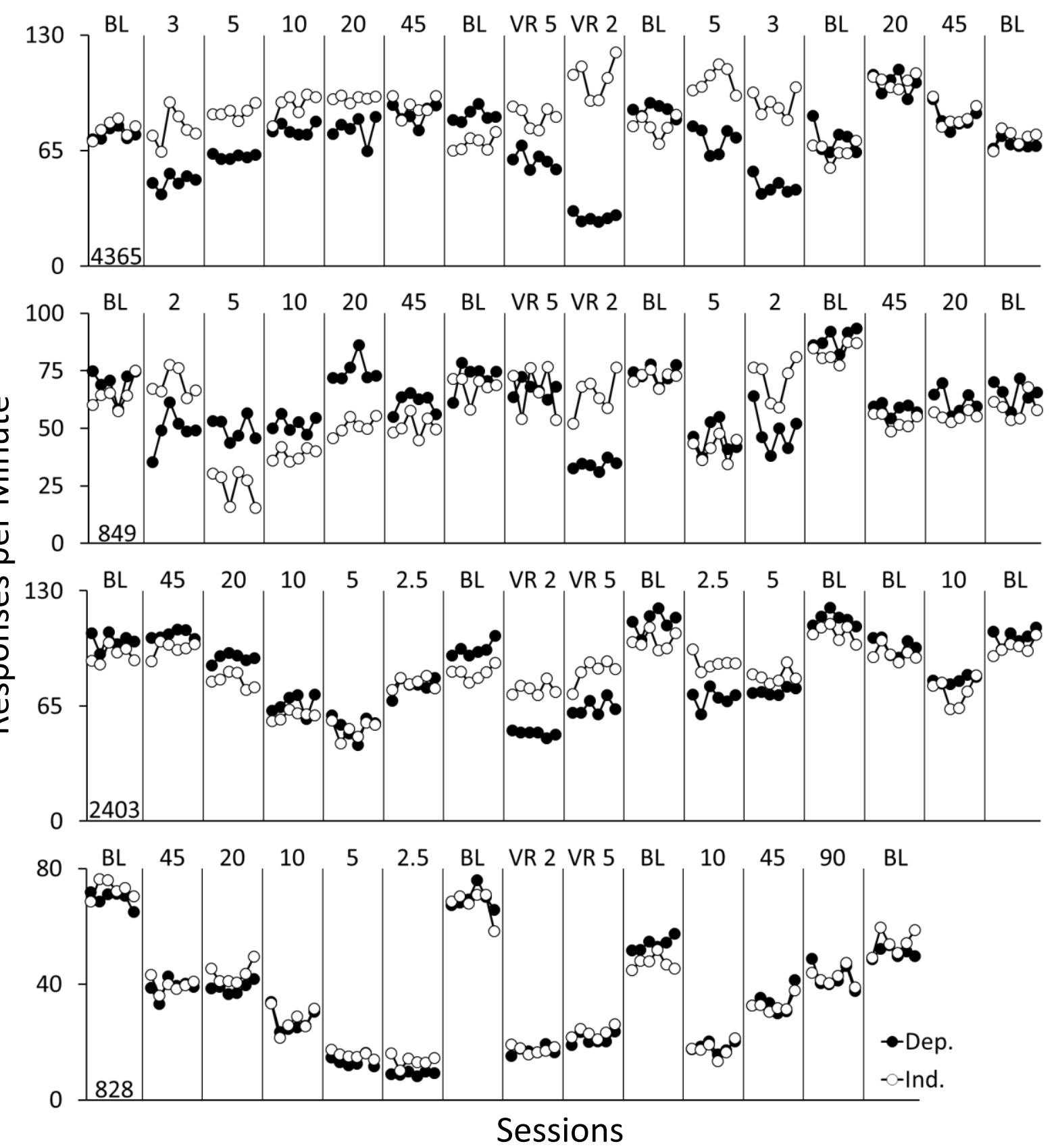

Figure 5. Mean responses per min from the last six stable sessions of each condition for pigeons in the VI sequence in Experiment 2 a. The filled data points indicate response-dependent (Dep.) timeout components and unfilled data points indicate response-independent (Ind.) timeout components. The number value above conditions shows the mean schedule value of timeout in a condition. 


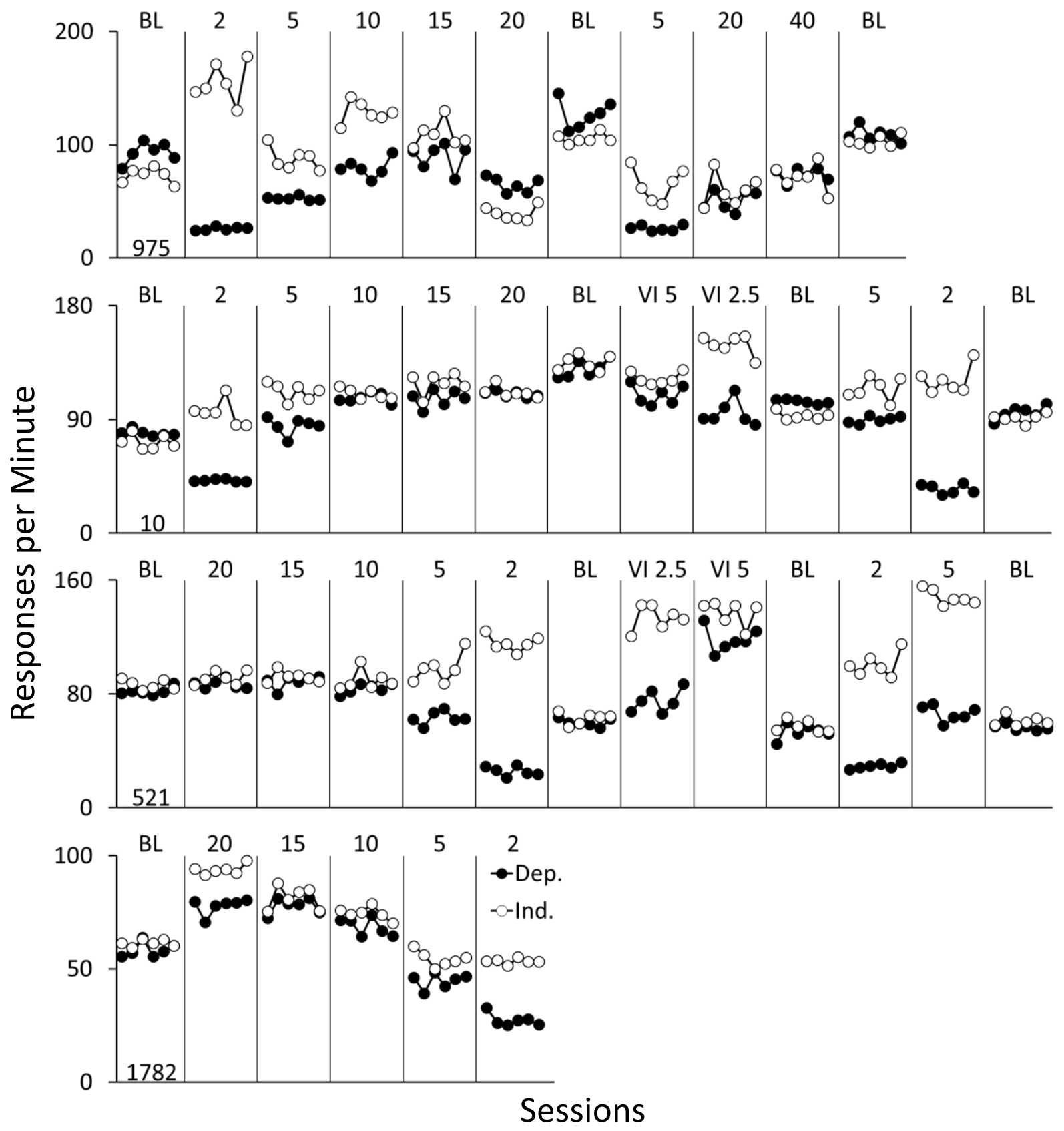

Figure 6. Mean responses per min for the last six stable sessions of each condition for pigeons in the VR sequence in Experiment 2 b. The filled data points indicate response-dependent (Dep.) timeout components and unfilled data points indicate response-independent (Ind.) timeout components. The number value above conditions shows the mean schedule value of timeout in a condition. 


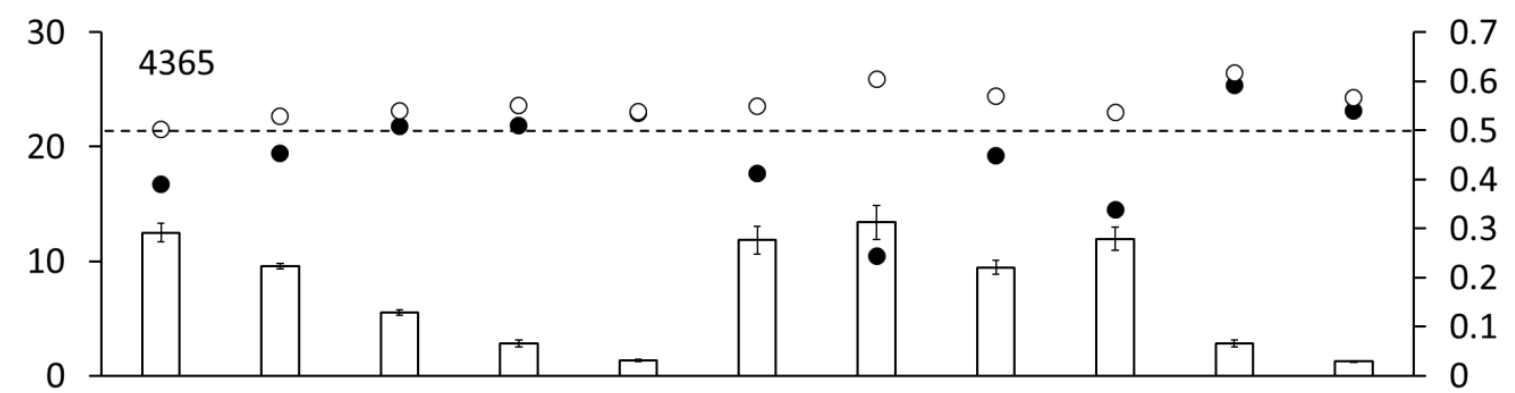

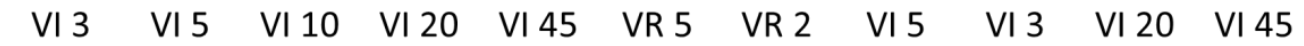
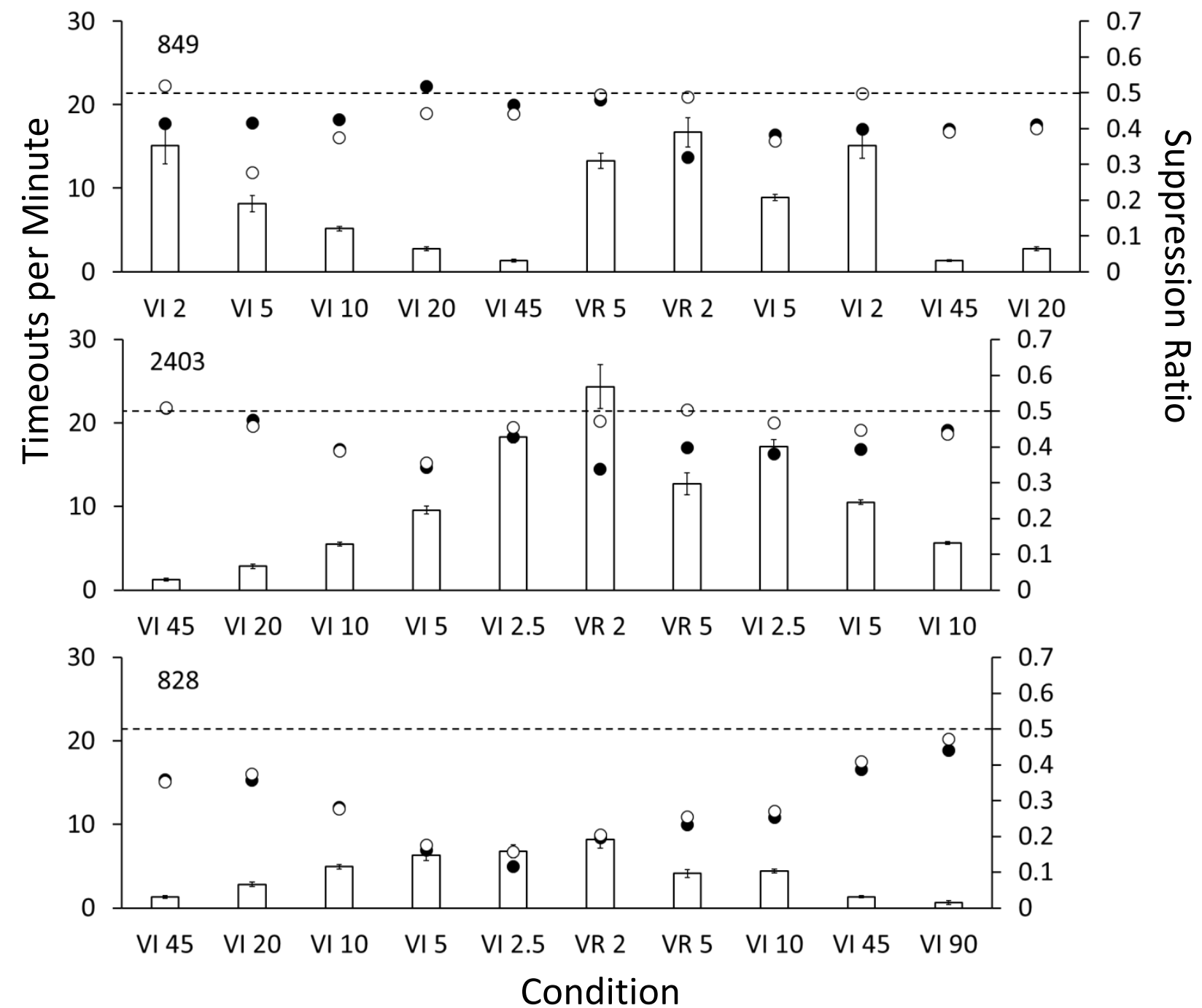

Figure 7. Timeouts per minute (bars) and suppression ratios (data points) for pigeons in Experiment 2 a. The filled data points are from the response-dependent components and the unfilled data points are from the response-independent timeout components. The error bars are the standard deviations. 

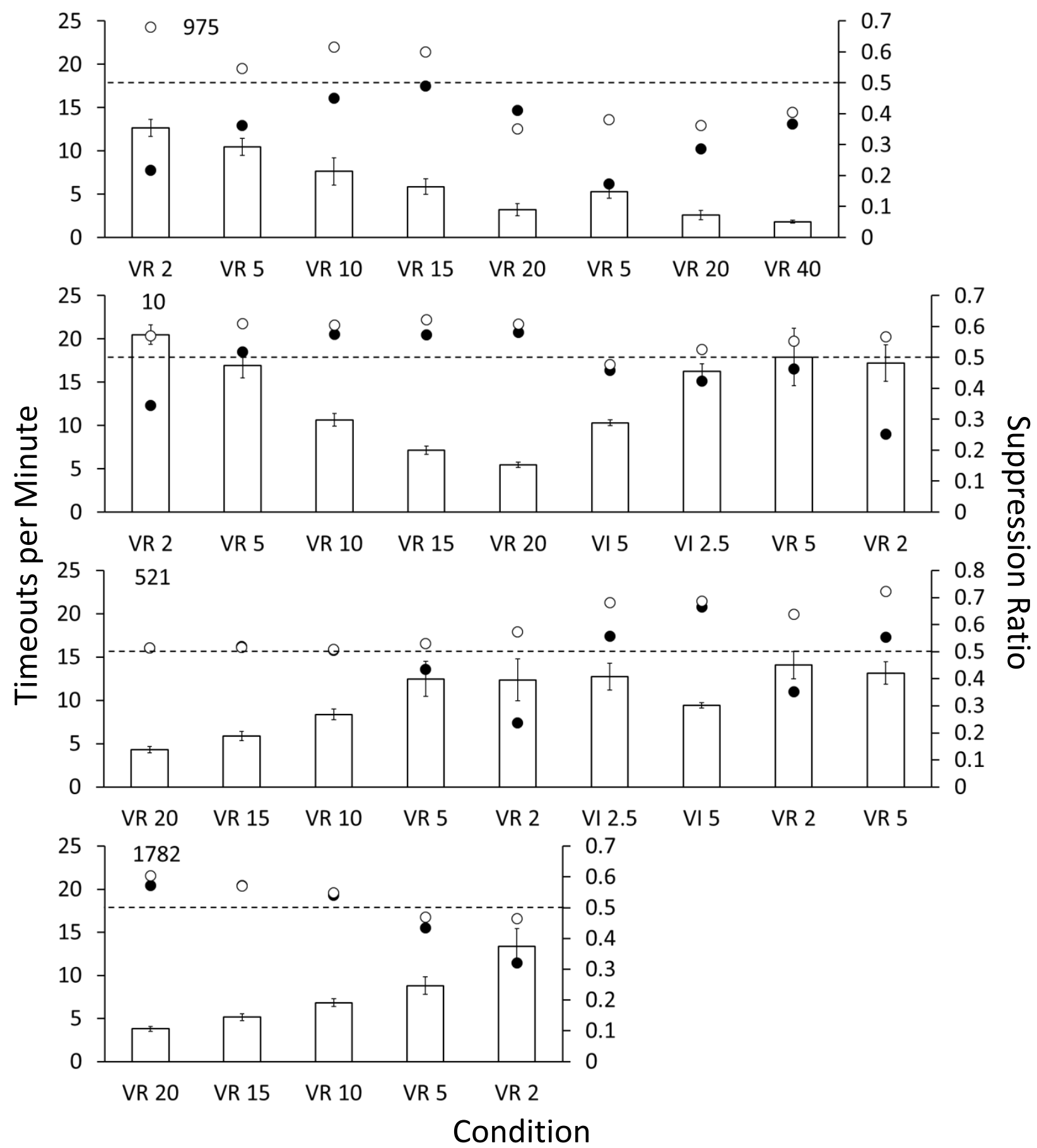

Figure 8. Individual-subject data for timeouts per minute (bars) and suppression ratios (data points) for pigeons in Experiment $2 \mathrm{~b}$. The filled data points are from the response-dependent components and the unfilled data points are from the response-independent timeout components. The error bars are the standard deviations. 


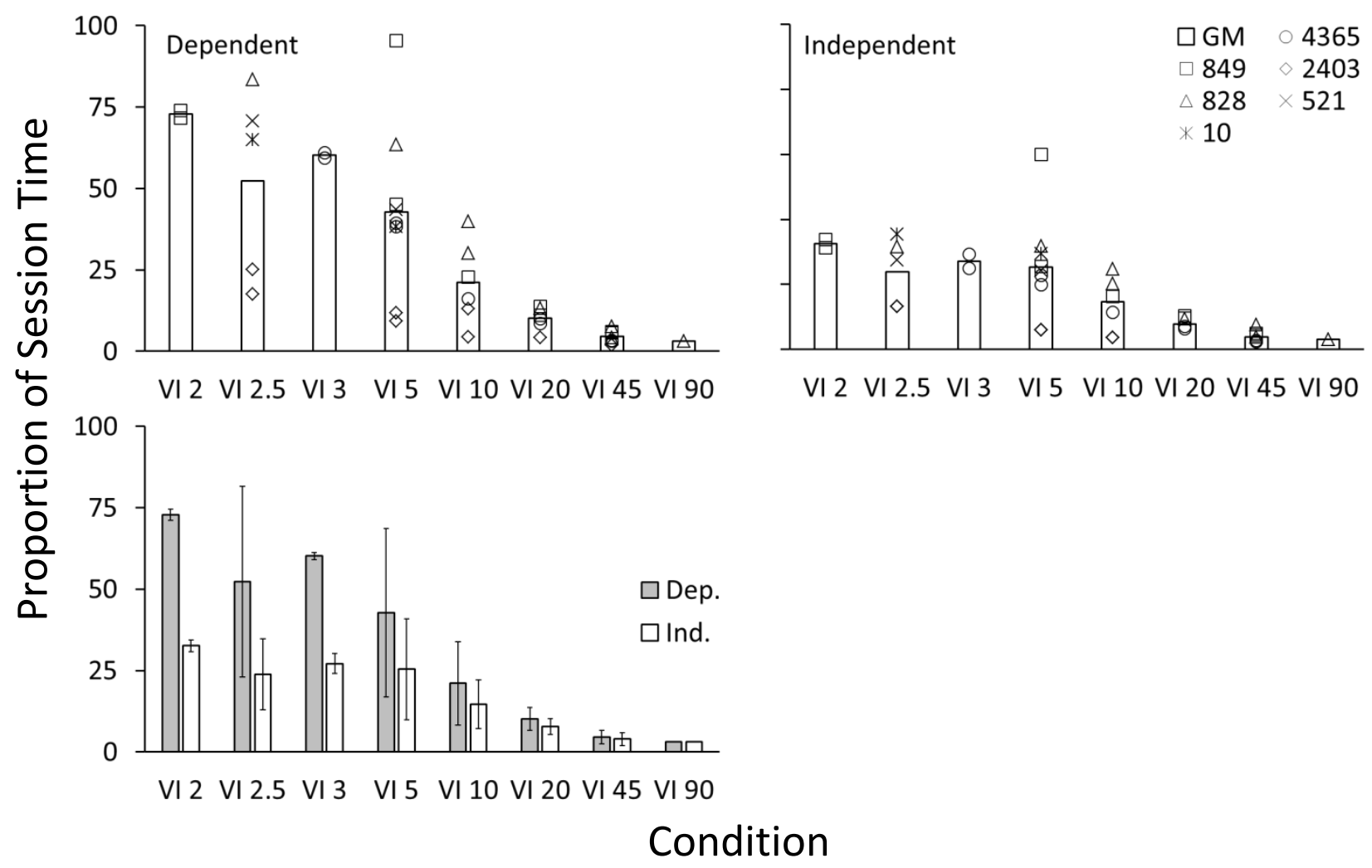

Figure 9. Mean proportion of total session time spent pausing following timeouts during the last six stable sessions for each individual pigeon (top two graphs) and the mean of all pigeons (bottom graph) for the aggregated VI conditions. The data points in the top two graphs show individual-subject data. The upper left graph is from the response-dependent (Dep.) timeout components and the upper right graph is from the response-independent (Ind.) timeout components. The error bars in the bottom graph show the standard deviations. 


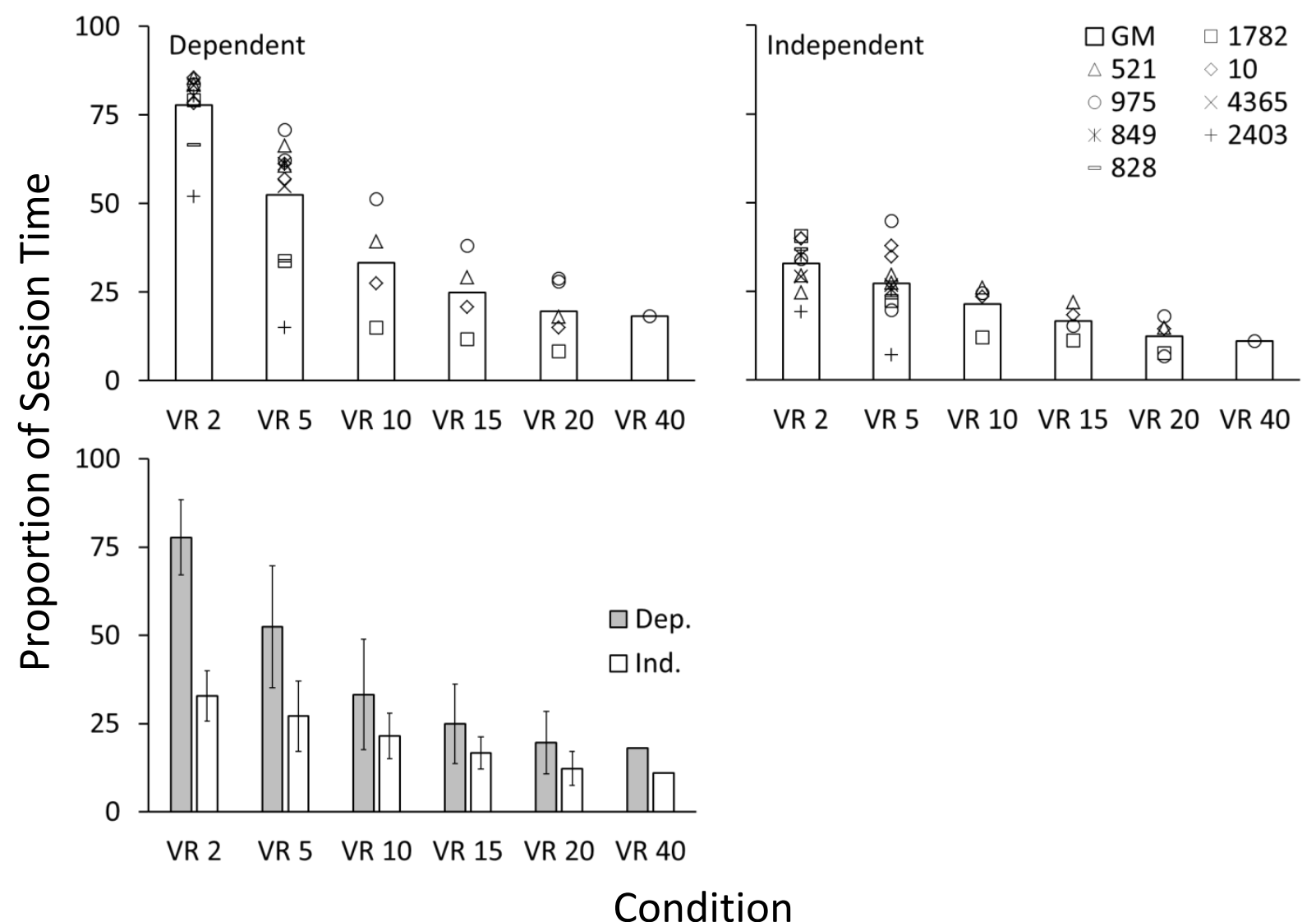

Figure 10. Mean proportion of total session time spent pausing following timeouts during the last six stable sessions for each individual pigeon (top two graphs) and the mean of all pigeons (bottom graph) for the aggregated VR conditions. The data points in the top two graphs show individual-subject data. The upper left graph is from the response-dependent (Ind.) timeout components and the upper right graph is from the response-independent (Dep.) timeout components. The error bars in the bottom graph show the standard deviations. 


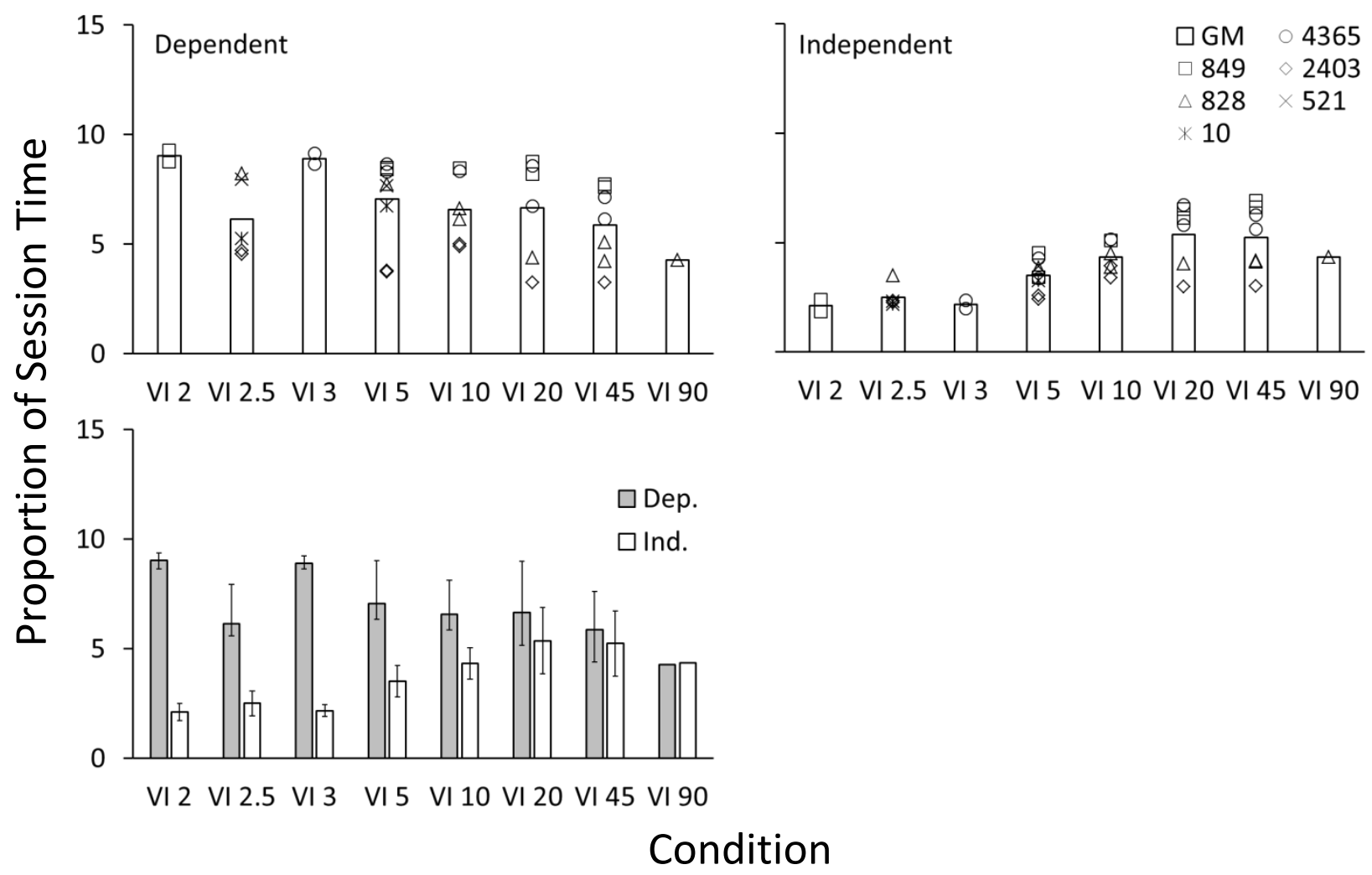

Figure 11. Mean proportion of total session time spent pausing following reinforcers during the last six stable sessions for each individual pigeon (top two graphs) and the mean of all pigeons (bottom graph) for the aggregated VI conditions. The data points in the top two graphs show individual-subject data. The upper left graph is from the response-dependent (Dep.) timeout components and the upper right graph is from the response-independent (Ind.) timeout components. The error bars in the bottom graph show the standard deviations. 


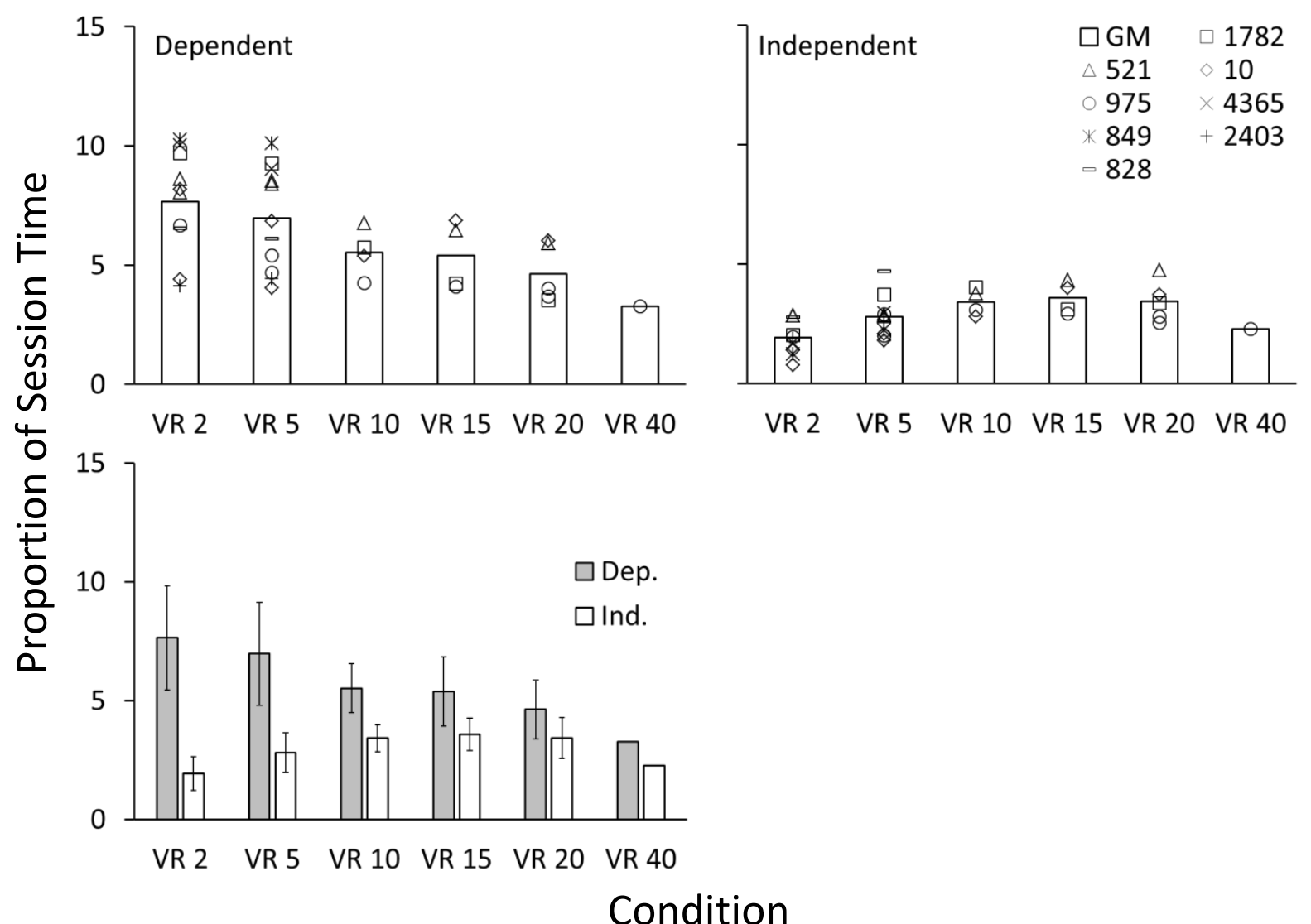

Figure 12. Mean proportion of total session time spent pausing following reinforcers during the last six stable sessions for each individual pigeon (top two graphs) and the mean of all pigeons (bottom graph) for the aggregated VR conditions. The data points in the top two graphs show individual-subject data. The upper left graph is from the response-dependent (Dep.) timeout components and the upper right graph is from the response-independent (Ind.) timeout components. The error bars in the bottom graph show the standard deviations. 


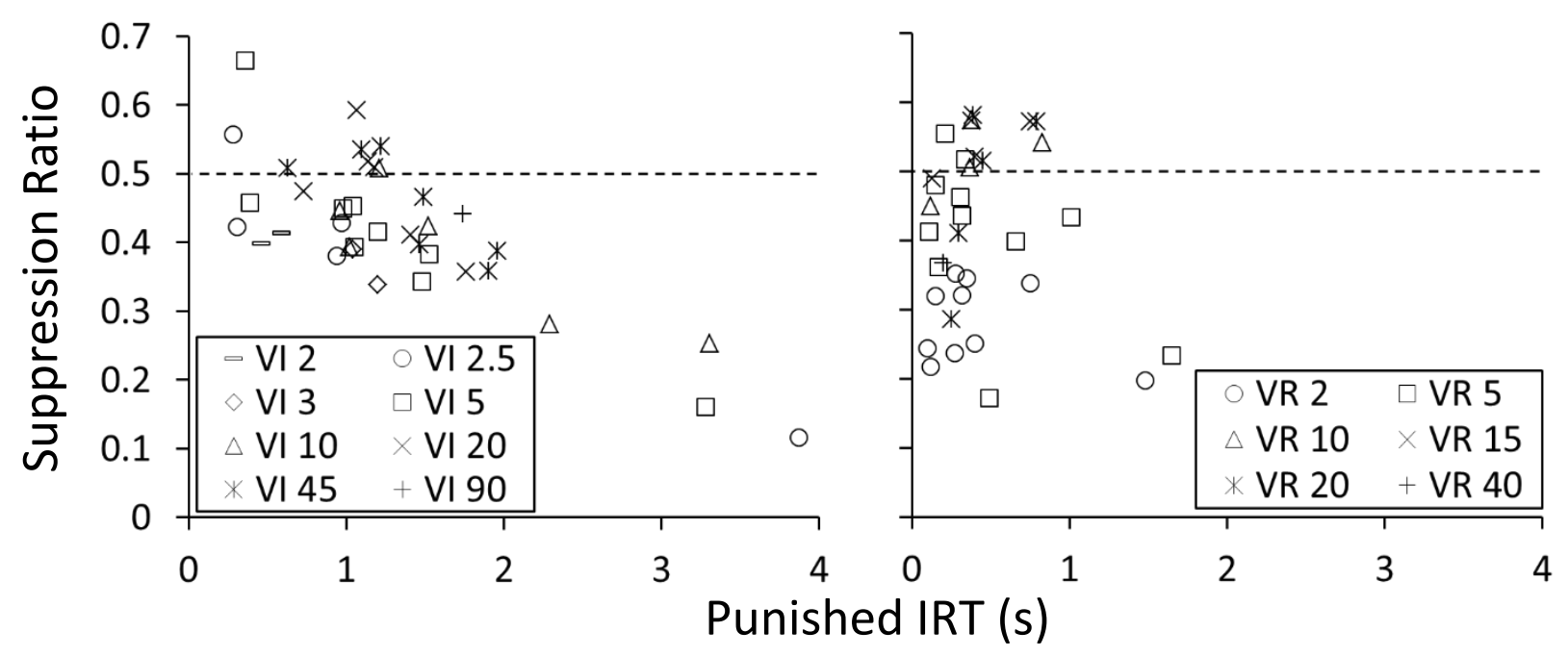

Figure 13. Suppression ratios plotted as a function of median punished IRTs in Experiment 2. The left graph shows all VI conditions and the right graph shows all VR conditions. 


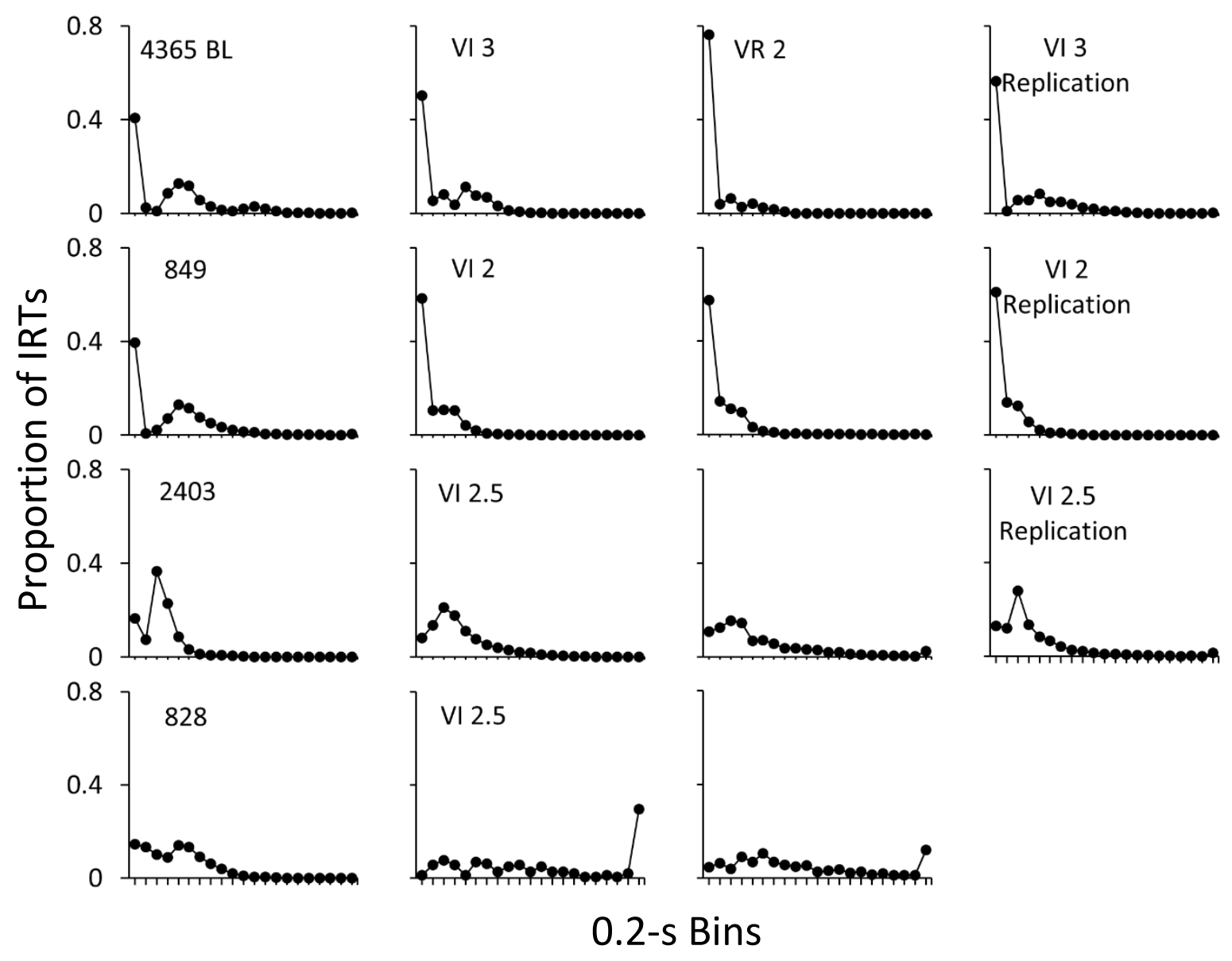

Figure 14. Proportion of interresponse times (IRTs) plotted in successive 0.2-s bins for the first baseline (BL; left most column) and the response-independent timeout components for the highest mean nominal VI and VR timeout conditions for each pigeon in Experiment 2 a. The last bin is the overflow bin for IRTs greater than $4 \mathrm{~s}$. Unless otherwise noted, the label at the top of each column indicates the timeout condition. 


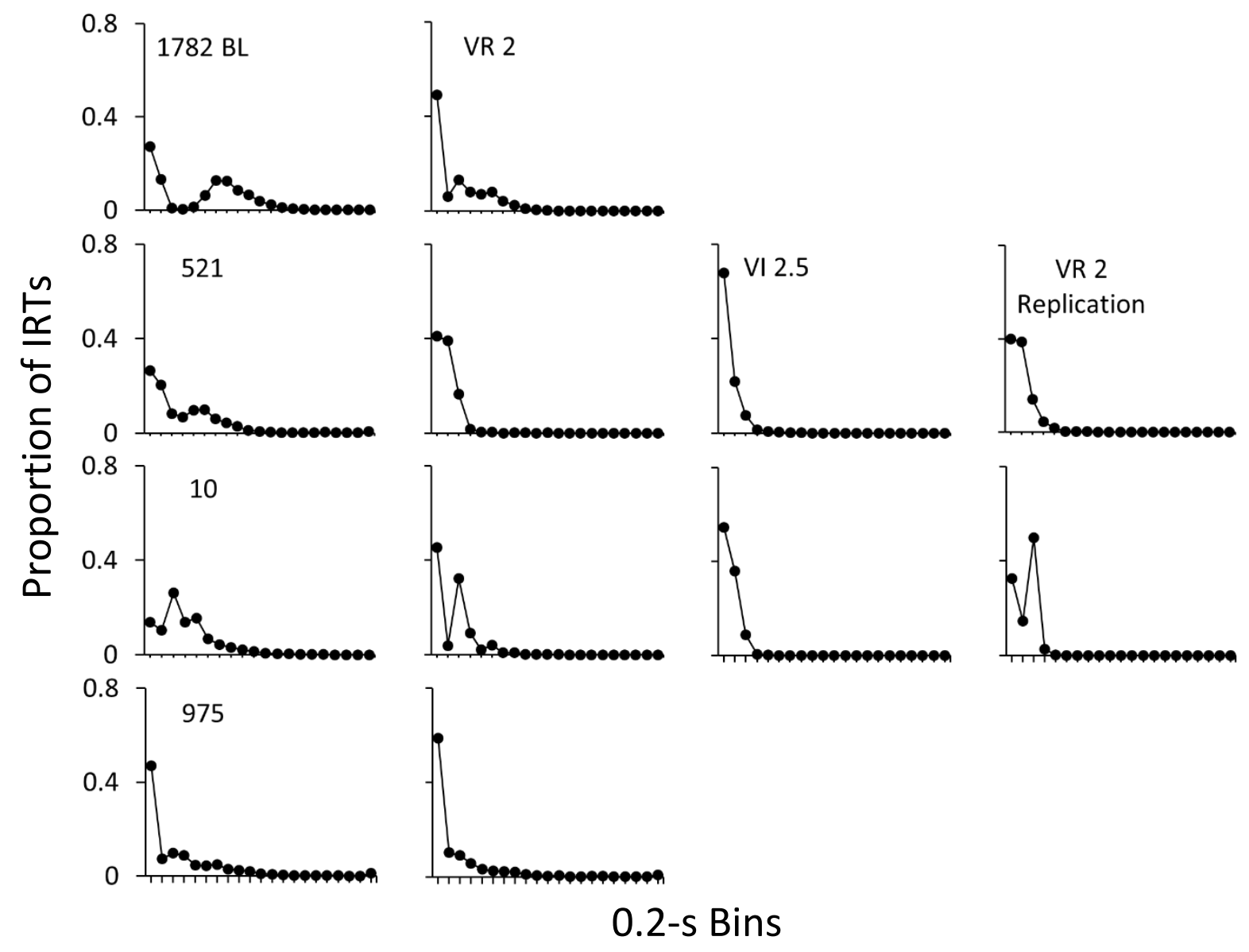

Figure 15. Proportion of interresponse times (IRTs) plotted in successive 0.2-s bins for the first baseline (BL; left most column) and the response-independent timeout components for the highest mean nominal VI and VR timeout conditions for each pigeon in Experiment $2 \mathrm{~b}$. The last bin is the overflow bin for IRTs greater than $4 \mathrm{~s}$. The label at the top of each column indicates the timeout condition. 


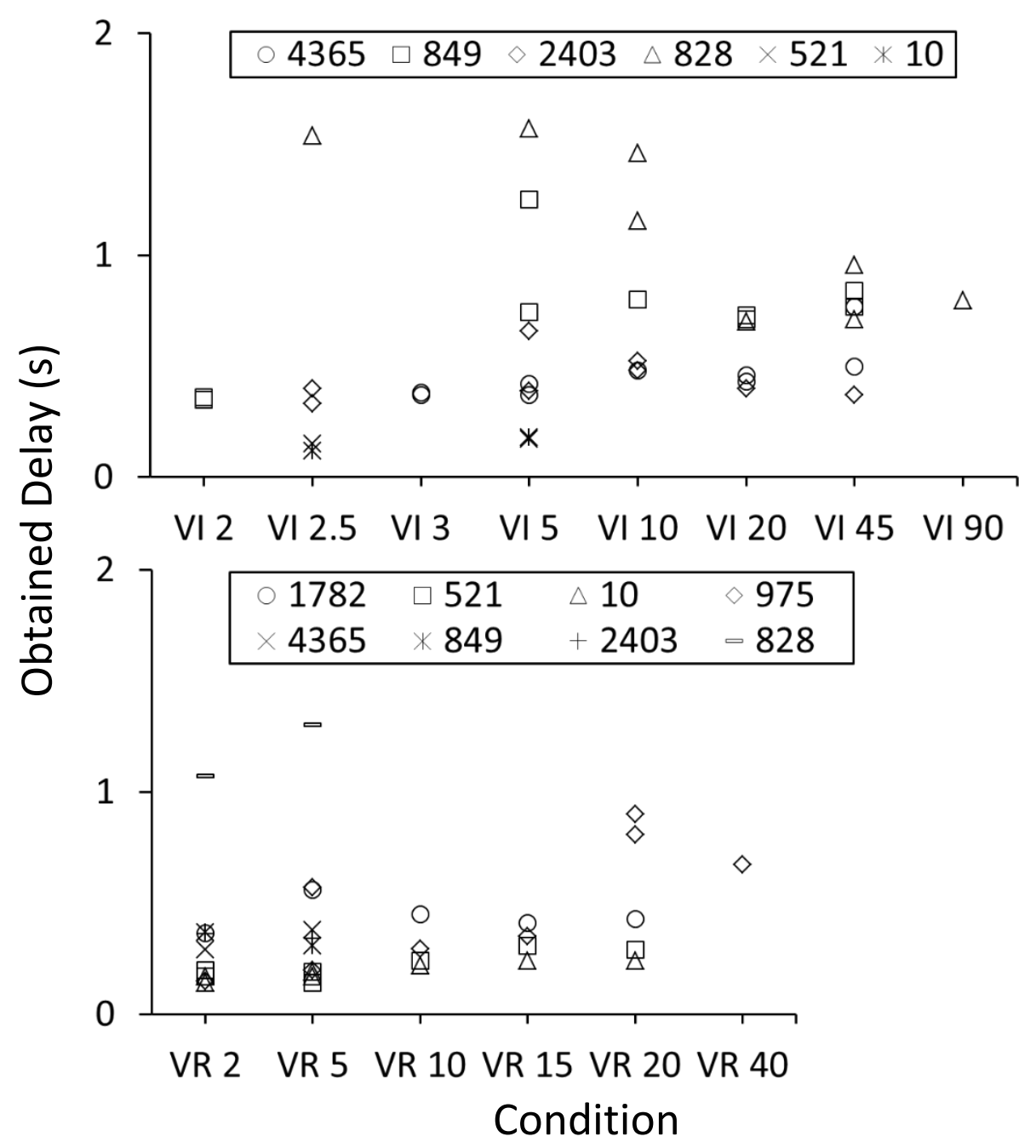

Figure 16. The median obtained delays to timeout in the response-independent timeout components in Experiment 2. The condition indicates the mean schedule value of timeout in effect. 

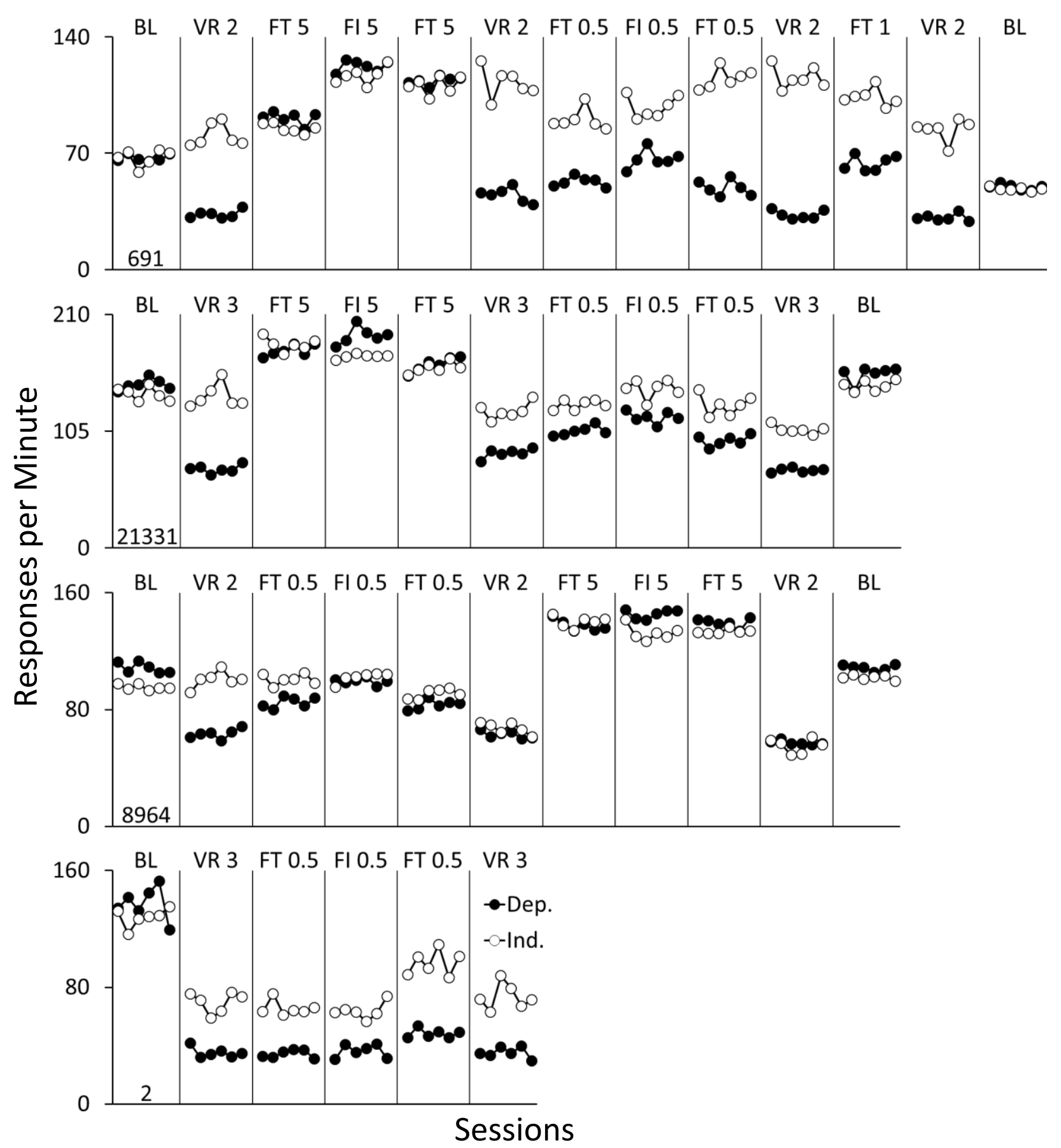

Figure 17. Mean responses per min for the last six stable sessions of each condition for the pigeons in Experiment 3. The filled data points indicate response-dependent (Dep.) timeout components and unfilled data points indicate response-independent (Ind.) timeout components. $\mathrm{BL}=$ baselines, VR 2 or $3=$ immediate timeout, FT and FI labels indicate the tandem schedule value in effect. 


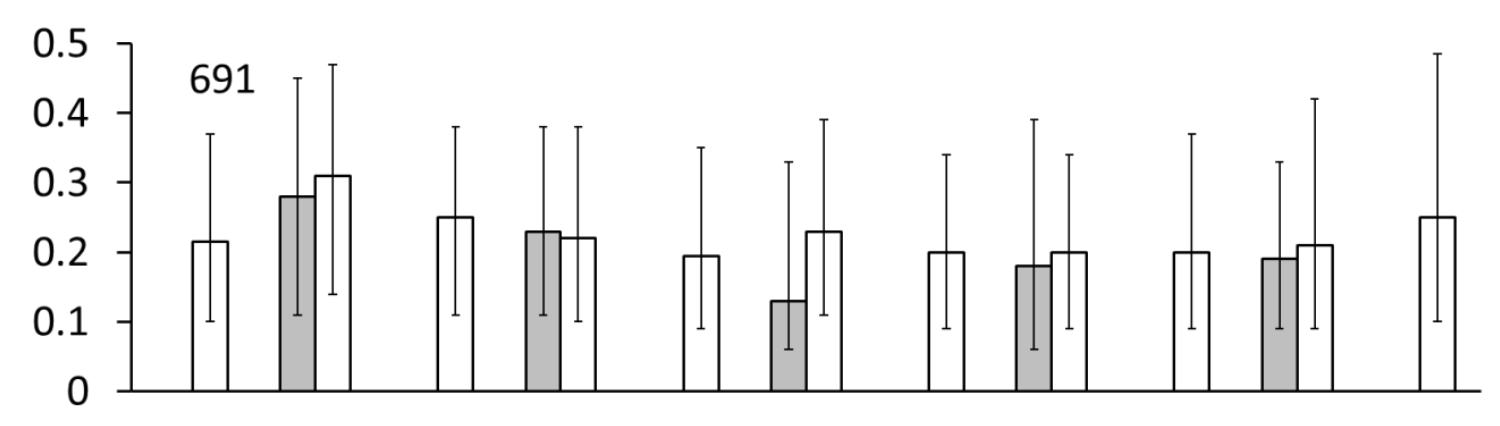

$\begin{array}{lllllllllll}\text { VR } 2 & \text { FT } 5 & \text { FI } 5 & \text { FT } 5 & \text { VR } 2 & \text { FT } 0.5 & \text { Fl } 0.5 & \text { FT } 0.5 & \text { VR } 2 & \text { FT } 1 & \text { VR } 2\end{array}$
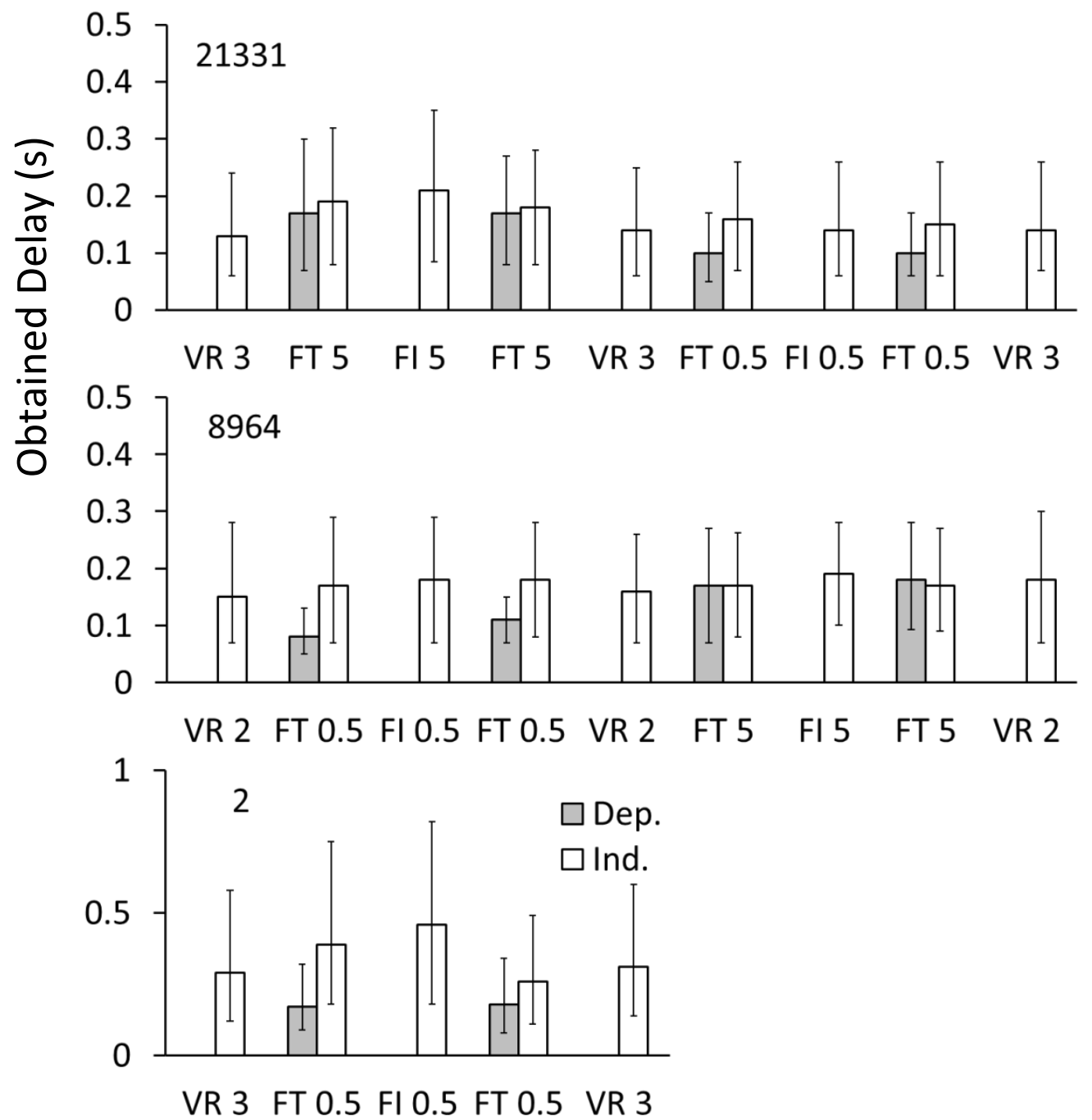

Condition

Figure 18. Median and ranges of the obtained delays to timeouts in Experiment 3. The grey bars are from the response-dependent (Dep.) delayed-timeout components and the unfilled bars are from the response-independent (Ind.) timeout components. VR 2 or $3=$ immediate timeout, FT and FI labels indicate the tandem schedule value in effect. 


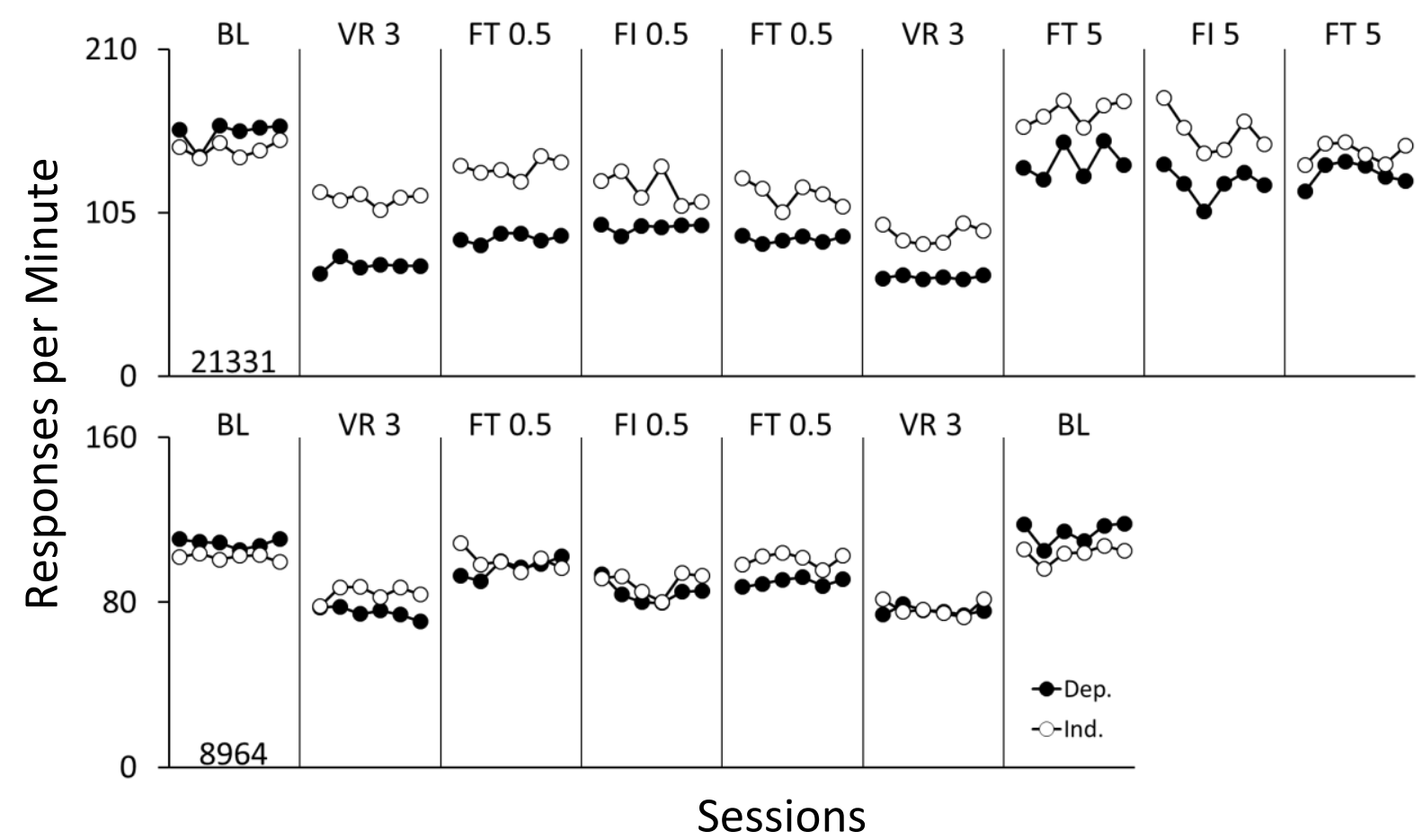

Figure 19. Mean responses per min for the last six stable sessions of each condition for pigeons in Experiment 4. The filled data points indicate response-dependent timeout components and unfilled data points indicate response-independent timeout components. BL $=$ baselines, VR 2 or $3=$ immediate timeout, FT and FI labels indicate the tandem schedule value in effect. 